\title{
CAirTOX: A Compartment Model for Assessing the Fate of and Human Exposure to Toxic- Chemical Emissions to Air
}

\author{
Prepared by: \\ Thomas E. McKone \\ Health and Ecological Assessments Division \\ Lawrence Livermore National Laboratory \\ P.O. Box 808, L-453 \\ Livermore, CA 94550-0617
}

Prepared for.

The California Air Resources Board

and

The Office of Environmental Health Hazard Assessment

California Environmental Protection Agency

October 1993 


\section{FORWARD AND ACKNOWLEDGEMENTS}

As part of an effort to improve the Health Risk Assessment (HRA) computer program developed by the State of California Air Resources Board (ARB), the objectives of this report are improve the current mathematical model used to estimate the relationship of chemical concentrations in air to concentrations in the air, soil, water, and food with which human populations have contact. The report describes research performed at the University of California, Lawrence Livermore National Laboratory (LLNL) to support this objective. This work was performed under the auspices of the U.S. Department of Energy (DOE) through LLNL as part of the Risk Science; Program under Contract W-7405-Eng-48 with funding provided by the ARB through Contract Agreement A147-111. 


\section{TABLE OF CONTENTS}

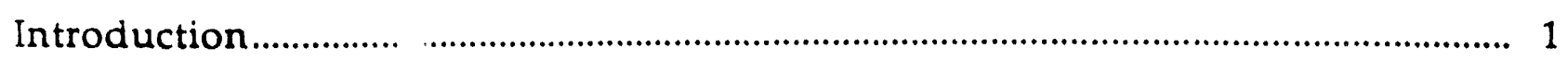

Part I. The Transport and Transformation Model...................................................... 3

Model Structure

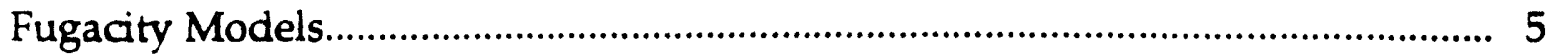

Intermedia Transfer Factors (ITFs) .................................................................... 7

The Seven CAirTOX Compartments ............................................................... 8

The Lower-Atmosphere or Air Compartment (a)................................... 8

The Ground-Surface-Soil Compartment $(\mathrm{g})$.............................................. 9

The Root-Zone-Soil Compartment. (s) ....................................................... 9

The Plant-Leaves Compartment (l) ............................................................ 10

The Plant-Roots Compartment (r) ......................................................... 10

The Surface-Water Compartment $(w)$....................................................... 11

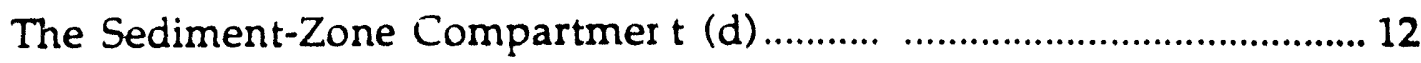

Physical Composition of Model Compartments and Fugacity Capacities........ 13

Fugacity Capacities in Pure Air, Pure Water, and Particles ...................... 13

Fugacity Capacity of theAir Compartment................................................. 15

Fugacity Capacity of Plants Leaves ............................................................ 15

Fugacity Capacity of Plants Roots ............................................................ 16

Fugacity Capacity of the Soil Compartment............................................... 17

Fugacity Capaicty of Surface Water ........................................................... 17

Fugacity Capacity of Sediment ..................................................................... 18

Modifications to Fugacity Capacities for Inorganic and Ionic-Organic Chemicals ......................................................................... 18

Transport Processes in the CAirTOX Model ....................................................... 19

Diffusive Mass Transfer at the Air and Surface-Water Interface........... 20

Diffusive Mass Transfer in Air at the Air and Ground-Surface Soil Interface............................................................... 21

Diffusive Mass Transfer in the Ground-Surface and Root-Zone Soil Layers............................................................................. 22

Diffusive Mass Transfer at the Surface-Water and

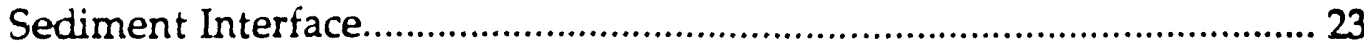

Mass Transfer by Advection in Water and Solids.............................................. 24 
Transformation Processes in the CAirTOX Model. 25

Transfer-Rate, Loss-Rate, and the Gain-Loss Equations. 27

Air (a)

Plant Leaves (1) 31

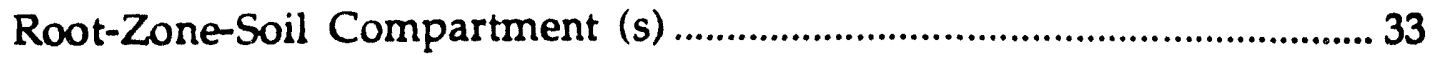

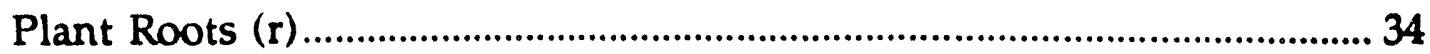

The Surface-Water Compartment $(w)$.................................................... 34

The Sediment-Zone Compartment (d) ................................................. 35

Solutions for the Molar Inventories ..................................................... 36

Part II. Model Input and Data Requirements............................................................ 38

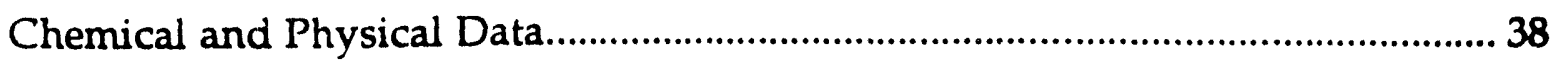

Preliminary Landscape Properties for California.......................................... 38

Part III. The Exposure Pathways Model..................................................................... 41

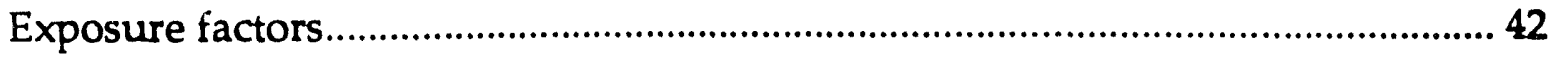

Exposure Duration and Averaging Time.............................................. 44

Anatomical and Dietary Properties........................................................ 44

Body Weight ........................................................................................ 44

Breathing Rate.................................................................................... 46

Body Surface Area............................................................................. 46

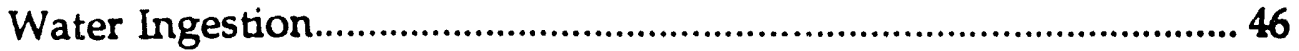

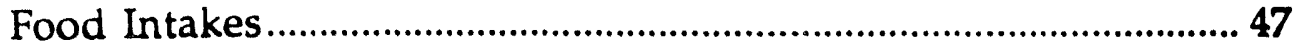

Food Consumption Patterns ....................................................... 48

Household Parameters ............................................................................. 50

Other Human Exposure Factors ............................................................. 51

Soil Ingestion and Soil Contact on Skin ....................................... 51

Ingestion of Breast Milk by Infants ............................................ 52

Parameters Associated with Food Crops and Food-Producing Animals................................................................ 52

Multiple-Pathway Exposures and Total Dose: The Ingestion Route.................54

Ingestion of Tap Water ............................................................................... 55

Ingestion of Contaminated Homegrown Fruits,

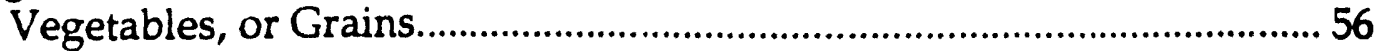

Contamination by Ambient-Air Contaminants.......................... 56 
Contamination by Irrigation Water................................................ 57

Contamination by Surface Soil ........................................................ 58

Contamination by Root-Zone Soil.................................................. 58

Ingestion of Contaminated Meat, Milk, and Eggs..................................... 59

Contamination by Transfer from Air to Animal Products .......... 59

Contamination by Transfer from Water to Animal Products.... 61

Contamination by Transfer from Surface Soil

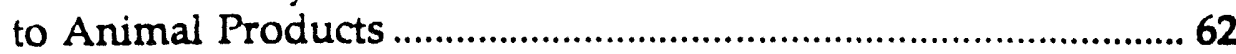

Contamination by Transfer from Root-Zone Soil to Animal

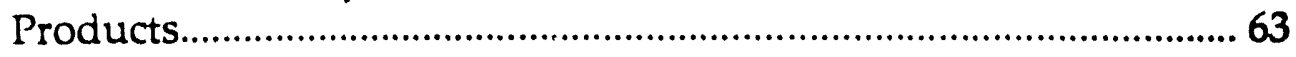

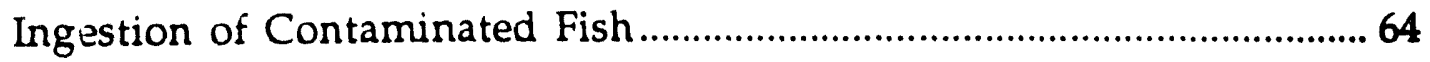

Soil Ingestion by Human ........................................................................ 65

Ingestion of Surface Water During Swimming......................................... 65

Multiple Pathway Exposures and Total Dose: The Inhalation Route............... 65

Inhalation of Contaminants in Ambient Air..............................................66

Inhalation of Contaminants Transferred from Soil to Indoor Air.........67

Dust migration from Surface Soil.................................................... 67

Vapor migration from Root-Zone Soil.......................................... 68

Inhalation of Contaminants Transferred from Water to Indoor Air ... 68 Multiple-Pathway Exposures and Total Dose: The Dermal-Uptake Route..... 69

Dermal Contact While Swimming or Bathing .......................................... 70

Dermal Contact with Soil............................................................................. 72

Contamination of Mother's Milk ....................................................................... 74

Part IV. Summary Comparison to HRA with Examples ............................................. 75

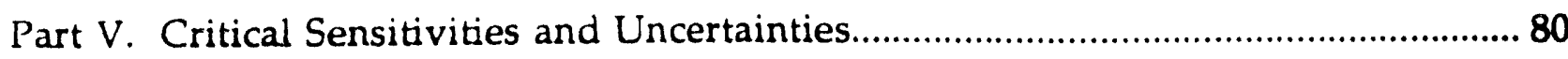

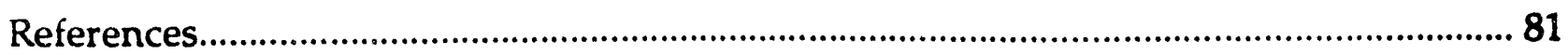




\section{INTRODUCTION}

Risk assessment is a quantitative evaluation of information on potential health hazards of environmental contaminants and the extent of human exposure to these contaminants. As applied to toxic chemical emissions to air, risk assessment involves four interrelated steps. These are (1) determination of source concentrations or emissions characteristics, (2) exposure assessment, (3) toxicity assessment, and (4) risk characterization. These steps can be carried out with assistance from analytical modeis isi order to estimate the potential risk associated with existing and future releases.

CAirTOX has been developed as a spreadsheet model to assist in making these types of calculations. CAirTOX follows an approach that has been incorporated into the CalTOX model, which was developed for the California Department of Toxic Substances Control (McKone, 1993a, 1993b, 1993c). With CAirTOX, we can address how contaminants released to an air basin can lead to contamination of soil, food, surface water, and sediments. The modeling effort includes a multimedia transport and transformation model, exposure scenario models, and efforts to quantify uncertainty in multimedia, multiple-pathway exposure assessments. This overall process is illustrated in Figure 1.

The multimedia transport and transformation model is a steady-state, but non-equilibrium model that can be used to assess concentrations of contaminants released continuously to air. This model assists the user in examining how chemical and landscape properties impact both the ultimate route and quantity of human contact. Using this model, we view the environment as a series of interacting compartments. The model allows the user to determine whether a substance will (a) remain or accumulate within the compartment of its origin, (b) be physically, chemically, or biologically transformed within the compartment of its origin (i.e., by hydrolysis, oxidation, etc.), or (c) be transported to another compartment by cross-media transfer that involves dispersion or advection (i.e., volatilization, precipitation, etc.).

Multimedia, multiple-pathway exposure models are used in CAirTOX to estimate average daily doses within a human population in a region having toxic chemicals released to its air. The exposure assessment process consists of relating contaminant concentrations in the multimedia compartments of the model to contaminant concentrations in the media with which a human population has 


\section{Environmental media concentrations}

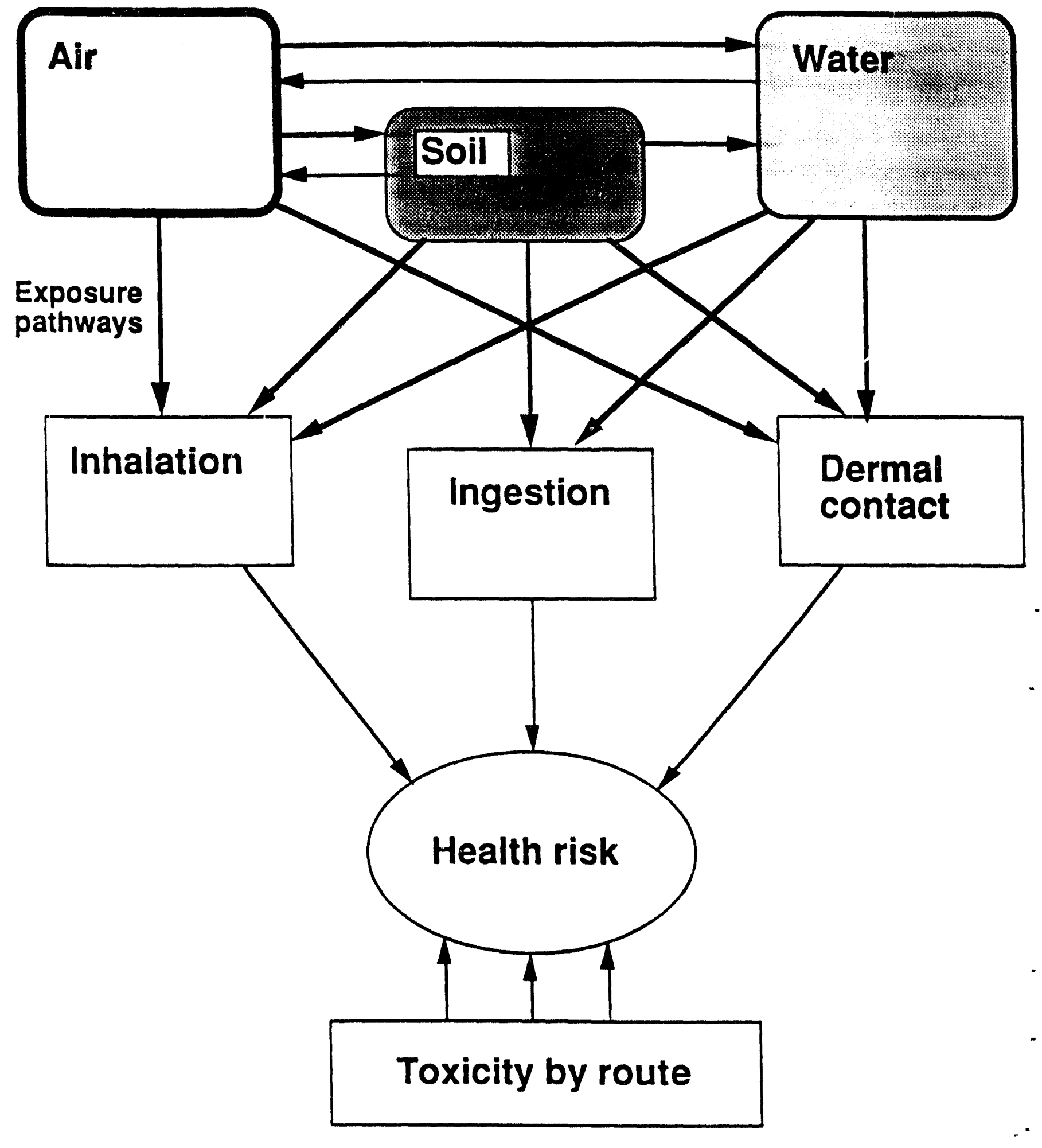

Figure 1. The relationship between source-medium concentration (e.g., air), subsequent concentrations in other environmental media, toxicology, and exposure -pathways. 
contact (personal air, tap water, foods, household dusts, soils, etc.). The average daily dose is the product of the exposure concentrations in these contact media and an intake or uptake factor that relates the concentrations to the distributions of potential dose within the population.

The remainder of this report is divided into five parts. In Part I, we describe the multimedia transport and transformation model used to determine the fate of air emissions. In Part II, we describe inputs and data needs for CAirTOX and the development of a set of landscape factors, which can be used to represent regional air basin/water-shed systems in California. In Part III, we describe the multiplepathway exposure scenarios and exposure algorithms. In Part IV, we compares the HRA approach and results and the CAirTOX exposure equations. We provide a summary table for the exposure scenarios in CAirTOX and compare these to the exposure scenarios in HRA. In Part $\mathrm{V}$, we consider model sensitivity and uncertainty to determine how variability and uncertainty in model inputs affects the precision, accuracy, and credibility of the model output.

\section{PART I. THE TRANSPORT AND TRANSFORMATION MODEL}

The multimedia-compartment model consists of seven compartments for assessing the fate $r$ air emissions in a regional air basin. These compartments are air, surface soil, $r$ it-zone soil, plant leaves, plant roots, surface water, and sediments. This compartment model provides an algorithm for calculating contaminant concentrations in air, water, and biota based on a defined steady-state concentration in air or a continuous input to air. The steady-state solution is based on a constant contaminant concentration in the air compartment. It is important to note that, in contrast to other models used for assessing environmental fate, this model imposes conservation of mass on the air-basin/water-shed systems. In addition, the model accounts systematically for gains and losses in each compartment and for the whole system in concert. This type of approach avoids many of the errors and omissions that exist in many multimedia models. The resulting model is tractable and credible.

Efforts to assess human exposure from multiple media date back to the 1950's when the need to assess human exposure to global fallout led rapidly to a framework that included transport both through and among air, soil, surface water, vegetation, and food chains (Whicker and Kirchner, 1987). Efforts to apply such a 
framework to nonradioactive organic and inorganic toxic chemicals have been more recent and have not as yet achieved the level of sophistication extant in the radioecology field. In an early book on multimedia transport, Thibodeaux (1979) proposed the term "chemodynamics" to describe a set of integrated methods for assessing the cross-media transfers of organic chemicals. The first widely used multimedia compartment models for organic chemicals were the "fugacity" models proposed by Mackay $(1979,1991)$ and Mackay and Paterson $(1981,1982)$. Cohen and his co-workers introduced the concept of the multimedia compartment model, MCM, (Cohen and Ryan, 1985) as a screening tool and more recently introduced the spatial multimedia compartment model (SMCM) model (Cohen et al., 1990), which allows for nonuriformity in some compartments. However, neither of these models explicitly addresses human exposure. Another multimedia screening model, called GEOTOX (McKone and Layton, 1986; McKone, et al., 1987), was one of the earliest multimedia models to explicitly address human exposure.

\section{Model Structure}

Three dynamic processes must be balanced in a multimedia model-sources, transport, and transformation. Knowledge of source-term characteristics is an important first step in the multimedia analysis. Pertinent information includes the physical and chemical properties of the substance(s) released and attributes of the source (e.g., emission rates). Sources can be categorized in terms of space (e.g., area source vs. point source), time (e.g., transient vs. chronic release), and mode of formation.

CAirTOX is a seven-compartment-, regional-, dynamic- and multimediafugacity model. The fugacity approach is best suited to nonionic organic chemicals for which partitioning is related strongly to chemical properties, such as vapor pressure, solubility, and the octanol-water partition coefficient. However, CAirTOX has been designed to also handle ionic organic contaminants, inorganic contaminants, radionuclides, and metals, with a modified fugacity-type approach. For all species, fugacity and fugacity capacities are used to represent mass potential and mass storage within compartments.

The seven-compartment structure used in CAirTOX is illustrated in Figure 2. The seven CAirTOX compartments are (1) air, (2) ground-surface soil, (3) root-zone 


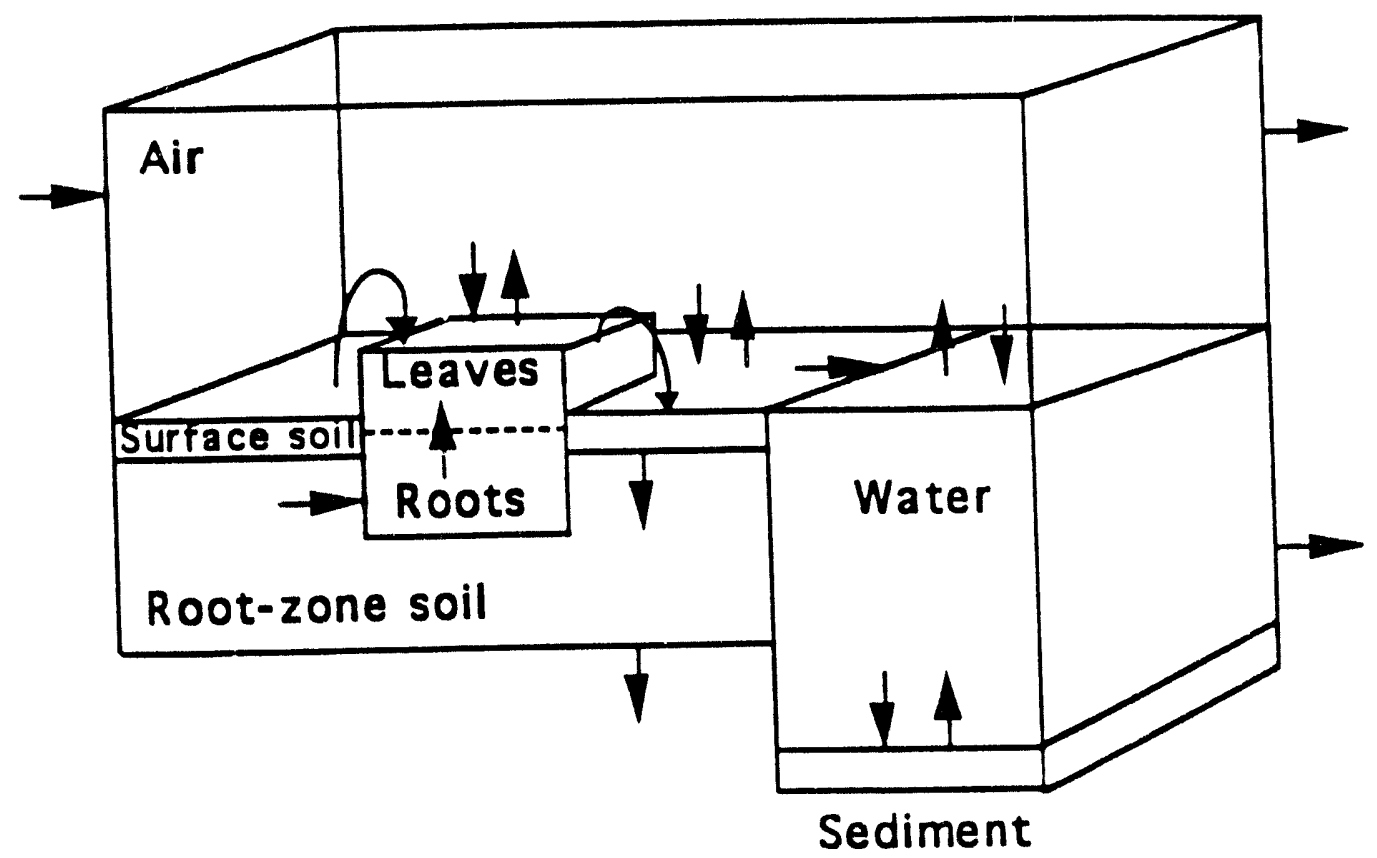

Figure 2. Mass-exchange processes modeled in a seven-compartment environmental transport model.

soil, (4) plant leaves, (5) plant roots (6) surface water, and (7) sediments. It is important to restate here that, in contrast to many models used for assessing environmental fate, CAirTOX imposes conservation of mass on the contaminated landscape unit. In addition, the model accounts systematically for gains and losses in each compartment and for the whole system in concert.

\section{Fugacity Models}

Fugacity models have been used extensively for modeling the transport and transformation of nonionic organic chemicals in complex environmental systems (see Mackay, 1991). Modified fugacity and fugacity-type models have also been used for ionic-organic and inorganic species, including metals. Fugacity is a way of representing chemical activity at low concentrations. Fugacity has units of pressure [pascal $(\mathrm{Pa})$ ] and can be regarded physically as the partial pressure or escaping potential exerted by a chemical in one physical phase or compartment on another (Mackay, 1979, 1991; Mackay and Paterson, 1981, 1982). When two or more media are in equilibrium, the escaping tendency (the fugacity) of a chemical is the same in all phases. This characteristic of fugacity-based modeling often simplifies the mathematics involved in calculating partitioning. Fugacity models can also be used to represent a dynamic system in which the fugacicies in two adjacent media are 
changing in time due to an imbalance of sources and losses, or a dynamic system that has achieved steady state by balancing gains and losses even though fugacities are not equal.

At low concentrations, like those typical of environmental interest, fugacity, $f$ $(\mathrm{Pa})$, is linearly related to concentration $\mathrm{C}\left(\mathrm{mol} / \mathrm{m}^{3}\right)$ through the fugacity capacity, $Z$ $\left(\mathrm{mol} / \mathrm{m}^{3}-\mathrm{Pa}\right)$,

$$
C=f Z
$$

$Z$ depends on the physical and chemical properties of the chemical and on various characteristics of phase, such as temperature and density. The property that fugacities are equal at equilibrium allows for simple determination of $Z$ values from partition coefficients. For example for two phases in equilibrium (phases 1 and 2),

$$
C_{1} / C_{2}=f Z_{1} / f Z_{2}=Z_{1} / Z_{2}=K_{12}
$$

where $C_{1}$ and $C_{2}$ are the concentrations in each phase, $Z_{1}$ and $Z_{2}$ are the fugacity capacities of each phase, and $K_{12}$ is a dimensionless partition coefficient, such as $\mathrm{K}_{\mathrm{ow}}$, the octanol-water partition coefficient. One of the major advantages of fugacity models is the ease with which they represent diffusive and advective intermediatransport processes. In a fugacity model, the net diffusive flux, in $\mathrm{mol} / \mathrm{m}^{2}-\mathrm{d}$, across an interface is given by

$$
\text { flux }=Y_{12}\left(f_{1}-f_{2}\right)
$$

where $Y_{12}$ is the fugacity mass-transfer coefficient across the boundary between medium 1 and medium 2 with units $\mathrm{mol} /\left(\mathrm{m}^{2}-\mathrm{Pa}-\mathrm{d}\right)$ and $f_{1}$ and $f_{2}$ are the fugacities of medium 1 and medium 2. Equation [3] is analogous to the flow of electrons in a circuit, in which $\left(f_{1}-f_{2}\right)$ acts as a voltage difference, $Y_{12}$ acts as a conductance, and the mass flux serves as the equivalent of electrical current. The fugacity mass-transfer coefficient depends only on the mass transfer coefficient on either side of the interface.

$$
Y_{12}=\left(\frac{1}{Z_{1} U_{1}}+\frac{1}{Z_{2} U_{2}}\right)^{-1}
$$


where $U_{1}$ and $U_{2}$ are the mass-transfer coefficients $(\mathrm{m} / \mathrm{d})$ in the boundary layers in medium 1 and medium 2 and $Z_{1}$ and $Z_{2}$ are the fugacity capacities of medium 1 and medium 2. The net advective flux between medium 1 and medium 2 is given by

$$
\text { flux }=Z_{\text {water }}\left[F_{12}^{\mathrm{W}} f_{1}-F_{21}^{\mathrm{w}} f_{2}\right]+Z_{1 p} F_{12}^{\mathrm{p}} f_{1}-Z_{2 p} F_{21}^{\mathrm{p}} f_{2}
$$

where $Z_{\text {water }}$ is the fugacity capacity of water, $\mathrm{mol} / \mathrm{m}^{3}-\mathrm{Pa} ; \mathrm{F}_{12}^{\mathrm{W}}$ is the flux of water from medium 1 to $2, \mathrm{~m}^{3} / \mathrm{m}^{2}-\mathrm{d} ; \mathrm{F}_{21}^{\mathrm{w}}$ is the flux of water from medium 2 to 1 , $\mathrm{m}^{3} / \mathrm{m}^{2}-\mathrm{d} ; Z_{1 \mathrm{p}}$ and $Z_{2 \mathrm{p}}$ are, respectively, the fugacity capacities of the solid phases of media 1 and $2, \mathrm{~mol} / \mathrm{m}^{3}-\mathrm{Pa} ; \mathrm{F}_{12}^{\mathrm{p}}$ is the flux of solids from medium 1 to $2, \mathrm{~m}^{3} / \mathrm{m}^{2}-\mathrm{d}$; and $F_{21}^{p}$ is the flux of solids from medium 2 to $1, \mathrm{~m}^{3} / \mathrm{m}^{2}-\mathrm{d}$.

\section{Intermedia Transfer Factors (ITFs)}

Multimedia models also require that we measure or estimate solid/liquid phase partition coefficients between soil and soil water and between surface water and sediments; air/liquid partition coefficients; and the diffusion coefficients of substances in air and water. A companion report to this one (McKone et al., 1993) describes methods for estimating the intermedia tranfer factors needed for the CAirTOX model.

The exchange of contaminants at the boundary between two environmental compartments that are made up in part of fluids in motion (i.e., air or water) involves advection (e.g., deposition, washout, etc.) and two modes of diffusionmolecular diffusion within a thin boundary layer and turbulent diffusion within the bulk of the compartment. In a compartment such as the atmosphere, in which turbulent mixing is rapid and continuous, molecular diffusion will only be significant at boundaries with other less turbulent compartments, such as soil and surface water. At these boundaries the air makes a transition from a well-mixed turbulent fluid to an essentially zero velocity boundary. In a multimedia model, it is assumed that turbulent diffusion within a compartment, such as the lower atmosphere, is so efficient that the bulk concentration is simply the compartment inventory divided by the compartment volume. However, at the boundary between two compartments, modeling of diffusive mass transfer must include both turbulent and molecular processes that can not be lumped or assumed away at these transition zones. 


\section{The Seven CAirTOX Compartments}

In this section, we describe the seven CAirTOX compartments in terms of their mass, volume, and the characteristics that influence advection and diffusion at the boundaries of each compartment. We put particular emphasis on those factors that determine whether a substance will (a) remain or accumulate within the compartment, (b) be physically, chemically, or biologically transformed within the compartment, or (c) be transported to another compartment by cross-media transfer that involves dispersion or advection. In the remaining sections of this report, we often refer to these compartments using a single letter representations as follows: air (a), ground-surface soil (g), root-zone soil (s), plant leaves (l), plant roots ( $\mathrm{r}$ ), surface water $(w)$, and sediments $(d)$.

\section{The Lower-Atmosphere or Air Compartment (a)}

Substances in outdoor (or ambient) air are dispersed by atmospheric advection and diffusion. The volume and mass of the air compartment is defined by the area of the contaminated landscape and the mixing height of the lower atmosphere. Meteorological parameters have an overwhelming influence on the behavior of contaminants in the lower atmosphere. Among them, wind parameters (direction, velocity, and turbulence) and thermal properties (stability) are the most important. A simple approach to the dispersion of substances in the atmosphere is based on the application of a mass balance to a volume element, such as a parcel or box of air. This gives rise to the "box" models for atmospheric dispersion. In this approach, the region to be studied is divided into cells or boxes. The concentration in each box is assumed to be uniform and is a function of the box volume, the rate at which material is being imported, emission rates within the box, and the rate at which material is exported from the box. Gifford and Hanna (1973) have shown that in a simple box model, the yearly average concentration of contaminant within the box is proportional to the source strength in mass per unit area divided by the wind speed. Based on data from U.S. cities, they have developed for both gases and particles proportionality coefficients that can be used to estimate long-term contaminant concentrations. The air-compartment model in CAirTOX is based on the box-model approach. 
The Ground-Surface-Soil Compartment ( $g$ ).

Soil, the thin outer zone of the earth's crust that supports rooted plants, is the product of climate and living organisms acting on rock. A true soil is a mixture of air, water, mineral, and organic components. The relative mix of these components determines to a large extent how a chemical will be transported and/or transformed within the soil. The movement of water and contaminants in soil is typically vertical as compared to horizontal transport in the ground-water (i.e., saturated) zone. A chemical in soil partitions among soil water, soil solids (mineral and organic phases), and soil air. For example, the rate of volatilization of an organic compound from soil depends on the partitioning of the compound into the soil air and on the porosity and permeability of the soil. Soils are characteristically heterogeneous. A trench dug into the soil zone reveals typically several horizontal layers having different colors and textures. These multiple layers are often divided into three major horizons: the $A$ horizon, which encompasses the root zone and contains a high concentration of organic matter; the $B$ horizon, which is unsaturated, is below the roots of most plants, and contains a much lower organic carbon content; and the $C$ horizon, which is the unsaturated zone of weathered parent rock consisting of bedrock, alluvial material, glacial material, and/or soil of an earlier geological period (Bowen, 1979).

Studies of radioactive fallout in agricultural land-management units reveal that, in the absence of tilling, particles deposited from the atmosphere accumulate in and are resuspended from a thin ground-surface-soil layer with a thickness in the range 0.1 to $1 \mathrm{~cm}$ (Whicker and Kirchner, 1987). The ground-surface-soil layer is at the top of the $A$ soil horizon. The ground-surface-soil layer has a lower water content and higher gas content than underlying layers. Contaminants in this surface-soil layer are transported horizontally by mechanical runoff and soilsolution runoff to nearby surface waters. Surface-soil contaminants are susceptible to wind erosion, volatilization, photolysis, biodegradation, and transfer to plant surfaces by rainsplash. These contaminants are transferred to and from the rootzone soil by diffusion and leaching.

\section{The Root-Zone-Soil Compartment. (s)}

Contaminants in the $A$ horizon below the surface layer, that is, in the rootzone soil, are transported upward by diffusion, volatilization, root uptake, and capillary motion of water; transported downward by diffusion and leaching; and transformed chemically primarily by biodegradation or hydrolysis. Soil-water 
content in the root zone is somewhat higher than that in surface soils, because the presence of clay in this layer serves to retain water. The roots of most plants are confined within the first meter of soil depth. In agricultural lands, the depth of plowing is 15 to $25 \mathrm{~cm}$. In addition, the diffusion depth, which is the depth below which a contaminant is unlikely to escape by diffusion, is on the order of a meter or less for all but the most volatile contaminants (Jury et al., 1990).

The Plant-Leaves Compartment ( $l$ )

The dominant component of the terrestrial biota compartment is land plants. Plants generally have contact with two environmental media-air and soil. Plant interactions with these media are not understood well enough to define an accurate method of predicting chemical uptake. The translocation of chemicals from soils appears to be a relatively minor pathway for the accumulation of these compounds in plants (Fiedler et al., 1991). In the absence of experimental studies, there has been a reliance on simple bioconcentration factors (BCFs) that relate either a soil or air concentration to a plant concentration. The earliest use of vegetation $B C F s$ was for assessing the effects of global fallout by relating concentrations of radionuclides in plants to concentrations in soil $(\mathrm{Ng}, 1982)$. More recently, vegetation $\mathrm{BCFs}$ have been proposed for organic chemicals (Travis and Arms, 1988). What is meant by the "concentration in a plant" is difficult to define in large plants where roots, stems, and leaves each may have different chemical concentrations. In the CAirTOX model, plant leaves are modeled as a single biota compartment consisting of air, water, and plant lipids. The fugacity capacity of this compartment is based on a simplified version of the model proposed by Paterson and Mackay (1989).

\section{The Plant-Roots Compartment ( $r$ )}

Plant roots have contact with roughly the top meter of the soil column. The plant-root hairs penetrate the pore spaces of soil in order to bring water and nutrients into the plant. Typically, only chemical species available in the soil water are capable of entering the plant from the root. Contaminants bound to the organic phase of soil cannot be transfered directly into the plant. Once contaminants have entered the root compartment, they can be transferred to the plant leaves by translocation in the xylem solution. In the CAirTOX model, plant roots are modeled as a single biota compartment consisting of air, water, and plant lipids. The fugacity capacity of this compartment is based on a simplified version of the model proposed by Paterson and Mackay (1989). 


\section{The Surface-Water Compartment (w)}

The behavior of chemicals in surface waters is determined by two factors-the rate of physical transport in the water system and chemical reactivity. Physical transport processes are dependent to a large extent on the type of water body under consideration-oceans, seas, estuaries, lakes, rivers, or wetlands. Schnoor (1981) and

Schnoor and MacAvoy (1981) have summarized important issues relating to surface-water transport. Fugacity models have been develop by Mackay et al. (1983a) for lakes and also by Mackay et al. (1983b) for rivers.

At low concentration, contaminants in natural waters exist in both a dissolved and a sorbed phase. In slow-moving surface waters, both advection and dispersion are important. In rapidly moving water systems, advection controls mass transport and dissolved substances move at essentially the same velocity as the bulk water in the water system. Contaminants that are sorbed to colloidal material and fine suspended solids can also be entrained in water currents, but they may undergo additional transport processes that alter their effective residence time in surface waters. Such processes include sedimentation and deposition and scouring and resuspension. Thus, determining the transport of contaminants in surface waters requires that we follow both water movement and deposition and resuspension from sediment.

A water balance is the first step in assessing surface-water transport. A water balance is established by equating gains and losses in a water system with storage. Water can be stored within estuaries, lakes, rivers, and wetlands by a change in elevation or stage. Water gains include inflows (both runotf and stream input) and direct precipitation. Water losses include outflows and evaporation.

In CAirTOX the surface-water compartment is composed of two phases, pure water and suspended sediment material that contains the sorbed contaminants. Surface waters are assumed to be well-mixed systems. The surface-water velocity relative to area, depth, and volume determines the residence time of the pure-water phase. The effective residence time of suspended sediments is determined by both the residence time of the water phase and the deposition and resuspension rates of the sediments. Contaminants in surface water are transported into this compartment by deposition from air, by runoff from soil, and by diffusion and resuspension from the sediment layer. Contaminants in surface water are transported out of this compartment by advection in both the liquid and sediment 
phases, by diffusion to air at the upper surface of the water body and by diffusion and deposition to sediments.

Contaminants in surface water are also taken up by aquatic organisms and this can also impact the distribution of these contamiriants. In CAirTOX, the modeling of contaminant transport in surface water is based on the assumption that essentially all the contaminant mass is in either liquid or suspended-solid phases. This assumption implies that a very small fraction of the total compartment inventory is distributed among aquatic species. However, this does not imply that there are low concentrations in these organisms. Quite the contrary is often the case.

\section{The Sediment-Zone Compartment (d)}

This compartment represents the porous, active layer of water and solid material that forms at the bottom of the surface-water compartment primarily as a result of sediment and organic-matter deposition from the surface water above. Reuber et al. (1991) note that the bottom sediments of surface-water bodies have at least two distinct layers-an active layer characterized by a high degree of chemical and biological activity and a deeper, inactive layer in which chemicals are essentially isolated from the water column.

Deposition, resuspension, burial, diffusion, oxidation, and biotransformation are continuous processes that impact the inventory of contaminants in bottom sediments. Deposition of mineral matter and organic matter from surface water to sediments is a continuous process in any water body and an important mechanism for transferring particle-bound contaminants to the sediment layer. In any water system, some of the deposited material is resuspended by water currents, which depend on the hydrology of the system. In lakes, deposition is typically greater than resuspension and, in rivers, resuspension can equal or exceed deposition. Burial refers to the rate at which contaminants move from the active to the inactive layer. The pore water of the sediment layer together with the colloidal organic matter in this pore water provide vehicles for diffusion. Contaminants dissolved in the pore water or sorbed to the colloids can diffuse or migrate from sediments up to the water column or down to deeper sediment layers. 


\section{Physical Composition of Model Compartments and Fugacity Capacities}

For each model compartment, we determine the fugacity capacity of the total compartment from the sum of the volume-fraction-weighted fugacity capacities of the constituent phases-air, water, particles, and lipids.

\section{Fugacity Capacities in Pure Air, Pure Water, and Particles}

The fugacity capacity in units of $\mathrm{mol} / \mathrm{m}^{3}-\mathrm{Pa}$ for a nonionic organic chemical in pure air, $Z_{\text {air }}$, is given by

$$
Z_{\mathrm{air}}=1 / \mathrm{R} T
$$

where $\mathrm{R}$ is the universal gas constant, $8.314 \mathrm{~Pa}-\mathrm{m}^{3} / \mathrm{mol}-\mathrm{K}$, and $T$ is temperature in kelvins (K).

The fugacity capacity in units of $\mathrm{mol} / \mathrm{m}^{3}-\mathrm{Pa}$ for a nonionic organic chemical in pure water, $Z_{\text {water, }}$ is given by

$$
Z_{\text {water }}=1 / H
$$

where $\mathrm{H}$ is the Henry's law constant, $\mathrm{Pa}-\mathrm{m}^{3} / \mathrm{mol}$, which expresses the ratio of equilibrium activities of a chemical in air (expressed as vapor pressure, $\mathrm{Pa}$ ) and in water $\left(\mathrm{mol} / \mathrm{m}^{3}\right)$ when the two phases are well mixed.

A chemical in the solid or particle phase of soils, sediments, and surface waters has a fugacity capacity given by

$$
Z_{\text {ip }}=K_{\mathrm{d} i} \times \rho \mathrm{s}_{\mathrm{i}} \times Z_{\text {water }} \times \frac{1 \mathrm{~m}^{3} \text { water }}{1000 \mathrm{~L} \text { water }}
$$

where $Z_{i p}$ is the fugacity capacity of the pure solid phase, $\mathrm{mol} / \mathrm{m}^{3}-\mathrm{Pa}$; i refers to the compartment name (i.e., $a, g, b$, s, etc.); $\mathrm{K}_{\mathrm{d} i}$ represents, for compartment $i$, the sorption coefficient, which is the ratio at equilibrium of chemical concentration attached to particles $(\mathrm{mol} / \mathrm{kg}$ ) to chemical concentration in the solution, $\mathrm{mol} / \mathrm{L}$; and $\rho s_{i}$ is the density of the actual particles in $\mathrm{kg} / \mathrm{m}^{3}$ (not the bulk density of the particles when mixed in solution).

In the air compartment contaminants bound to aerosol particles achieve equilibrium with gas-phase contaminants. The derivation here of the fugacity capacity of aerosol particles is based on a model originally developed by Junge (1977) 
but used frequently by others (for example, Cohen and Ryan, 1985; Mackay et al., 1986; Pankow, 1987; Ryan and Cohen, 1986). In this model the fraction of contaminant bound to aerosol particles, $\varphi$, is given by

$$
\varphi=\frac{c \theta}{(V P+c \theta)}
$$

where, $\theta$ is the total suspended particle surface area concentration in $\mathrm{m}^{2} / \mathrm{m}^{3}$, VP is the vapor pressure of the pure contaminant in $\mathrm{Pa}$, and $\mathrm{c}$ is an approximate constant that Junge (1977) sets equal to $0.173 \mathrm{~m}-\mathrm{Pa}$. Whitby (1978) reports values for $\theta$ ranging from $4.2 \times 10^{-5} \mathrm{~m}^{2} / \mathrm{m}^{3}$ for a clean continental site to $1.1 \times 10^{-3} \mathrm{~m}^{2} / \mathrm{m}^{3}$ for urban sites. Following the recommendation of Mackay et al. (1986), we use the sub-cooled liquid vapor pressure to estimate the fugacity capacity of air particles. The fugacity capacity for air particles, $Z_{\text {ap }}$ in $\mathrm{mol} / \mathrm{m}^{3}-\mathrm{Pa}$, is derived from equation [9] by noting that

$$
f_{\text {vap }} \times Z_{\text {ap }} / Z_{\text {air }}=\frac{c \theta}{V P}
$$

where $f_{\text {vap }}$ is the volume fraction of the air that is occupied by air particles. Under the assumption that the particle load in the air is $100 \mu \mathrm{g} / \mathrm{m}^{3}$ and that particle density is $1500 \mathrm{~kg} / \mathrm{m}^{3}$, this fraction is $6.7 \times 10^{-11}$. Substituting this value into equation [10] with $\theta$ equal to $1.1 \times 10^{-3} \mathrm{~m}^{2} / \mathrm{m}^{3}$, c equal to $0.173 \mathrm{~m}-\mathrm{Pa}$, and $Z_{\text {air }}$ equal to $1 / \mathrm{RT}$ gives

$$
Z_{\mathrm{ap}}=\frac{3 \times 10^{6}}{\mathrm{VP} \times \mathrm{RT}}
$$

This expression is similar to one derived by Mackay et al. (1986) using a somewhat different approach. For contaminants that exist as solids at ambient temperatures, it is not clear whether the vapor pressure, VP is that of the sub-cooled liquid, or the vapor pressure of the solid, should be used (Mackay et al. 1986; Mackay, 1991; Taylor, 1992). Following the recommendation of Mackay et al. (1986) for solids we use the vapor pressure of the subcooled liquid, which is equal to the vapor pressure of the solid times $\exp \left[6.79\left(T_{m} / T-1\right)\right]$, where $T_{m}$ is the melting point of the compound and $\mathrm{T}$ is the ambient temperature. 


\section{Fugacity Capacity of theAir Compartment}

In the air compartment, the total fugacity capacity, $Z_{\mathrm{a}}$ in $\mathrm{mol} / \mathrm{m}^{3}-\mathrm{Pa}$, is composed of the volume-weighted average of the fugacity capacities of its two constituent phases, air and air particles,

$$
Z_{\mathrm{a}}=Z_{\mathrm{air}}+\left(\mathrm{f}_{\mathrm{vap}} \times Z_{\mathrm{ap}}\right)
$$

where $f_{\text {vap }}$ is the volume fraction of particles in air. The volume fraction of the gas phase is essentially unity.

\section{Fugacity Capacitil of Plants Leaves}

Riederer (1990) has shown that, for foliar uptake of gas-phase organic contaminants, the most general form of a steady-state plant-air partition model is

$$
K_{p a}=f_{p a}+\left(f_{p w}+f_{p l} \times K_{o w}\right) \times \frac{R T}{H}
$$

where $\mathrm{K}_{\mathrm{pa}}$ is the ratio of contaminant concentration in plant tissue to that in air, $\mathrm{mol} / \mathrm{m}^{3}$ per $\mathrm{mol} / \mathrm{m}^{3} ; \mathrm{f}_{\mathrm{pa}}$ is the volume fraction of plant tissue that is air; $\mathrm{f}_{\mathrm{pw}}$ is the volume fraction of plant tissue that is water; $f_{p l}$ is the volume fraction of the plant tissue that is lipid; $R$ is the universal gas constant, $8.31 \mathrm{~Pa}-\mathrm{m}^{3} / \mathrm{mol}-\mathrm{K}$; $\mathrm{T}$ is the temperature in kelvins ( $293 \mathrm{~K})$; and $\mathrm{H}$ is the Henry's law constant of the contaminant in Pa-m $\mathrm{m}^{3} / \mathrm{mol}$. Based on azalea-leaf experiments with five chemicals, Bacci et al. (1990) have developed a correlation of leaf-air bioconcentration factors with air-water and octanol-water partition coefficients and have shown that $f_{\mathrm{pl}}$ is on the order of 0.01 . Paterson and Mackay (1989) have estimated that $f_{p a}$ is 0.5 . This implies that the remainder of the plant volume fraction, 0.49 , is either water or nonlipid solids. Based on our assumption that $80 \%$ of total plant mass is water, we set $f_{p w}$ equal to 0.4 . These assumptions together with the recognition that $K_{p a}$ is the ratio of plant fugacity capacity to air fugacity capacity-that is, $Z_{1} / Z_{\text {air }}$ or $Z_{1} \times \mathrm{RT}$ leads to the following expression to estimate the plant fugacity capacity $Z_{1}$ for organic chemicals in plant tissue relative to air,

$$
Z_{1}=\frac{0.5}{R T}+\left(0.4+0.01 \times K_{o w}\right) \times Z_{\text {water }}
$$




\section{Fugacity Capacity of Plants Roots}

The fugacity capacity of plant-root tissues relative to soil can be related to the plant-soil partition coefficient, $K_{p s}$, which expresses the ratio of contaminant concentration, $\mathrm{mol} / \mathrm{kg}$, in the fresh mass of vegetation to the contaminant concentration in the root-zone soil, mol $/ \mathrm{kg}$. This means $K_{\mathrm{ps}}$ is equal to $\left(Z_{p} \rho b_{s}\right) /\left(Z_{s} \rho_{p}\right)$, where $\rho b_{s}$ is the soil bulk density in $\mathrm{kg} / \mathrm{m}^{3}$ and $\rho_{\mathrm{p}}$ is the plant density, assumed to be $1000 \mathrm{~kg} / \mathrm{m}^{3}$. For nonionic organic chemicals, there are methods for estimating $K_{p s}$ or $Z_{p}$ from chemical solubility in the absence of measured data. Briggs et al. $(1982,1983)$ have developed an equation to estimate uptake of contaminants by roots from soil solution. They refer to this partition coefficient as the root concentration factor, RCF. It represents the ratio of contaminant concentration in root tissue, $\mathrm{mol} / \mathrm{kg}$ (fresh mass), to contaminant concentration in soil solution, $\mathrm{mol} / \mathrm{kg}$, and it takes the form

$$
\mathrm{RCF}=0.82+\left(0.03 \mathrm{~K}_{\mathrm{ow}}^{0.77}\right)
$$

We note that $R C F$ is the ratio of plant-root fugacity capacity to soil-solution fugacity capacity, that is, $Z_{\mathrm{r}} / Z_{\text {water }}\left(\right.$ or $Z_{\mathrm{r}} \times \mathrm{H}$ ). This means that equation [15] leads to the following expression for estimating the plant-root fugacity capacity $Z_{r}$,

$$
Z_{\mathrm{r}}=\left(0.82+0.03 \times K_{\mathrm{ow}}^{0.77}\right) \times Z_{\text {water }}
$$

It is of interest that, based on experiments that measured chemical uptake from air to leaves and experiments that measured chemical uptake from soil solution to roots, the implied fugacity capacity of plants in both cases as expressed by, respectively, equations [14] and [16], are quite similar.

For inorganic species and ionic organic compounds, we estimated $Z_{1}$ and $Z_{r}$ as

$$
Z_{1}=Z_{r}=K_{p s} \times Z_{\text {soil }} / \rho b_{s}
$$

As a rule, for inorganic species and ionizing organic compounds, $K_{\mathrm{ps}}$ should be obtained from measured data. In the absence of measured data, we obtain $K_{p s}$ by assuming that the contaminant concentration is plant water is equal to that in soil water so that $K_{\mathrm{ps}}$ is equal to $\left(1-\mathrm{bio}_{\mathrm{dm}}\right) / \mathrm{K}_{\mathrm{ds}}$, where bio ${ }_{\mathrm{dm}}$ is the dry-mass fraction of plants and $\left(1-b_{i o}\right)$ is the water-mass fraction of the plants. 


\section{Fugacity Capacity of the Soil Compartment}

For the soil compartments, which have air, water, and solid components all at the same fugacity, the total compartment fugacity capacities are the volumeweighted average of the fugacity capacities of three component phases. For groundsurface and root-zone soil; these compartment fugacities are, respectively, $Z_{g}$, and $Z_{s}$, in $\mathrm{mol} / \mathrm{m}^{3}-\mathrm{Pa}$. As an example, for the root-zone soil compartment (s), the equation describing the overall fugacity capacity of this compartment is

$$
Z_{\mathrm{s}}=\alpha_{\mathrm{s}} Z_{\mathrm{air}}+\beta_{\mathrm{s}} Z_{\text {water }}+\left(1-\phi_{\mathrm{s}}\right) Z_{\mathrm{sp}}
$$

where $\alpha_{s}$ is the volume fraction of air in the soil compartment, $\beta_{s}$ is the volume fraction of water in the compartment, $\left(1-\phi_{s}\right)$ is the volume traction of solid in the compartment, $\phi_{s}\left(=\alpha_{s}+\beta_{s}\right)$ is the total void fraction in soil, and $Z_{s p}$ is the fugacity capacity of the soil particles, $\mathrm{mol} / \mathrm{m}^{3}-\mathrm{Pa}$.

\section{Fugacity Capaicty of Surface Water}

In the surface-water compartment the total fugacity capacity, $Z_{w}$ in $\mathrm{mol} / \mathrm{m}^{3}-\mathrm{Pa}$, is composed of the volume-weighted average of the fugacity capacities of its two constituent phases, water and suspended particles,

$$
Z_{w}=Z_{\text {water }}+\left(\rho b_{w} / \rho s_{w}\right) \times Z_{w p}
$$

where $\rho b_{w}$ is the suspended particle load in surface water, $\mathrm{kg} / \mathrm{m}^{3}, \rho \mathrm{s}_{\mathrm{w}}$ is density of the suspended-particle material, $\mathrm{kg} / \mathrm{m}^{3}$, and $Z_{w p}$ is the fugacity capacity of the particles and given by

$$
Z_{w p}=K_{d w} \times \rho s_{w} \times Z_{\text {water }} \times \frac{1 \mathrm{~m}^{3} \text { water }}{1000 \mathrm{~L} \text { water }}
$$

in which $\mathrm{K}_{\mathrm{d} w}$ represents the sorption coefficient of suspended particles, $\mathrm{L} / \mathrm{kg}$. The volume fraction of suspended particles in water is assumed to be so small that the volume fraction of the water phase is essentially unity. 


\section{Fugacity Capacity of Sediment}

In the sediment compartment the total fugacity capacity, $Z_{d}$ in $\mathrm{mol} / \mathrm{m}^{3}-\mathrm{Pa}$, is composed of the volume-weighted average of the fugacity capacities of its two constituent phases, sediment particles and water,

$$
Z_{d}=\beta_{d} \times Z_{\text {water }}+\left(1-\beta_{d}\right) \times Z_{d p}
$$

where $\beta_{\mathrm{d}}$ is the void fraction of the sediment compartment, $1-\beta_{\mathrm{d}}$ is the volume fraction of sediment particles in the sediment compartment, and $Z_{\mathrm{dp}}$ is the fugacity capacity of the sediment layer particles and given by

$$
Z_{\mathrm{dp}}=K_{\mathrm{dd}} \times \rho \mathrm{s}_{\mathrm{d}} \times \frac{1 \mathrm{~m}^{3} \text { water }}{1000 \mathrm{~L} \text { water }}
$$

in which $K_{d d}$ represents the sorption coefficient of sediment layer particles, $L / \mathrm{kg}$.

Modifications to Fugacity Capacities for Inorganic and Ionic-Organic Chemicals

The traditional fugacity approach was developed for nonionic organic chemicals. The modifications described here make possible the treatment of inorganic species (including radionuclides), metals, and fully ionized organic species. In order to make these adjustments, it should be recognized that the basic premise of the fugacity approach is that the mass potential of any compartment can be scaled to a single phase through a series of partition coefficients. In the traditional fugacity approach this scaling is $1 / \mathrm{RT}$. However, for chemicals that have extremely low vapor pressure and relatively high water solubility this leads to the problem of having extremely large fugacity capacities in water. To avoid this problem for chemicals with very low vapor pressure, such as inorganic chemicals and speciated or ionized organic chemicals, we assume that these chemicals can be described by zero fugacity in air, that is, $Z_{\text {air }}=0$. We then set the fugacity capacity of water, $Z_{\text {water }}$ equal to $1 \mathrm{~mol} / \mathrm{m}^{3}-\mathrm{Pa}$. This approach has been used by Mackay and Diamond (1989) and Diamond et al. (1992) for inorganic species in lakes. They refer to this modification as "aquivalence." This leads to a scaling of other phases and compartment fugacity capacities based on the fugacity capacity of the water phase. Thus, as above, the fugacity capacity of the particles of compartments $(i=g, s, w, d)$ is of the form 


$$
Z_{\text {ip }}=K_{\mathrm{di}} \times \rho s_{\mathrm{i}} \times Z_{\text {water }} \times \frac{1 \mathrm{~m}^{3} \text { water }}{1000 \mathrm{~L} \text { water }},
$$

and, since $Z_{\text {air }}$ is now assumed equal to zero, the fugacity capacity of air particles becomes the same as that of the ground-surface-soil particles,

$$
Z_{\text {ap }}=Z_{\mathrm{gp}}=K_{\mathrm{dg}} \times \rho \mathrm{s}_{\mathrm{g}} \times Z_{\text {water }} \times \frac{1 \mathrm{~m}^{3} \text { water }}{1000 \mathrm{~L} \text { water }}
$$

\section{Transport Processes in the CAirTOX Model}

In a multirnedia model, major components of the environment are lumped into homogensous subsystems or compartments that can exchange mass with other adjacent compartments. Mass flows among compartments include solid-phase tlows, such as dust suspension or deposition, and liquid-phase flows, such as surface runoff and ground-water recharge. In the previous section, we considered the use of fugacity to describe how each chemical species is partitioned among the phases within a single compartment. The nature of this partitioning in combination with mass flows at compartment boundaries defines the overall rate of cross-media transfer of contaminants between any two adjacent compartments. The transport of individual chemical species among compartments occurs by diffusion and advection at the compartment boundaries. The modeling of these two processes is described in this section.

As was noted earlier in this report, one of the major advantages of fugacity models is their ability to more easily represent diffusive transfer. In a fugacity model, the net diffusive flux, in $\mathrm{mol} / \mathrm{m}^{2}-\mathrm{d}$, across the interface described above is

$$
\text { net flux at the surface }=Y_{\mathrm{aw}}\left(f_{\mathrm{a}}-f_{\mathrm{w}}\right) \text {, }
$$

where $Y_{a w}$ is the fugacity mass-transfer coefficient across the boundary between air and water with units $\mathrm{mol} /\left(\mathrm{m}^{2}-\mathrm{Pa}-\mathrm{d}\right)$ and $f_{a}$ and $f_{w}$ are the fugacities of air and water. $Y_{\mathrm{aw}}$ acts as a conductance, and the difference in fugacities is the mass potential driving mass transfer across this boundary. The overall fugacity masstransfer coefficient depends only on the mass-transfer coefficient on either side of the interface.

$$
Y_{\mathrm{aw}}=\left[1 /\left(Z_{\mathrm{a}} U_{\mathrm{a})}+1 /\left(Z_{\mathrm{w}} U_{\mathrm{w}}\right)\right]^{-1}\right.
$$


It should be noted that the overall fugacity mass-transfer coefficient, $Y_{a w}$, is related to the air-side fugacity mass-transfer coefficient for this interiace, $Y_{\mathrm{aw}}^{\mathrm{a}}$, and the waterside fugacity mass-transfer coefficient for this interface, $Y_{\mathrm{aw}}^{\mathrm{w}}$. These mass-transfer coefficients have units of $\mathrm{mol} /\left(\mathrm{m}^{2}-\mathrm{Pa}-\mathrm{d}\right)$ and are given by

$$
Y_{\mathrm{aw}}^{\mathrm{a}}=Z_{\mathrm{a}} U_{\mathrm{a}}=Z_{\mathrm{a}} \frac{D_{\mathrm{air}}}{\delta_{\mathrm{aw}}}
$$

and

$$
Y_{\mathrm{aw}}^{\mathrm{w}}=Z_{\mathrm{w}} \cdot I_{\mathrm{w}}=Z_{\mathrm{w}} \frac{D_{\mathrm{w}}}{\delta_{\mathrm{wa}}}
$$

where $D_{\text {air }}$ is the diffusivity in the air compartment, $\mathrm{m}^{2} / \mathrm{d} ; \delta_{\mathrm{aw}}$ is the boundarylayer thickness in the air above water, $m$; where $D_{w}$ is the effective diffusivity in the water compartment, $\mathrm{m}^{2} / \mathrm{d}$; and $\delta_{\mathrm{wa}}$ is the boundary-layer thickness in the water below the air, $m$. The relationships derived in this section for mass transfer at the air-water interface can be generalized to mass transfer at air-soil, soil-soil, and watersediment interfaces.

\section{Diffusive Mass Transfer at the Air and Surface-Water Interface}

The exchange by diffusion of organic chemicals between the lower atmosphere and surface-water bodies is an important component of the overall rate constant defining transport between air and water. The exchange of chemicals between air and water bodies depends on both the physicochemical properties of the contaminant and the physical properties of the air and water compartments involved. Important physicochemical properties include solubility, molecular weight, vapor pressure, and diffusion coefficients in air and water. The important landscape properties include temperatures of air and water, wind speed, water-flow velocity, water depth, and water turbulence.

The air-side fugacity mass transfer coefficient, $\gamma_{\mathrm{aw}}^{\mathrm{a}}$, and the water-side fugacity mass-transfer coefficient, $Y_{a w}^{w}$, for the air-watt $r$ interface are given by equations [27] and [28]. These mass-transfer coefficients have units of $\mathrm{mol} /\left(\mathrm{m}^{2}-\mathrm{Pa}-\mathrm{d}\right)$. Lyman et al. (1982) have reviewed several methods for estimating water-side and gas-side mass transfer coefficients for atmosphere-surface water exchange of organic chemicals. In CAirTOX, the estimation of the water-side boundary mass-transfer 
coefficient, $D_{\text {water }} / \delta_{\text {wa }}$, is based on methods developed by Southworth (1979) from laboratory data for chemicals with $\mathrm{H}$ in the range 1 to $100 \mathrm{~Pa}-\mathrm{m}^{3} / \mathrm{mol}$. When the surface-water current, current $t_{w}$ in $\mathrm{m} / \mathrm{s}$, is less than 0.04 times the wind velocity, $\mathrm{v}_{\mathrm{w}}$ in $\mathrm{m} / \mathrm{s}$, to the 0.67 power, then $D_{\text {water }} / \delta_{\text {wa }}$ is $0.24 \mathrm{~m} / \mathrm{d}$. For larger surface-water currents and for land units in which the yearly average wind velocity, $v_{w}$, is less than $1.9 \mathrm{~m} / \mathrm{s}$,

$$
D_{\text {water }} / \dot{d}_{\text {wa }}=5.64\left(\frac{\text { current }_{w}^{0.969}}{d_{w}^{0.673}}\right) \sqrt{\frac{32}{M W_{x}}} \mathrm{~m} / \mathrm{d}
$$

where $d_{w}$ is the average depth of the surface-water body in $m$ and $M W$ is the molecular weight of the contaminant. For land units in which the yearly average wind velocity, $\mathrm{v}_{\mathrm{w}}$, is larger than $1.9 \mathrm{~m} / \mathrm{s}$,

$$
D_{\text {water }} / \delta_{\text {wa }}=5.64\left(\frac{\text { current }_{w}^{0.969}}{d_{w}^{0.673}}\right) \sqrt{\frac{32}{M W_{x}}} e^{0.526\left(v_{w}-1.9\right)} \mathrm{m} / \mathrm{d}
$$

For estimating the air-side mass-transfer coefficient, $D_{\text {air }} / \delta_{\mathrm{aw}}$, we also used methods developed by Southworth (1979), based on laboratory data for chemicals with $\mathrm{H}$ in the range from 1 to $100 \mathrm{~Pa}-\mathrm{m}^{3} / \mathrm{mol}$. In this case the mass-transfer coefficient, $D_{a} / \delta_{a w}$, in $m / d$, is given by

$$
D_{\mathrm{air}} / \delta_{\mathrm{aw}}=273\left(v_{\mathrm{w}}+\text { current }_{\mathrm{w}}\right) \sqrt{\frac{18}{M W_{\mathrm{x}}}} \mathrm{m} / \mathrm{d},
$$

when the sum, $v_{\text {wind }}+$ current $_{w}$, is greater than $0.5 \mathrm{~m} / \mathrm{s}$, and by

$$
D_{\mathrm{air}} / \delta_{\mathrm{aw}}=140 \sqrt{\frac{18}{M W_{\mathrm{x}}}} \mathrm{m} / \mathrm{d},
$$

when the sum, $\mathrm{v}_{\text {wind }}+$ current $_{\mathrm{w}}$, is less than $0.5 \mathrm{~m} / \mathrm{s}$.

\section{Diffusive Mass Transfer in Air at the Air and Ground-Surtace Soil Interface}

Diffusive mass transfer at the soil-air interface accounts for both net volatilization of contaminants from soil and deposition of gas-phase contaminants to the ground-surface-soil layer. Once again, net mass transfer depends on mass 
transfer through both the air-side and ground-soil-side boundary layers. The fugacity mass transfer coefficient on the air side of the air-ground-soil interface is given by

$$
Y_{\mathrm{ag}}^{\mathrm{a}}=Z_{\mathrm{a}} \frac{D_{\mathrm{air}}}{\delta_{\mathrm{ag}}}
$$

where, $\delta_{\mathrm{ag}}$ is the boundary layer thickness in the air above the ground-soil layer. This thickness is assumed to be on the order of $0.005 \mathrm{~m}$. On smooth surfaces the boundary layer thickness varies from about $1 \mathrm{~cm}$ in still air to $1 \mathrm{~mm}$ when the air moves over the surface at $1 \mathrm{~m} / \mathrm{s}$.

Diffusive Mass Transfer in the Ground-Surface and Root-Zone Soil Layers

Because soil is not a well-mixed compartment such as air or surface water, the boundary-layer approach described above is not readily applicable to soil. The concentration gradient of contaminants may not level off for several meters. In well-mixed air and water compartments, the boundary layer thickness is on the order of centimeters. Cohen et al. (1990) have noted that the soil compartment in a multimedia model should include a spatial-diffusion model. Jury et al. (1990) have shown that the "limiting soil-cover depth" varies from $0.001 \mathrm{~m}$ (for chrysene) to $160 \mathrm{~m}$ (for dichlorodifluoromethane) in sandy soil and from $<0.001$ to $61 \mathrm{~m}$ for the same compounds in clay soil. The limiting soil depth is the thickness of soil that is required to limit volatilization loss over an infinite time to less than $1 \%$ of the initial concentration. This is the depth at which volatilization at the surface has essentially no impact on concentration. Above this depth, there is a gradient of concentration that will be controlled by the rate of evaporation at the surface of the soil.

There have been several approaches to the problem of devising a simple but accurate model of soil transport. In one of the more simple approaches, Mackay and Paterson (1991) use a diffusion-path length that is half the depth of the soil compartment as the boundary-layer thickness in their regional fugacity model. This value is independent of chemical species.

In CAirTOX we deal with the problem of nonuniform concentration in soils by using two soil layers to represent the region between the soil surface and the bottom of the "limiting soil layer depth". An approach developed by McKone (1993b) was used to determine an effective soil diffusion coefficients to estimate 
boundary layer thicknesses in each of these two soil layers by an optimized fit against the more exact soil transport model of Jury et al. (1983). The optimization goal was to minimize the estimation error in the surface flux and compartment inventories predicted for the surface and root-zone soil layers relative to values obtained from the Jury et al. (1983) analytical solution. In effect, this procedure allows us to mimic the Jury et al (1983) model with a more simple regression model based on effective diffusivity. The price we pay for this increased simplicity is less precision. However, we can calculate this loss of precision and note that so long as it is comparable to the variability or uncertainty in characterizing the initial soil concentrations, it should not lead to significant degradation of the model reliability relative to the Jury et al. (1983) model from which it is derived. The following expressions were used to estimate the boundary layer thickness or diffusion length in CAirTOX,

$$
\begin{aligned}
& \delta_{g}=0.108 \times D_{g}^{0.229} \text { and } \\
& \delta_{s}=318 \times D_{s}^{0.683} .
\end{aligned}
$$

In these expressions, $\delta_{\mathrm{g}}$ and $\delta_{\mathrm{s}}$ are the diffusion lengths (in $\mathrm{m}$ ) in the ground-surface and root-zone-soil compartments and $D_{g}$ and $D_{s}$ are the effective diffusivities in these compartments (in $\mathrm{m}^{2} / \mathrm{d}$ ) as obtained from

$$
D_{\mathrm{i}}=\frac{Z_{\text {air }}}{Z_{\mathrm{i}}}\left(\alpha_{\mathrm{i}}^{10 / 3} / \phi_{1}^{2}\right) D_{\text {air }}+\frac{Z_{\text {water }}}{Z_{\mathrm{i}}}\left(\beta_{\mathrm{i}}^{10 / 3} / \phi_{\mathrm{i}}^{2}\right) D_{\text {water }}
$$

where $i$ is replaced by $g$ for ground-surface soil and by $s$ for root soil; $D_{i}$ is the effective tortuous, mixed-phase diffusion coefficient in soil zone $i$, the $Z$ 's are the fugacity capacities derived previously, and other parameters are as defined previously.

\section{Diffusive Mass Transfer at the Surface-Water and Sediment Interface}

Diffusive mass transfer at the sediment-water interface accounts for the net volatilization of contaminants from sediment and deposition of dissolved contaminants to the sediment layer. In each case, total mass transfer depends on both the water-side and sediment-side boundary layers. The fugacity mass-transfer coefficient on the water side is given by 


$$
Y_{w d}^{w}=Z_{w} \frac{D_{w a t e r}}{\delta_{w d}}
$$

where $Z_{w}$ is the fugacity capacity in the surface-water compartment, $D_{\text {water }}$ is the effective diffusivity in the surface-water compartment, and $\delta_{w d}$ is the boundarylayer thickness in the water above the sediment layer. The fugacity mass-transfer coefficient on the sediment side is given by

$$
Y_{w d}^{d}=Z_{d} \frac{D_{d}}{\varepsilon_{d w}},
$$

where $Z_{d}$ is the fugacity capacity in the sediment compartment, $D_{d}$ is the effective diffusivity in the sediment compartment, and $\delta_{\mathrm{dw}}$ is the boundary-layer thickness in the sediment layer below water. Formica et al. (1988) have described a method for calculating for the sediment layer effective diffusivity based on corrections for the solids content of sediment. This approach is similar to that used by Jury et al. (1983) as described in equation [36] with the volume fraction of the gas phase set to zero. We use fluxes of radon from the Hudson river estuary measured by Hammond et al. (1975) to estimate the water-side boundary-layer thickness. The reported flux is 200 atoms $/ \mathrm{m}^{2} \mathrm{~s}$ above sediments with a concentration of radon in water of $2.6 \times 10^{9}$ atoms per $\mathrm{m}^{3}$ with a diffusion coefficient of $1.4 \times 10^{-9} \mathrm{~m}^{2} / \mathrm{s}$. This implies a boundary-layer thickness of $0.02 \mathrm{~m}$, which is what we use in CAirTOX for the water-side boundarylayer thickness above sediments. For the boundary-layes thickness in sediments below the water column, we use equation [36] with $d$ substituted for $i$.

\section{Mass Transfer by Advection in Water and Solids}

In CAirTOX, the cross-media transfer of contaminants by advection is treated as an advection flux. This flux is modeled as the product of the velocity of the moving phase times the contaminant concentration in that phase. This flux has units of $\mathrm{mol} / \mathrm{m}^{2}-\mathrm{d}$, the velocity of the moving phase is in $\mathrm{m} / \mathrm{d}$, and the concentration in the moving phase is the product of the contaminant fugacity in that phase, $\mathrm{Pa}$, and the fugacity capacity of that phase in $\mathrm{mol} / \mathrm{m}^{3}-\mathrm{Pa}$,

$$
\text { advection flux }=\text { velocity } \times Z_{\mathrm{ik}} f_{\mathrm{i}} \text {, }
$$


where $Z_{\mathrm{ik}}$ and $f_{\mathrm{i}}$ represent the fugacity capacity of the moving phase and the fugacity, respectively, in compartment $i$. As an example, the flux of contaminant from air to surface soil through particle deposition is the product of deposition velocity, $v_{d}$; the fugacity capacity of air particles, $Z_{a p ;}$ and the total fugacity of the air compartment, $f_{\mathrm{a}}$ :

$$
\text { flux (air to ground-surface soil) }=v_{\mathrm{d}} \times Z_{\mathrm{ap}} \times f_{\mathrm{a}} .
$$

Advection processes used in the CAirTOX model include deposition of aerosol particles, resuspension of particles from soil, water-borne erosion of soil, rainfall, evaporation, runoff of precipitation, infiltration of water through soil, deposition of sediment particles in surface water, resuspension of sediment particles from the sediment layer, and surface water flows. The advective or nondiffusive flux terms used in the CAirTOX model are summarized in Table $\mathrm{I}$.

\section{Transformation Processes in the CAirTOX Model}

The transformation of contaminants in the environment can have a profound effect on their potential for persistence. Chemical transformations, which may occur as a result of biotic or abiotic processes, can significantly reduce the concentration of a substance. For organic chemicals, knowledge of a compound's half-life for any given transformation process provides a very useful index of persistence in environmental media. Because these processes determine the persistence and form of a chemical in the environment, they also determine the amount and cype of substance that is available for the exposure of species of interest. Experimental methods (Howard et al., 1978) and estimation methods (Lyman et al., 1982) are available for defining these fate processes in a variety of media. Specific information on the rates and pathways of transformation for individual chemicals of concern must be obtained directly from experimental determinations or derived indirectly from information on chemicals that are structurally similar. In CAirTOX, all removal reactions are modeled using a first-order rate constant with units of day ${ }^{-1}$. 
Table I. Advective or non-diffusive flux terms used for intermedia transfers in the CAirTOX model.

\begin{tabular}{|c|c|c|}
\hline Intermedia Transfer & $\begin{array}{l}\text { Description of the non- } \\
\text { diffusive process }\end{array}$ & Formula \\
\hline Air to ground-surface soil & $\begin{array}{l}\text { Rain scavenging of } \\
\text { gaseous contaminants } \\
\text { from air to ground }\end{array}$ & $f l u x=\operatorname{rain} \times Z_{\text {water }} \times f_{\mathrm{a}}$ \\
\hline Air to plant leaves ${ }^{a}$ & $\begin{array}{l}\text { Wet and dry deposition of } \\
\text { particle-bound species }\end{array}$ & $f l u x=F_{\mathrm{v}} \times v_{\mathrm{d}} \times Z_{\mathrm{ap}} \times f_{\mathrm{a}}$ \\
\hline $\begin{array}{l}\text { Air to ground-surface } \\
\text { soila }\end{array}$ & $\begin{array}{l}\text { Wet and dry deposition of } \\
\text { particle-bound species }\end{array}$ & $f l u x=\left(1-F_{\mathrm{v}}\right) \times v_{\mathrm{d}} \times Z_{\mathrm{ap}} \times f_{\mathrm{a}}$ \\
\hline Air to surface water & $\begin{array}{l}\text { Rain scavenging of } \\
\text { gaseous contaminants } \\
\text { from air to ground }\end{array}$ & flux $=\operatorname{rain} \times Z_{\text {water }} \times f_{\mathrm{a}}$ \\
\hline Air to surface water & $\begin{array}{l}\text { Wet and dry deposition of } \\
\text { particle-bound } \\
\text { contaminants }\end{array}$ & $f l u x=v_{\mathrm{d}} \times Z_{\mathrm{ap}} \times f_{\mathrm{a}}$ \\
\hline $\begin{array}{l}\text { From air compartment } \\
\text { out of the system }\end{array}$ & $\begin{array}{l}\text { Wind induced movement } \\
\text { of the air mass out of the } \\
\text { landscape boundary }\end{array}$ & $f l u x=z_{\mathrm{a}} \frac{0.23 \times v_{\mathrm{w}} \times d_{\mathrm{a}}}{\sqrt{\text { Area }}}$ \\
\hline Ground-surface soil to air & $\begin{array}{l}\text { Resuspension of soil } \\
\text { particles }\end{array}$ & $f l u x=v_{\mathrm{d}} \times Z_{\mathrm{gp}} \times f_{\mathrm{g}}$ \\
\hline $\begin{array}{l}\text { Ground-surface soil to } \\
\text { root-zone soil }\end{array}$ & $\begin{array}{l}\text { Leaching due to ground- } \\
\text { water recharge }\end{array}$ & flux $=$ recharge $\times Z_{\text {water }} \times f_{\mathbf{g}}$ \\
\hline $\begin{array}{l}\text { Ground-surface soil to } \\
\text { surface water }\end{array}$ & Soil-solution runoff & flux $=$ runoff $\times Z_{\text {water }} \times f_{\mathbf{g}}$ \\
\hline $\begin{array}{l}\text { Ground-surface soil to } \\
\text { surface water }\end{array}$ & $\begin{array}{l}\text { Erosion (mineral runoff) } \\
\text { to surface water }\end{array}$ & flux $=$ erosion $\times Z_{g p} \times f_{g}$ \\
\hline $\begin{array}{l}\text { Root-zone soil to vadose- } \\
\text { zone soil }\end{array}$ & $\begin{array}{l}\text { Leaching due to ground- } \\
\text { water recharge }\end{array}$ & flux $=$ recharge $\times Z_{\text {water }} \times f_{s}$ \\
\hline Surface water to sediment & Sediment deposition & $f l u x=$ deposit $\times Z_{w p} \times f_{w}$ \\
\hline $\begin{array}{l}\text { From surface water out of } \\
\text { the landscape }\end{array}$ & Surface-water outflow & flux $=$ outflow $\times Z_{w} \times f_{w}$ \\
\hline Sediment to surface water & Sediment resuspension & flux $=$ resuspend $\times Z_{\mathrm{dp}} \times f_{\mathrm{d}}$ \\
\hline
\end{tabular}

a $F_{v}$ is the fraction of deposited material intercepted by vegetation and given by $1-\exp \left(-2.8 \times\right.$ bio $\left._{\text {inv }} / 2\right)$, where bio $_{\text {inv }} / 2$ is the dry-mass inventory of above-ground biomass in $\mathrm{kg} / \mathrm{m}^{2}$. 


\section{Transfer-Rate, Lose-Rate, and the Gain-Loss Equations}

The steady-state equations describing gains and losses in each of the seven compartments are used to solve for the steady-state inventory in each compartment. Table II lists the gains and losses considered for each compartment. The following equations express losses and gains for each of the seven CAirTOX compartments.

$$
\begin{array}{ll}
S_{\mathrm{a}}+T_{\mathrm{la}} N_{\mathrm{l}}+T_{\mathrm{ga}} N_{\mathrm{g}}+T_{\mathrm{wa}} N_{\mathrm{w}}=L_{\mathrm{a}} N_{\mathrm{a}} & \text { (air) } \\
T_{\mathrm{g}} N_{\mathrm{a}}+T_{\mathrm{g} 1} N_{\mathrm{g}}+T_{\mathrm{r} l} N_{\mathrm{r}}=L_{\mathrm{l}} N_{\mathrm{l}} & \text { (plant leaves) } \\
T_{\mathrm{ag}} N_{\mathrm{a}}+T_{\mathrm{lg}} N_{\mathrm{l}}+T_{\mathrm{sg}} N_{\mathrm{s}}=L_{\mathrm{g}} N_{\mathrm{g}} & \text { (ground-surface soil) } \\
T_{\mathrm{gs}} N_{\mathrm{g}}=L_{\mathrm{g}} N_{\mathrm{s}} & \text { (root-zone soil) } \\
T_{\mathrm{sr}} N_{\mathrm{s}}=L_{\mathrm{r}} N_{\mathrm{r}} & \text { (plant root) } \\
T_{\mathrm{aw}} N_{\mathrm{a}}+T_{\mathrm{gw}} N_{\mathrm{g}}+T_{\mathrm{dw}} N_{\mathrm{d}}=L_{\mathrm{w}} N_{\mathrm{w}} \text { and } & \text { (surface water) } \\
T_{\mathrm{wd}} N_{\mathrm{w}}=L_{\mathrm{d}} N_{\mathrm{d}} & \text { (sediments) }
\end{array}
$$

In the equations above the $N^{\prime} s$ represent compartment inventories and the $T_{i j}\left(i, j=a, l, g, s, r, w\right.$, or $d$ ) are transfer rate constants, with units of day ${ }^{-1}$, that express fraction per unit time of the inventory of compartment $i$ that is transferred to compartment $j$. The compartment abbreviations are $a$ for air, $l$ for plant leaves, 8 for ground-surface soil, $s$ for root-zone soil, $r$ for plant roots, $w$ for surface water, and $d$ for sediments. The product of an $N$ term and a $T$ term is the rate of change of inventory in mol/d. $L_{\mathrm{i}} N_{\mathrm{i}}$ represents all losses from compartment $i, \mathrm{~mol} / \mathrm{d}$. The term $S_{a}$, in equation [41] is the rate of contaminant input to the air compartment, $\mathrm{mol} / \mathrm{d}$. In the sections below, the transfer-rate constants are defined in terms of landscape properties, chemical properties, fugacity capacities, and other parameters used to construct them and the loss-rate constants are defined in terms of transferand transformation-rate constants.

In terms of fugacity, the balance in $\mathrm{mol} / \mathrm{d}$ is expressed as a loss from a compartment $i$ and transfer to a compartment $j$ in the form

$$
\text { loss }=\text { Area } \times v_{i j} \times Z_{i k} \times f_{i},
$$


Table II. Summary of the processes by which contaminants are exchanged and lost among the seven CAirTOX compartments.

\begin{tabular}{|c|c|c|}
\hline Compartment & Gains & Losses \\
\hline $\begin{array}{l}\text { (1) Air (both the gas } \\
\text { phase and particles } \\
\text { of the troposphere) }\end{array}$ & $\begin{array}{l}\text { diffusion from soil } \\
\text { diffusion from plants } \\
\text { diffusion from surface water } \\
\text { resuspension of deposited soil } \\
\text { particles } \\
\text { contaminant sources }\end{array}$ & $\begin{array}{l}\text { diffusion to ground-surface soil } \\
\text { diffusion to surface water } \\
\text { diffusion to plants } \\
\text { washout by rainfall } \\
\text { convection losses } \\
\text { deposition to soil } \\
\text { deposition to plants } \\
\text { deposition to surface water } \\
\text { chemical/physical transformation }\end{array}$ \\
\hline (2) Plant leaves & $\begin{array}{l}\text { deposition of particles from air } \\
\text { foliar uptake }\end{array}$ & $\begin{array}{l}\text { diffusion from leaf surfaces } \\
\text { washoff from leaf surfaces } \\
\text { chemical/physical transformation }\end{array}$ \\
\hline (3) Ground-surface soil & $\begin{array}{l}\text { diffusion from air } \\
\text { diffusion from root-zone soil } \\
\text { washout from air by rainfall } \\
\text { dry deposition of air particles } \\
\text { contaminant sources }\end{array}$ & $\begin{array}{l}\text { diffusion to air } \\
\text { diffusion to root-zone soil } \\
\text { advection to root-zone soil } \\
\text { soil solution runoff } \\
\text { erosion (mineral runoff) to surface } \\
\text { water } \\
\text { resuspension of soil particles } \\
\text { chemical/physical transformation }\end{array}$ \\
\hline (5) Root-zone soil & $\begin{array}{l}\text { diffusion from ground-surface soil } \\
\text { advection from ground-surface } \\
\text { soil } \\
\text { plant decomposition }\end{array}$ & $\begin{array}{l}\text { diffusion to ground-surface soil } \\
\text { infiltration (leaching) to vadose- } \\
\text { zone soil } \\
\text { chemical/physical transformation }\end{array}$ \\
\hline (6) Plant roots & $\begin{array}{l}\text { Translocation from leaves } \\
\text { root-uptake from root-zone soil }\end{array}$ & $\begin{array}{l}\text { translocation to leaves } \\
\text { plant decomposition }\end{array}$ \\
\hline (6) Surface water & $\begin{array}{l}\text { diffusion from air } \\
\text { washout by rainfall } \\
\text { deposition of atmospheric } \\
\text { particles } \\
\text { soil solution runoff } \\
\text { erosion (mineral runofn } \\
\text { diffusion from sediment } \\
\text { sediment resuspension }\end{array}$ & $\begin{array}{l}\text { sediment deposition } \\
\text { diffusion to air } \\
\text { diffusion to sediment } \\
\text { surface-water outflow } \\
\text { chemical/physical transformation }\end{array}$ \\
\hline (7) Sediment layer & $\begin{array}{l}\text { diffusion from surface water } \\
\text { sediment deposition (from surface } \\
\text { water) }\end{array}$ & $\begin{array}{l}\text { diffusion to surface water } \\
\text { sediment resuspension } \\
\text { chemical/physical transformation }\end{array}$ \\
\hline
\end{tabular}


where Area in $\mathrm{m}^{2}$ is that across which mass exchange occurs, $\mathrm{v}_{i j}$ is the advection or diffusion velocity from $i$ to $j$ at the exchange boundary, and $Z_{i k}$ is the fugacity capacity of the moving phase $k$ from $i$ to $j$, and $f_{i}$ represents the fugacity of compartment $i$. Equation [48] can also be written as

$$
\text { loss }=T_{i j} N_{i},
$$

in which

$$
\begin{aligned}
& N_{i}=Z_{i} f_{i} V_{i}, \\
& T_{i j}=\frac{\operatorname{area} \times 0_{i i}}{V_{i}} \frac{Z_{i k}}{Z_{i}}=\frac{v_{i j}}{d_{i}} \frac{Z_{i k}}{Z_{i}} \text {, and }
\end{aligned}
$$

$V_{i}$ is the compartment volume, $d_{i}$ is the compartment depth or thickness, and $Z_{i}$ is the total fugacity capacity of compartment $i$. This is the general approach used in the sections below to obtain the transfer-rate constants.

$\operatorname{Air}(a)$

The air compartment is represented by a simple box model in which losses include deposition to soil, vegetation, and surface water; convective losses; and transformation losses. In the box model used for air, the inventory, $N_{\mathrm{a}}$ in mol, is described by solving equations [41] to [47]. $L_{\mathrm{a}}$ is the sum of all loss-rate constants from the air compartment,

$$
L_{\mathrm{a}}=T_{\mathrm{al}}+T_{\mathrm{ag}}+T_{\mathrm{aw}}+T_{\mathrm{ao}}+R_{\mathrm{a}}
$$

where $L_{\mathrm{a}} N_{\mathrm{a}}$ is the sum of all losses from the air compartment, mol/d; $T_{1 \mathrm{a}} N_{\mathrm{p}}, T_{\mathrm{ga}}$ $N_{g}$, and $T_{w a} N_{w}$ are the gains from plant leaves, ground soil, and water, $\mathrm{mol} / \mathrm{d} ; T_{a g}$, $T_{\mathrm{al}}$, and $T_{\mathrm{aw}}$ are the rate constants for deposition losses, to ground soil, plant leaves, and water, day ${ }^{-1} ; T_{\mathrm{ao}}$ is the rate constant for convective losses, day ${ }^{-1}$ and $R_{\mathrm{a}}$ is the rate constant for transformation losses, day ${ }^{-1}$.

According to Benarie (1980), the long-term average pollutant concentration in a region bordered by a box model with volume $V_{\mathrm{a}}$ and pollution source, $S_{\mathrm{a}}$ in $\mathrm{mol} / \mathrm{d}$, is given by

$$
C_{\text {air }}=N_{\mathrm{a}} / V_{\mathrm{a}}=\frac{c S_{\mathrm{a}}}{\operatorname{Area} \times v_{\mathrm{w}}}
$$


where $c$ is a unitless proportionality constant; Area is the area of the region being modeled, and $v_{w}$ is the long-term average wind speed in $\mathrm{m} / \mathrm{d}$. This implies that the inverse of the rate constant, $T_{a o}$, is the convective residence time and is given by the expression, $c d_{a} / v_{w}$, where $d_{a}$ is the atmospheric mixing height. Based on a model for area sources developed by Turner (1970), the constant $c$ can be estimated as 4.3 $\sqrt{\text { Area }} / d_{a}$, where $\sqrt{\text { Area }}$ is the cross-sectional length of an assumed square area containing the source $S_{\mathrm{a}}$. Making the appropriate substitutions gives the following expression for the convective loss-rate constant in the air compartment:

$$
T_{\text {ao }}=\frac{0.23 v_{w}}{\sqrt{\text { Area }}}
$$

The rate constant, $T_{\mathrm{ag}}$, accounts for gross diffusion, rain-water washout, and particle-deposition losses from air to ground-surface soil.

$$
T_{\mathrm{ag}}=\left(1-f_{\mathrm{arw}}\right) \times \frac{\left(\gamma_{\mathrm{ag}}+\text { rain } \times \mathrm{Z}_{\text {water }}+\mathrm{v}_{\mathrm{d}} \times \mathrm{Z}_{\mathrm{ap}} \times \frac{\rho \mathrm{b}_{\mathrm{a}}}{\rho s_{\mathrm{g}}}\right)}{\left(\mathrm{Z}_{\mathrm{a}} \times \mathrm{d}_{\mathrm{a}}\right)} .
$$

In this expression, $f_{a r w}$ is the fraction of land area that is covered by surface water; $\rho b_{a}$ is the particle loading in the air, $\mathrm{kg} / \mathrm{m}^{3}$, and $\rho s_{\mathrm{g}}$ is the particle density, $\mathrm{kg} / \mathrm{m}^{3}$. If the land-unit area is greater than or equal to $6 \times 10^{8} \mathrm{~m}^{2}$, then the air-compartment mixing depth, $d_{a}$, is $700 \mathrm{~m}$; if the area is less than $6 \times 10^{8} \mathrm{~m}^{2}$, then $d_{a}$ is $0.22(\sqrt{\text { Area }}) 0.8$ (Hanna et al., 1982). The net diffusion from air ground-surface soil is given by $Y_{\mathrm{ag}}\left(f_{\mathrm{a}}-f_{\mathrm{g}}\right)$. Thus, $Y_{\mathrm{ag}} f_{\mathrm{a}}$ is the gross diffusion from air to soil and $Y_{\mathrm{ag}} f_{\mathrm{g}}$ is the gross diffusion from ground-surface soil to air.

The rate constant, $T_{\mathrm{aw}}$, accounts for gross diffusion, rain-water washout, and particle deposition losses from air to surface water and has the form

$$
T_{\mathrm{aw}}=\mathrm{f}_{\mathrm{arw}} \times \frac{\left(Y_{\mathrm{aw}}+\text { rain } \times Z_{\mathrm{water}}+v_{\mathrm{d}} \times Z_{\mathrm{ap}} \times \frac{\rho \mathrm{b}_{\mathrm{a}}}{\rho \mathrm{s}_{\mathrm{g}}}\right)}{\left(Z_{\mathrm{a}} \times \mathrm{d}_{\mathrm{a}}\right)} .
$$

The rate constant $T_{\mathrm{al}}$ is derived in the next section. 
Plant Leaves (l)

The plant leaves compartment interacts with the air, ground-surface, and plant roots compartments. Its inventory in steady-state, $N_{p}$ in mol, is described by equation [42]. $L_{1}$ is the sum of all loss-rate constants from the plants compartment,

$$
L_{1}=T_{1 \mathbf{a}}+T_{1 \mathrm{~g}}+R_{\mathrm{p}}
$$

where $L_{1} N_{1}$ is the sum of all losses from the plant-leaves compartment, mol/d; $T_{\mathrm{al}} N_{\mathrm{a}}, T_{\mathrm{gl}} N_{\mathrm{g}}$, and $T_{\mathrm{rl}} N_{\mathrm{r}}$ are the gains from air, ground soil, and plant-roots compartments, mol/d; $T_{1 \mathrm{a}}$ and $T_{\mathrm{lg}}$ are the rate constants for diffusion losses to air and for losses due to washoff from leaves and from plant senescance, day ${ }^{-1} ;$ and $R_{1}$ is the rate constant for transformation losses, day ${ }^{-1}$.

The expressions relating transfer of contaminants from air to plant leaves allows for transfer by deposition of the gas phase from air (deposition velocity $v_{d g}$ in $\mathrm{m} / \mathrm{d}$ ) and deposition of particles,

$$
T_{\mathrm{al}}=\left(1-f_{\mathrm{arw}}\right) \frac{\left(v_{\mathrm{dg}} \times Z_{\mathrm{air}}\right)+\left(F_{\mathrm{v}} \times v_{\mathrm{d}} \times Z_{\mathrm{ap}} \times \rho \mathrm{b}_{\mathrm{a}} / \rho \mathrm{s}_{\mathrm{g}}\right)}{Z_{\mathrm{a}} \times d_{\mathrm{a}}} .
$$

The expressions relating transfer of contaminants from plant leaves to air is defined by requiring that the net effect of gas deposition and transfer, $T_{\text {la }}$, from air to leaves will, at steady state, result in a concentration ratio $C_{1}\left(\mathrm{~mol} / \mathrm{m}^{3}\right) / C_{\text {air }}\left(\mathrm{mol} / \mathrm{m}^{3}\right)$ equal to $K_{p a} \times \rho_{p}$

$$
T_{l a}=\left(1-f_{a r w}\right) \frac{o_{d g} \times \text { Area }}{K_{p a} \times \rho_{p} \times V_{l}}
$$

The expression defining the transfer-rate constant from leafe surfaces to ground surface accounts for washoff and plant decay and is assumed to be 0.029 day $^{-1}$ (based on a residence time of $35 \mathrm{~d}$ ),

$$
T_{\text {lg }}=0.029
$$

The expressions relating transfer of contaminants from ground soil to plant leaves is defined by requiring that the net effect of $T_{\mathrm{lg}}$ and $T_{\mathrm{gl}}$ is to move the ratio of 
plant contamination on leaves relative to surface soil in the direction of the rainsplash partition coefficient, which has units of $\mathrm{kg}($ soil) $/ \mathrm{kg}$ (plant),

$$
T_{g 1}=K_{p e}^{\text {rain }} T_{18} \frac{V_{1}}{V_{g}}
$$

$T_{\mathrm{rl}}$ is described in the seciton below on the plant-roots compartment.

\section{Ground-Surface Soil (g)}

The ground-soil compartment represents the thin suriace layer of soil in which losses include diffusion to air, diffusion to root-zone soil, infiltration to rootzone soil, runoff to surface water, rainsplash to plant surfaces, and transformation processes. The inventory, $N_{g}$, in mol of contaminant in the ground-soil compartment is described by equation [43]. $L_{g}$ is the sum of all loss-rate constants from the ground-surface-soil compartment,

$$
L_{g}=T_{g a}+T_{g 1}+T_{g s}+T_{g w}+R_{g}
$$

where $L_{g} N_{g}$ is the sum of all losses from the ground-soil compartment, mol/d; $T_{\mathrm{ag}} N_{\mathrm{a}}, T_{\mathrm{lg}} N_{1}$, and $T_{\mathrm{gg}} N_{\mathrm{g}}$ are the gains from air, plant leaves, and root-soil compartments, mol/d; $T_{\mathrm{ga}}, T_{\mathrm{gl}}, T_{\mathrm{gs}}$ and $T_{\mathrm{gw}}$ are the rate constants for resuspension losses to air, for losses due to rainsplash and resuspension transfer from ground soil to plant leaves, for gross diffusion losses to air and to root soil, for advection losees due to rain-water infiltration and for runoff losses to surface water, day ${ }^{-1} ;$ and $R_{8}$ is the rate constant for transformation losses, day ${ }^{-1}$. These loss-rate constants are given by

$$
\begin{aligned}
& T_{\mathrm{ga}}=\frac{\gamma_{\mathrm{ag}}+v_{\mathrm{d}} \times \rho \mathrm{pb}_{\mathrm{a}} \times \frac{Z_{\mathrm{gp}}}{\rho \mathrm{s}_{\mathrm{g}}}}{Z_{\mathrm{g}} \times \mathrm{d}_{\mathrm{g}}}, \\
& T_{\mathrm{gs}}=\frac{\text { recharge } \times Z_{w a t e r}+Y_{\mathrm{gg}}}{Z_{\mathrm{g}} \times \mathrm{d}_{\mathrm{g}}},
\end{aligned}
$$




$$
\begin{aligned}
& T_{g w}=\frac{\text { runoff } \times Z_{\text {water }}+\text { erosion } \times \frac{Z_{g p}}{p s_{g}}}{Z_{g} \times d_{g}} \text {, and } \\
& \text { recharge }=\text { rain } \times\left(1-f_{a r w}\right)-\text { evapotrans }- \text { runoff } .
\end{aligned}
$$

Equation (63) reflects the assumption that resuspension of soil particles is, on average, equal to deposition. $T_{9 g}$ is taken up below in the seciton on the root-zone soil. Other parameters in these expressions have been defined previously.

\section{Root-Zone-Soil compartment (s)}

The root-zone-soil compartment represents the layer of soil in which losses include gross diffusion to ground-surface soil, uptake by vegetation, infiltration to vadose-zone soil, and transtormation processes. The inventory, $N_{s}$ in $\mathrm{mol}$, of contaminant in the root-zone-soil compartment is described by equation [44]. $L_{s}$ is the sum of all loss-rate constants from the root-zone-soil compartment,

$$
L_{s}=T_{s r}+T_{s g}+T_{s o}+R_{s},
$$

where $L_{g} N_{\mathrm{g}}$ is the sum of all losses from the root-soil compartment, mol/d; $\mathrm{T}_{\mathrm{gs}} \mathrm{N}_{\mathrm{g}}$ is the gain by diffusion and infiltration from the ground-soil compartment, $\mathrm{mol} / \mathrm{d}$; $T_{s r}, T_{s g}$, and $T_{s v}$ are the rate constants for uptake losses to plant roots, for gross diffusion losses to ground soil, and for diffusion and advection losses to deeper soil, day $^{-1}$; and $R_{9}$ is the rate constant for transformation losses, day ${ }^{-1}$. These loss-rate constants are given by

$$
\begin{aligned}
& T_{\mathrm{sg}}=\frac{Y_{\mathrm{sg}}}{Z_{\mathrm{s}} \times \mathrm{d}_{\mathrm{s}}} . \\
& T_{\mathrm{sr}}=\left(1-f_{\mathrm{arw}}\right) \frac{\text { evapotrans } \times \text { Area } \times Z_{\text {water }}}{Z_{\mathrm{s}} \times \mathrm{V}_{\mathrm{s}}} \\
& T_{\mathrm{so}}=\frac{\text { recharge } \times Z_{\text {water }}}{Z_{\mathrm{g}} \times \mathrm{d}_{\mathrm{s}}} .
\end{aligned}
$$

$T_{\mathrm{sr}}$ relates to the transfer of soil solution into plant roots as a result of transpiration. Other parameters in these expressions have been defined previously. 


\section{Plant Roots ( $r$ )}

The plant-roots compartment represents the portion of plants below the soil surface in which losses include translocation to plant leaves, transfer to soils through root decomposition, and biodegradation within the plant tissues. The inventory, $N_{r}$ in mol, of contaminant in the root-zone-soil compartment is described by equation [45]. $L_{r}$ is the sum of all loss-rate constants from the root-zonesoil compartment,

$$
L_{\mathrm{r}}=T_{\mathrm{rl}}+T_{\mathrm{rl}}+R_{\mathrm{r}}
$$

where $L_{r} N_{r}$ represents total losses from the plant-roots compartment, mol/d; $T_{1 r} N_{1}$ and $T_{s r} N_{s}$ are the gains from leaves by translocation and from root-zone soil by root uptake, mol/d; $T_{\mathrm{rl}}$ is the rate constants for losses from roots to leaves by translocation, day ${ }^{-1}$; and $R_{\mathrm{r}}$ is the rate constant for transformation losses, day ${ }^{-1}$. The expression relating transfer of contaminants from plant roots to root soil is defined by requiring that the net effect of $T_{\mathrm{rs}}$ and $T_{\mathrm{sr}}$ is to move the ratio of plant contamination in roots relative to root soil in the direction of the plant-soil partiton coefficient, which has units of $\mathrm{kg}($ soil) $/ \mathrm{kg}$ (plant),

$$
T_{\mathrm{rg}}=\frac{T_{\mathrm{gr}} \times V_{\mathrm{g}} \times \mathrm{Z}_{\mathrm{g}}}{V_{\mathrm{r}} \times \mathrm{Z}_{\mathrm{r}}}
$$

$T_{\mathrm{rl}}$ relates to the transfer of root solution into plant leaves as a result of transpiration,

$$
T_{\mathrm{rl}}=\left(1-\mathrm{f}_{\mathrm{arw}}\right) \frac{\text { evapotrans } \times \text { Area } \times Z_{\text {water }}}{Z_{\mathrm{r}} \times \mathrm{V}_{\mathrm{r}}}
$$

Other parameters in these expressions have been defined previously.

The Surface-Water Compartment (w)

The surface-water compartment represents bodies of water in which losses include diffusion to air, diffusion to sediment, deposition to sediment, outflow to other surface-water bodies, and transformation processes. The inventory, $N_{w}$, in mol of contaminant in the surface-water compartment is described by equation [46] 
and $L_{w}$ is the sum of all loss-rate constants from the ground-surface-soil compartment,

$$
L_{\mathrm{w}}=T_{\mathrm{wa}}+T_{\mathrm{wd}}+T_{\text {wo }}+R_{\mathrm{w}}
$$

where $L_{w} N_{w}$ is the sum of all losses from the surface-water compartment, mol/d; $T_{\mathrm{aw}} N_{\mathrm{a}}$ is the gain by diffusion and deposition from the air compartment, $\mathrm{mol} / \mathrm{d}$; $T_{g w} N_{g}$ is the gain by runoff from the surface-soil compartment, $\mathrm{mol} / \mathrm{d} ; T_{\mathrm{dw}} i_{\mathrm{d}}$ is the gain by diffusion and deposition from the sediment compartment, mol/d; $T_{\text {wao }}$ $T_{w d}$, and $T_{\text {wo }}$ are rate constants for gross diffusion loss to air, for deposition and gross diffusion losses to sediments, and for loss due to outflow, day ${ }^{-1}$; and $R_{w}$ is the rate constant for transformation losses, day ${ }^{-1}$. The loss-rate constants are given by

$$
\begin{aligned}
& T_{w a}=\frac{Y_{\mathrm{aw}}}{Z_{w} \times d_{w}}, \\
& T_{w d}=\frac{Y_{w d}+\text { deposit } \times Z_{d p} / \rho s_{d}}{Z_{w} \times d_{w}}, \\
& T_{w o}=\text { outflow } \times \frac{\left[Z_{w a t e r}+\left(Z_{w p} \times \rho b_{w} / \rho s_{d}\right)\right]}{Z_{w} \times d_{w} \times f_{a r w}} \text {, and } \\
& \text { outflow = inflow }+ \text { runoff }+ \text { rain } \times\left(f_{a r w}\right)-\text { evaporate. }
\end{aligned}
$$

\section{The Sediment-Zone Compartment (d)}

The sediment compartment represents the sediment layer at the bottom of a surface-water column. In this compartment, losses include diffusion to water, resuspension of sediment particles, sediment burial, and transformation processes. The inventory, $N_{\mathrm{d}}$ in mol, of contaminant in the sediment compartment is described by equation [47]. $L_{d}$ is the sum of loss-rate constants from the groundsurface-soil compartment,

$$
L_{\mathrm{d}}=T_{\mathrm{dw}}+R_{\mathrm{d}}
$$


$T_{w d} N_{w}$ is the gain by diffusion and deposition from the water compartment, $\mathrm{mol} / \mathrm{d} ; T_{\mathrm{dw}}$ is rate constant for gross diffusion and particle resuspension losses to water, day ${ }^{-1}$; and $R_{\mathrm{w}}$ is the rate constant for sediment burial and for transformation losses, day ${ }^{-1}$. The loss-rate constant to water is given by

$$
T_{\mathrm{dw}}=\frac{Y_{\mathrm{wd}}+\text { resuspend } \times Z_{\mathrm{dp}} / \rho s_{\mathrm{d}}}{Z_{\mathrm{d}} \times \mathrm{d}_{\mathrm{d}}}
$$

Other parameters used to describe the transport to and from the sedmiment compartment have been defined previously.

Solutions for the Molar Inventories

Equations [41] through [47] and matrix inversion methods are used to solve for the inventories, $N_{\mathrm{i}}$, of contaminant in the seven compartments included in the model. These solutions give the following relationships,

$$
\mathrm{N}_{\mathrm{a}}=\mathrm{C}_{\mathrm{a}} \mathrm{V}_{\mathrm{a}}
$$

when the steady-state concentration, $C_{a}$ in $\mathrm{mol} / \mathrm{m}^{3}$ in air is specified

and the inventories in other compartments are

$$
\begin{aligned}
& N_{l}=N_{a} \frac{T_{a l}}{L_{l}}+a_{3} N_{g} \\
& N_{g}=a_{4} N_{a} \\
& N_{s}=N_{g} \frac{T_{g s}}{L_{s}} \\
& N_{r}=N_{s} \frac{T_{s r}}{T_{r l}} \\
& N_{w}=a_{1} \frac{N_{a}}{a_{2}} N_{g} \\
& N_{d}=N_{w} \frac{T_{w d}}{L_{d}}
\end{aligned}
$$


where,

$$
\begin{aligned}
& a_{1}=\frac{T_{a w}}{\left[L_{w}-\frac{T_{d w} T_{w d}}{L_{d}}\right]} \\
& a_{2}=\frac{T_{g w}}{\left[L_{w}-\frac{T_{d w} T_{w d}}{L_{d}}\right]} \\
& a_{3}=\left[\frac{T_{s r} T_{g s}}{L_{l} L_{s}}+\frac{T_{g l}}{L_{l}}\right] \\
& a_{4}=\frac{\left.T_{\text {ag }}+\frac{T_{l g} T_{a l}}{L_{l}}\right]}{\left[L_{g}-T_{l g} a_{3}-\frac{T_{s g} T_{g s}}{L_{s}}\right]} \\
& a_{5}=\frac{\left[T_{a w}+a_{4} T_{g w}\right]}{\left.L_{w}-\frac{T_{d w} T_{w d}}{L_{w}}\right]}
\end{aligned}
$$

when the steady-state source, $S_{a}$, in mol/d to air is specified in place of $C_{a}$ then

$N_{a}=S_{a} /\left[L_{a}-\frac{T_{l a} T_{a l}}{L_{l}}-a_{3} a_{4} T_{l a}-a_{4} T_{g a}-a_{5} T_{w a}\right]$

with equations [82] to [85] being applied as above. 


\section{PART II. MODEL INPUT AND DATA REQUIREMENTS}

The CAirTOX multimedia transport and transformation model uses two sets of input data, one describing the properties of the contaminants and the other providing properties of the environment or landscape receiving the contaminants. Each of the inputs is described in terms of the physical process associated with the input and with an estimated coefficient of variation, which describes the uncertainty or variability associated with that parameter. The coefficient of variation or $\mathrm{CV}$ is the ratio of arithmetic standard deviation to arithmetic mean for a parameter that can have a range of values. Because the process of assigning CVs is itself an uncertain process, we use only five $\mathrm{CV}$ values corresponding to five uncertainty or $\mathrm{CV}$ classes to characterize these parameters. The term " $\mathrm{CVa}$ " represents a parameter that has a CV of 0.1 or less and is considered a highly reliable parameter that will contribute little to the overall uncertainty or variability of the final results so the uncertainty in the parameter need not be expressed. " $\mathrm{CVb}$ " represents a $\mathrm{CV}$ between 0.1 and 0.3 and indicates a parameter that has been measured or obtained from a highly reliable estimation method. A CV in this range reflects both the typical variability in the measurement and the uncertainty in extrapolating that value from an experimental setting to an environmental setting. " $\mathrm{CVC}$ " represents a $\mathrm{CV}$ between 0.3 and $3(\log$ mean $C V$ of 1$)$ and indicates a parameter for which a somewhat reliable estimation method exists. "CVd" represents a $\mathrm{CV}$ between 3 and 10 ( $\log$ mean equal to 5) and is used for parameters for which the estimation method is much less reliable. "CVe" represents a CV between 10 and 15 (log mean equal to 12) and is used for parameters for which the estimated value is highly uncertain.

\section{Chemical and Physical Data}

The CAirTOX model also requires a set of physical-chemical properties inputs. These inputs and their approximate CVs are described in a companion report dealing with intermdia transfer factors.

\section{Preliminary Landscape Properties for California}

We have developed a landscape data set that is representative of California ai/ water sheds. In Table III, we summarize the landscape data that is used to represent this California landscape in the CAirTOX analyses. Also listed in this table . are the $\mathrm{CV}$ classes associated with variability and uncertainty in this data. 
Table III. The list of landscape properties used to carry out the environmental transport and transformation analysis for California residential sites.

\begin{tabular}{|c|c|c|c|c|}
\hline Landscape Property & Value & Symbol & CV & Notes \\
\hline Contaminated area in $\mathrm{m}^{2}$ & $10^{7}$ & Area & & \\
\hline Annual average precipitation $(\mathrm{m} / \mathrm{d})$ & $1.01 \times 10^{-3}$ & rain & C & $0.37 \mathrm{~m} / \mathrm{y}$ \\
\hline $\begin{array}{l}\text { Flow of surface water into landscape } \\
(\mathrm{m} / \mathrm{d})\end{array}$ & 0 & inflow & $\mathrm{n} / \mathrm{a}$ & $0 \mathrm{~m} / \mathrm{y}$ \\
\hline Land surface runoff $(\mathrm{m} / \mathrm{d})$ & $2.80 \times 10^{-4}$ & runoff & $\mathrm{C}$ & $0.1 \mathrm{~m} / \mathrm{y}$ \\
\hline Atmospheric dust load $\left(\mathrm{kg} / \mathrm{m}^{3}\right)$ & $6.15 \times 10^{-8}$ & $\rho b_{a}$ & $b$ & \\
\hline $\begin{array}{l}\text { Deposition velocity of air particles } \\
(\mathrm{m} / \mathrm{d})\end{array}$ & $5.00 \times 10^{2}$ & $v_{d}$ & $\mathrm{~b}$ & \\
\hline $\begin{array}{l}\text { Plant dry mass inventory } \\
\left(\mathrm{kg}[\mathrm{DM}] / \mathrm{m}^{2}\right)\end{array}$ & $7.00 \times 10^{-1}$ & bio $_{\text {inv }}$ & $\mathrm{b}$ & \\
\hline $\begin{array}{l}\text { Plant dry-mass production } \\
\left(\mathrm{kg}[\mathrm{DM}] / \mathrm{m}^{2}-\mathrm{d}\right)\end{array}$ & $2.00 \times 10^{-2}$ & bioprd & $\mathrm{b}$ & \\
\hline Plant dry mass fraction & $2.00 \times 10^{-1}$ & bio $_{\mathrm{dm}}$ & $\mathrm{b}$ & \\
\hline Plant density $\mathrm{kg} / \mathrm{L}$ & 1.00 & $\rho_{p}$ & b & \\
\hline Evapotranspiration from soil $(\mathrm{m} / \mathrm{d})$ & $5.15 \times 10^{-4}$ & evapotrans & $\mathrm{C}$ & $0.19 \mathrm{~m} / \mathrm{y}$ \\
\hline Evaporation from surface water $(\mathrm{m} / \mathrm{d})$ & $4.38 \times 10^{-6}$ & evaporate & C & \\
\hline Thickness of the ground-soil layer (m) & $1.00 \times 10^{-2}$ & $\mathrm{~d}_{\mathrm{g}}$ & c & \\
\hline $\begin{array}{l}\text { Soil particle density; ground-surface } \\
\text { soil layer }\left(\mathrm{kg} / \mathrm{m}^{3}\right)\end{array}$ & $2.40 \times 10^{3}$ & $\rho s_{g}$ & a & \\
\hline $\begin{array}{l}\text { Water content in surface soil (volume } \\
\text { fraction) }\end{array}$ & $1.00 \times 10^{-1}$ & $\beta_{g}$ & b & \\
\hline $\begin{array}{l}\text { Air content in the surface soil (volume } \\
\text { fraction) }\end{array}$ & $2.00 \times 10^{-1}$ & $\alpha_{\mathrm{g}}$ & $\mathrm{b}$ & \\
\hline Erosion of surface soil $\left(\mathrm{kg} / \mathrm{m}^{2}-\mathrm{d}\right)$ & $3.30 \times 10^{-3}$ & erosion $_{\mathrm{g}}$ & $\mathrm{b}$ & \\
\hline Thickness of the root-zone layer (m) & 2.00 & $\mathrm{~d}_{\mathrm{s}}$ & $\mathrm{b}$ & \\
\hline $\begin{array}{l}\text { Soil particle density; root-zone soil } \\
\text { layer }\left(\mathrm{kg} / \mathrm{m}^{3}\right)\end{array}$ & $2.40 \times 10^{3}$ & $\rho s_{s}$ & $\mathbf{a}$ & \\
\hline $\begin{array}{l}\text { Water content of root-zone soil layer } \\
\text { (vol. fraction.) }\end{array}$ & $2.00 \times 10^{-1}$ & $\beta_{\mathbf{s}}$ & $\mathrm{b}$ & \\
\hline $\begin{array}{l}\text { Air content of root-layer (vol. } \\
\text { fraction.) }\end{array}$ & $1.00 \times 10^{-1}$ & $\alpha_{s}$ & $\mathrm{~b}$ & \\
\hline Fraction of land area in surface water & $8.15 \times 10^{-3}$ & $\mathrm{f}_{\text {arw }}$ & $b$ & \\
\hline Average depth of surface waters (m) & 6 & $\mathrm{~d}_{\mathrm{w}}$ & $\mathrm{C}$ & \\
\hline
\end{tabular}


California Landscape properties (continued)

\begin{tabular}{|c|c|c|c|c|}
\hline Landscape Property & Value & Symbol & CV & Notes \\
\hline $\begin{array}{l}\text { Suspended sediment in surface water } \\
\left(\mathrm{kg} / \mathrm{m}^{3}\right)\end{array}$ & 0.8 & $\rho b_{w}$ & c & \\
\hline $\begin{array}{l}\text { Suspended sediment deposition } \\
\left(\mathrm{kg} / \mathrm{m}^{2} / \mathrm{d}\right)\end{array}$ & $1.05 \times 10^{1}$ & deposit & b & \\
\hline Thickness of the sediment layer (m) & $5.00 \times 10^{-2}$ & $d_{d}$ & c & \\
\hline $\begin{array}{l}\text { Solid material density in sediment } \\
\left(\mathrm{kg} / \mathrm{m}^{3}\right)\end{array}$ & $2.40 \times 10^{3}$ & $\rho s_{d}$ & a & \\
\hline Porosity of the sediment zone & $2.00 \times 10^{-1}$ & $\beta_{d}$ & $\mathrm{~b}$ & \\
\hline Sediment resuspension rate $\left(\mathrm{kg} / \mathrm{m}^{2} / \mathrm{d}\right)$ & $1.05 \times 10^{1}$ & resuspend & $\mathrm{d}$ & \\
\hline $\begin{array}{l}\text { Ambient environmental temperature } \\
(\mathrm{K})\end{array}$ & $2.83 \times 10^{2}$ & $\mathrm{~T}$ & c & \\
\hline Surface water current in $\mathrm{m} / \mathrm{d}$ & 0 & current $_{w}$ & c & \\
\hline Organic carbon fraction in surface soil & $1.20 \times 10^{-2}$ & $\mathrm{f}_{\mathrm{og}}$ & c & \\
\hline $\begin{array}{l}\text { Organic carbon fraction in root-zone } \\
\text { soil }\end{array}$ & $1.20 \times 10^{-2}$ & $f_{o c s}$ & c & \\
\hline $\begin{array}{l}\text { Organic carbon fraction in vadose } \\
\text { zone }\end{array}$ & $1.00 \times 10^{-2}$ & $f_{\text {ocr }}$ & c & \\
\hline Organic carbon fraction in sediments & $2.00 \times 10^{-2}$ & $f_{\text {od }}$ & c & \\
\hline $\begin{array}{l}\text { Boundary layer thickness in air above } \\
\text { ground-surface soil }(\mathrm{m})\end{array}$ & 0.005 & $\delta_{\mathrm{ag}}$ & $\mathrm{b}$ & \\
\hline Yearly average wind speed $(\mathrm{m} / \mathrm{d})$ & $1.50 \times 10^{5}$ & $\mathbf{v}_{\mathbf{w}}$ & $\mathrm{b}$ & $1.74 \mathrm{~m} / \mathrm{s}$ \\
\hline
\end{tabular}

The types of data needed to construct a landscape data set include metoorological data such as average annual wind speed, deposition velocities, air temperature, and depth of the mixing layer; hydrological data, such as annual rainfall, runoff, soil infiltration, ground-water recharge, and surface water depth and sediment loads; and soil properties, such as bulk density, porosity, water content, erosion rates, and root zone depth. Primary references for these data are van der Leeden et al. (1991), Soil Conservation Service (1975), the U.S. National Oceanic and Atmospheric Administration (1974), U.S. Department of Agriculture (1978), and Gleick (1987). 


\section{PART III. THE EXPOSURE PATHWAYS MODEL}

The concentrations in air, water and soil used for an exposure assessment are those measured or estimated to be available in these environmental media at the nearest receptor point to the source (e.g., the hazardous-waste site). When an environmental concentration is assumed constant over time, the populationaveraged potential dose (for ingestion or inhalation routes) or absorbed dose (for dermal contact) is expressed as an average daily dose rate (ADD), in $\mathrm{mg} / \mathrm{kg}-\mathrm{d}$

$$
A D D=\frac{C_{i}}{C_{k}} \times\left[\frac{I_{i}}{B W}\right] \times \frac{E F \times E D}{A T} \times C_{k}
$$

In this expression $C_{i} / C_{k}$ is the intermedia-transfer factor, which expresses the ratio of contaminant concentration in the exposure medium $i$ (i.e., personal air, tap water, milk, soil, etc.) to the concentration in an environmental medium $k$ (ambient-air gases or particles, surface soil, root-zone soil, surface water, and ground water) and $\left[\mathrm{IU}_{\mathrm{i}} / \mathrm{BW}\right]$ is the intake or uptake factor per unit body weight associated with the exposure medium $i$. For exposure through the inhalation or ingestion route, $\left[\mathrm{IU}_{\mathrm{i}} / \mathrm{BW}\right]$ is $\mathrm{I}_{\mathrm{i}}$ the intake rate per unit body weight of the exposure medium such as $\mathrm{m}^{3}$ (air) $/ \mathrm{kg}$-d, $\mathrm{L}$ (milk) $/ \mathrm{kg}$-d, or $\mathrm{kg}$ (soil) $/ \mathrm{kg}$-d. For exposure through the dermal route, $\left[\mathrm{U}_{\mathrm{i}} / \mathrm{BW}\right]$ is replaced by $U \mathrm{~F}_{\mathrm{i}}$, the uptake factor per unit body weight and per unit initial concentration in the applied medium ( $\mathrm{L}$ (water) $/ \mathrm{kg}$-d or - $\mathrm{kg}($ soil) $/ \mathrm{kg}-\mathrm{d}$ ). EF is the exposure frequency for the exposed population, in days per year; ED is the exposure duration for the exposed population, in years; AT is the averaging time for the exposed population, in days; and $C_{k}$ is the contaminant concentration in environmental medium $k$. The potential dose factor, $\operatorname{PDF}(k \rightarrow i)$, is defined as the ratio of dose to concentration, as expressed in the following equation.

$$
\operatorname{PDF}(k \rightarrow i)=\frac{A D D}{C_{k}}=\frac{C_{i}}{C_{k}} \times\left[\frac{U_{i}}{B W}\right] \times \frac{E F \times E D}{A T}
$$

The PDF is used to make pathway and route-to-route comparisons in the absence of concentration values and allows one to consider the relative significance of several exposure pathways. With the PDF, we compare inhalation, ingestion, or dermal exposures to the same medium such as tap water and compare exposures through indirect pathways (such as food-chain transfers) to those from direct pathways such 
as inhalation or ingestion. As an example, the PDF for a 70-kg individual ingesting $2 \mathrm{~L} / \mathrm{d}$ of tap water 365 days per year for a lifetime is $2 \mathrm{~L}$ divided by $70 \mathrm{~kg}$ or $0.029 \mathrm{~L} / \mathrm{kg}$ d. This PDF and other PDFs like it can be used as the basis for determining the relative significance of dermal, inhalation, and other ingestion exposures attributable to tap water.

In summary, the exposure assessment process consists of relating contaminant concentrations in the environmental media-air, surface soil, rootzone soil, surface water, and ground water-to contaminant concentrations in exposure media with which a human population has contact (personal air, tap water, foods, household dusts and soils, etc.). The average daily dose is the product of the exposure concentrations in these contact media and an intake or uptake factor that relates the concentrations to the distributions of potential dose by the inhalation, ingestion, and dermal contact routes within the population. Listed in Table IV are the potential interactions among environmental media, exposure media, and exposure routes that are addressed in the models presented below.

\section{Exposure factors}

In constructing exposure models one needs to define the characteristics of individuals in various age/sex categories and the characteristics of the microenvironments in which they live or from which they obtain water and food. This section defines both the types of data needed to carry out the exposure assessment and how this data is obtained. For all exposure factors used in CAirTOX, we define both an arithmetic mean value and a coefficients of variation (CV), which is the arithmetic standard deviation divided by the arithmetic mean. In the sections below, we describe how we derived means and CVs for exposure duration and averaging time, anatomical and dietary properties, activity patterns and exposure times, household parameters, other human factors such as soil ingestion and breast milk intake, and parameters associated with food crops and food product animals. 
Table IV. Matrix of exposure pathways linking environmental media, exposure scenarios, and exposure routes.

\begin{tabular}{|c|c|c|c|}
\hline \multirow{2}{*}{$\begin{array}{l}\text { Exposure } \\
\text { routes }\end{array}$} & \multicolumn{3}{|c|}{ Media } \\
\hline & $\begin{array}{l}\text { Air } \\
\text { (gases and particles) }\end{array}$ & $\begin{array}{l}\text { Soil (surface soil and } \\
\text { root-zone soil) }\end{array}$ & Water (surface water) \\
\hline Inhalation & $\begin{array}{l}\text {-Inhalation of gases and } \\
\text { particles in outdoor air } \\
\text { - Inhalation of gases and } \\
\text { particles transferred from } \\
\text { outdoor air to indoor air }\end{array}$ & $\begin{array}{l}\text {-Inhalation of soil } \\
\text { vapors that migrate to } \\
\text { indoor air } \\
\text { - Inhalation of soil } \\
\text { particles transferred to } \\
\text { indoor air }\end{array}$ & $\begin{array}{l}\text { - Indoor inhalation of } \\
\text { contaminants transferred } \\
\text { from tap water }\end{array}$ \\
\hline Ingestion & $\begin{array}{l}\text {-Ingestion of fruits, } \\
\text { vegetables, and grains } \\
\text { contaminated by transter } \\
\text { of atmospheric chemicals } \\
\text { to plant tissues } \\
\text { - Ingestion of meat, milk, } \\
\text { and eggs contaminated by } \\
\text { transfer of contaminants } \\
\text { from air to plants to } \\
\text { animals } \\
\text { - Ingestion of meat, milk, } \\
\text { and eggs contaminated } \\
\text { through inhalation by } \\
\text { animals } \\
\text { - Ingestion of mother's } \\
\text { milk }\end{array}$ & $\begin{array}{l}\text { - Human soil ingestion } \\
\text { - Ingestion of fruits, } \\
\text { vegetables, and grains } \\
\text { contaminated by } \\
\text { transfer from soil } \\
\text { - Ingestion of meat, } \\
\text { milk, and eggs } \\
\text { contaminated by } \\
\text { transfer from soil to } \\
\text { plants to animals } \\
\text { - Ingestion of meat, } \\
\text { milk, and eggs } \\
\text { contaminated through } \\
\text { soil ingestion by } \\
\text { animals } \\
\text {-Ingestion of mother's } \\
\text { milk }\end{array}$ & $\begin{array}{l}\text { - Ingestion of tap water } \\
\text { - Ingestion of irrigated } \\
\text { fruits, vegetables, and } \\
\text { grains } \\
\text { - Ingestion of meat, milk, } \\
\text { and eggs from animals } \\
\text { consuming contaminated } \\
\text { water } \\
\text { - Ingestion of fish and sea } \\
\text { food } \\
\text { - Ir gestion of surface water } \\
\text { during swimming or other } \\
\text { water recreation } \\
\text { - Ingestion of mother's } \\
\text { milk }\end{array}$ \\
\hline $\begin{array}{l}\text { Dermal } \\
\text { contact }\end{array}$ & (not considered) & $\begin{array}{l}\text { - Dermal contact with } \\
\text { soil }\end{array}$ & $\begin{array}{l}\text { - Dermal contact in baths } \\
\text { and showers } \\
\text { - Dermal contact while } \\
\text { swimming }\end{array}$ \\
\hline
\end{tabular}




\section{Exposure Duration and Averaging Time}

In the basic exposure model, the exposure duration (ED) is the amount of time, in years, that the exposed population is assumed to be in contact with a specified environmental contaminant. The averaging time (AT) is the period, in days, over which exposure is averaged. More specifically, averaging time is the number of days from the total lifetime of an individual selected at random from the population over which human contact will be averaged so as to be representative of exposure in the total population. However, according to the EPA (1989a), because of the mobility of the U.S. population, the exposure duration at a specific site for an individual selected at random from the adjacent population is often significantly less than an average lifetime of 70 years. For all exposure calculations used to make chemical- and site-specific exposure estimates for noncarcinogens, the exposure duration, ED, and the exposure averaging time, AT, represent the same span of time (the units however are different, ED is in years and $\mathrm{AT}$ is in days). For carcinogens, the mean exposure duration, ED, is assumed to be 14 years with a $C V$ of 1.15 (geometric mean and standard deviation of 9.0 and 2.5 respectively) (EPA, 1989b) and the averaging time, AT, is 25,550 days ( 70 years).

\section{Anatomical and Dietary Properties}

The potential dose calculation requires as input the ratio of intake to body weight averaged over the representative age group. In this section we describe how we developed mean values and CVs for air, water, and food intakes per unit body weight for children, for adults, and for a lifetime exposure.

\section{Body Weight}

We calculate the arithmetic-mean body weight and $\mathrm{CV}$ of body weight for three age groups-infant, child, and adult. The body weight for infants is needed for estimating exposures to contaminants in breast milk or other pathways that are unique to children in roughly the 0 - to 1-year age group. Body weight for adults and children are needed to calculate lifetime-average contact rates per unit body weight and contact rates for an exposure duration of less than a full lifetime. The child age category applies to ages 0 to 15 years, but excludes breast-fed babies. General data on body-weight distributions by age and sex are available from the ICRP (1975), the U.S. EPA (1985, 1989a) and Najjar and Roland (1987). We used the Najjar and Roland (1987) data to develop the mean value and CV of body weight for ages 0 to 1 , for ages 0 to 15,15 to 70 , and for lifetime. These value:; are listed in Table V. 
Table V. Values of human anatomical and dietary properties for use as default values in the exposure calculations. ${ }^{\mathrm{a}}$

\begin{tabular}{|c|c|c|c|c|c|c|c|}
\hline Parameter, symbol & \multicolumn{2}{|l|}{ Childb } & \multicolumn{2}{|c|}{ Adultb } & \multicolumn{2}{|c|}{ Combined $b$} & Unite \\
\hline $\begin{array}{l}\text { Body weight of infants } \\
\text { age } 0 \text { to } 1 \mathrm{y}, \mathrm{BW}\end{array}$ & 7.2 & $(0.3)$ & $-\cdot$ & & -- & -- & $\mathbf{k g}$ \\
\hline $\begin{array}{l}\text { Body weight of lactating } \\
\text { women, } \mathrm{BW}_{\text {mo }}\end{array}$ & -- & $\cdots$ & 65.4 & $(0.2)$ & -- & -- & $k 8$ \\
\hline Body weight, BW & 29 & $(0.24)$ & 71 & $(0.2)$ & 62 & $(0.2)$ & 18 \\
\hline Surface area, $S_{A_{b}}$ & 0.032 & $(0.09)$ & 0.024 & $(0.06)$ & 0.026 & $(0.07)$ & $m^{2 / k g}$ \\
\hline $\begin{array}{l}\text { Working breathing } \\
\text { rate, } \mathrm{BR}_{\mathbf{w}}\end{array}$ & $-\cdot$ & -. & 0.030 & $(0.3)$ & -- & -- & $\mathrm{m}^{3} / \mathrm{kg}-\mathrm{h}$ \\
\hline $\begin{array}{l}\text { Active breathing } \\
\text { rate, } \mathrm{BR}_{\mathrm{a}}\end{array}$ & 0.023 & $(0.3)$ & 0.018 & $(0.3)$ & 0.019 & $(0.3)$ & $m^{3} / k_{g}-h$ \\
\hline $\begin{array}{l}\text { Resting breathing } \\
\text { rate, BR. }\end{array}$ & 0.008 & $(0.3)$ & 0.006 & $(0.2)$ & 0.0064 & $(0.2)$ & $\mathrm{m}^{3} / \mathrm{kg}-\mathrm{h}$ \\
\hline Fluid intake, $I_{f}$ & 0.029 & $(0.2)$ & 0.020 & $(0.2)$ & 0.022 & $(0.2)$ & $L / k g-d$ \\
\hline $\begin{array}{l}\text { Fruit and } \\
\text { vegetable intake, } \mathrm{I}_{\mathrm{fv}}\end{array}$ & 0.0075 & $(0.2)$ & 0.0042 & $(0.2)$ & 0.0049 & $(0.2)$ & $\mathrm{kg} / \mathrm{kg}-\mathrm{d}$ \\
\hline Grain intake, $L_{B}$ & 0.0070 & $(0.2)$ & 0.0028 & $(0.2)$ & 0.0037 & $(0.2)$ & $\mathrm{kg} / \mathrm{kg}-\mathrm{d}$ \\
\hline $\begin{array}{l}\text { Exposed produce } \\
\text { intake }=I g+f_{f v}^{a b g} \times I_{f v}\end{array}$ & 0.011 & $(0.2)$ & 0.0048 & $(0.2)$ & 0.0060 & $(0.2)$ & $\mathrm{kg} / \mathrm{kg}-\mathrm{d}$ \\
\hline $\begin{array}{l}\text { Protected produce } \\
\text { intake }=\left(1-f_{f v}^{a b g}\right) \times I_{f v}\end{array}$ & 0.0040 & $(0.2)$ & 0.0022 & $(0.2)$ & 0.0026 & $(0.2)$ & $k_{8} / k_{q}-d$ \\
\hline Meat intake, I mt & 0.0043 & $(0.2)$ & 0.0026 & $(0.2)$ & 0.0030 & $(0.2)$ & $\mathrm{kg} / \mathrm{kg}_{\mathrm{g}} \mathrm{d}$ \\
\hline Milk/Dairy intake, $I_{m k}$ & 0.017 & $(0.2)$ & 0.0037 & $(0.2)$ & 0.0065 & $(0.2)$ & $\mathrm{kg} / \mathrm{kg}-\mathrm{d}$ \\
\hline Egg intake, legg & 0.00061 & $(0.2)$ & 0.00041 & $(0.2)$ & 0.00046 & $(0.3)$ & $\mathrm{kg} / \mathrm{kg}_{\mathrm{g}} \mathrm{d}$ \\
\hline Fish intake, Ifsh & 0.00035 & $(0.4)$ & 0.00028 & $(0.3)$ & 0.00029 & $(0.4)$ & $\mathrm{kg} / \mathrm{kg}-\mathrm{d}$ \\
\hline
\end{tabular}

a Listed are the arithmetic-mean value and (in parentheses) the estimated coefficient of variation $(\mathrm{CV})$, equal to the standard deviation divided by the mean. Body weights are from Najjar and Roland (1987), breathing rates are from ICRP (1975), and food intakes are from Yang and Nelson (1986).

b The child category covers ages 0 to 15 , the adult category covers ages 16 to 70 , the combined category is used to represent lifetime equivalent exposure and is obtained by multiplying the child category by $15 / 70$, the adult category by $55 / 70$, and then summing these products. 


\section{Breathing Rate}

General data on breathing rates by age and sex are available from the EPA (1985, 1989a) and the ICRP (1975). Values in Table $V$ are taken primarily from the ICRP (1975) with variances estimated by McKone and Daniels (1991). The working breathing rate is for 8 hours of work and, when combined with 8 hours of breathing at the active rate and 8 hours at the resting rate, gives a daily equivalent intake of 30 $\mathrm{m}^{3}$ for an adult (EPA, 1989a). Layton (1992) has derived breathing rates that are consistent with the quantities of oxygen needed to metabolize reported dietary intakes of fats, carbohydrates, and proteins. He has shown that the values in Table $V$ could be high by a factor of from 20 to $30 \%$. But this is within the CV reported here.

\section{Body Surface Area}

Information on the relation between human body weight and surface area has been published by the ICRP (1975) and the U.S. EPA (1989a). In the EPA report, it is suggested that surface area (SA) in $\mathrm{m}^{2}$ can be estimated as 0.1 times body weight (BW) in $\mathrm{kg}$ raised to the $2 / 3$ power. Using this formula, along with methods described in Bevington (1969), we estimate the mean value and standard deviation of surface area per unit body weight, $\mathrm{SA}_{b}$ in $\mathrm{m}^{2} / \mathrm{kg}$, for children and adults using the formula

$$
S A_{b}=\left[\frac{S A}{B W}\right]=0.1 \times B W^{-1 / 3} \pm\left(0.1 \frac{\sigma_{B W}}{3}\right) B W^{-4 / 3}
$$

where the second term is the standard deviation of the surface area-body weight ratio. The resulting surface-area values and CVs are given in Table V.

\section{Water Ingestion}

Tap-water intake includes all household tap water that is consumed as a beverage or used to prepare foods and beverages. Yang and Nelson (1986) have published tap-water and total-fluid intakes in $\mathrm{mL} / \mathrm{d}$ for the U.S. population by age, sex, and region of the country. Ershow and Cantor (1989) have published population-based estimates of sex-, region-, and season-averaged tap-water intakes per unit body weight by the U.S. population in $\mathrm{mL} / \mathrm{kg}-\mathrm{d}$. From these two papers, we have derived intakes of tap water in L/kg-d for children, adults, and lifetime equivalent. The mean values of tap-water intake and CVs in these age groups are listed in Table $\mathrm{V}$. 


\section{Eood Intakes}

For food intakes included in the exposure assessment, we calculate the arithmetic mean and standard deviation of each food intake per unit body weight in all age categories used and also combine these intake rates to determine the population average and standard deviation of each food intake per unit body weight. The following food groups are considered in the exposure assessment: meat including beef, pork, poultry, and other meats; milk and dairy products; eggs; leafy vegetables, such as cabbage, cauliflower, broccoli, celery, lettuce, and spinach; exposed produce, such as apples, pears, berries, cucumber, squash, grapes, peaches, tomatoes, string beans, etc.; protected produce or root crops, such as carrots, beets, turnips, potatoes, legumes, melons, citrus fruits, etc.; grains such as wheat, com, rice, barley, millet, etc.; and fresh fish and seafood.

In the Nationwide Food Consumption Survey (NFCS) (USDA, 1983), the U.S. Department of Agriculture (USDA) used a stratified probability sample of households in the 48 conterminous states and the District of Columbia in each of four seasons from April 1977 through March 1978. The samples were designed to be representative of the United States and were classified according to geographic regions of the country; geographic divisions within each of the regions; and central city, suburban, and non-metropolitan populations. Data were collected for 30,770 individuals within 114 primary sampling units-indicating approximately 270 individuals per sampling unit. We calculate food intakes using results compiled by Yang and Nelson (1986), who analyzed the data from the USDA survey. According to Yang and Nelson (1986), 47\% of all consumed produce (fruits and vegetables) consists of leafy vegetables and exposed produce, which intercept contaminants from the atmosphere. The remaining $53 \%$ of fruits and vegetables consists of protected produce or root crops, in which contaminant transfer to the edible portion is primarily by root uptake. All grain crops are assumed to be exposed primarily to air contaminants. For the food groups including milk, fruits and vegetables, grains, exposed produce and grains, protected produce, meat, eggs, and fish, we use the Yang and Nelson (1986) results to estimate the arithmetic mean and CV for daily intake per $\mathrm{kg}$ body weight for children, adults, and combined or lifetime-equivalent exposures. Table II lists these estimates. The variance of intake-per-body-weight ratio used to determine the $\mathrm{CV}$ is calculated under the assumption that food intake correlates with body weight to the two-thirds power. The mean and variance of body weight used in this estimate are taken from Table $\mathrm{V}$. 


\section{Food Consumption Patterns}

We consider homegrown foods those foods produced on the land associated with a household and, for the most part, consumed within that household; whereas locally grown foods are those that are produced in home gardens and commercial farms with air, soil, and/or water that have been contaminated by the local waste site and are consumed by the local population. Ideally, distributions describing local consumption of produce, grain, milk and dairy products, meat, eggs, and fish are needed to assess food-chain exposures. However, limited data are available on the amount of locally grown and consumed food products. The U.S. EPA (1989a) has compiled data for U.S. households on the fractions of consumed produce that comes from home gardens. For all categories of fruits and vegetables reported in this study, the fraction that is homegrown is in the range 0.04 to 0.75 , and for the one grain listed (com) the average fraction that is homegrown is 0.45 for $25 \%$ of the individuals surveyed (the other $75 \%$ did not consume homegrown corn). From these data we determined that the fraction of consumed fruits and vegetables that are homegrown is 0.24 with CV of 0.7 , and that the fraction of consumed grains (mostly corn) that are homegrown is 0.11 also with a CV of 0.7. These values represent households with home gardens and not necessarily the average of total homegrown consumption in either the U.S. or California population.

The U.S. EPA (1989a) also reports that, in farm households that consume homegrown beef, the annual fraction of consumed beef that is homegrown is 0.44 with CV of roughly 0.5 and, in farm households that consume homegrown dairy products, the average fraction of consumed dairy products that are homegrown is 0.4 with CV of roughly 0.7 . We applied the fraction of homegrown beef to all meat types. Because we could locate no information on consumption of homegrown eggs, we applied the same fraction as for dairy products.

According to U.S. EPA (1989a) data, recreational fishermen can consume as much as 30 to $140 \mathrm{~g} / \mathrm{d}$ of fish and seafood. But these values do not necessarily apply to a specific body of water as is the case for our exposure assessment. The average consumption of fish and seafood in the U.S., as listed in Table V, is $18 \mathrm{~g} / \mathrm{d}$. To accommodate data regarding consumption of fish that is caught by recreational fishing, we assume that the fraction of fish consumed locally is a triangular distribution with a mean value of 0.7 , a variance of 0.56 , and $C V$ of 0.3 .

Fractions of consumed food that are from local supplies are listed in Table VI. 
Table VI. Activity patterns, household parameters and other exposure factors.

\begin{tabular}{|c|c|c|c|c|}
\hline Parameter name and symbol & $\begin{array}{c}\text { Estimated } \\
\text { mean } \\
\text { value }\end{array}$ & \begin{tabular}{|c|}
$\begin{array}{c}\text { Coefficient } \\
\text { of } \\
\text { variation }\end{array}$ \\
\end{tabular} & Units & Reference \\
\hline $\begin{array}{l}\text { Fraction of fruits and vegetables that } \\
\text { are exposed produce, } f_{\text {abv-grd }}^{v}\end{array}$ & 0.47 & 0.1 & none & Yang and Neleon (1986) \\
\hline $\begin{array}{l}\text { Fraction of fruits and vegetables local, } \\
f_{\text {local }}^{v}\end{array}$ & 0.24 & 0.7 & none & U.S. EPA (1989a) \\
\hline Fraction of grains local, flocal & 0.12 & 0.7 & none & U.S. EPA (1989a) \\
\hline Fraction of milk local, f local & 0.4 & 0.7 & none & U.S. EPA (1989a) \\
\hline Fraction of meat local, $f_{\text {local }}^{\mathrm{mt}}$ & 0.44 & 0.5 & none & U.S. EPA (1989a) \\
\hline Fraction of eggs local, $f_{\text {local }}^{\mathrm{egg}}$ & 0.4 & 0.7 & none & this report \\
\hline Fraction of fish local, flocal & 0.7 & 0.3 & none & U.S. EPA (1989a) \\
\hline Exposure time, at home indoors, $\mathrm{ET}_{h}$ & 16 & 0.14 & h/dav & U.S. EPA (1989a) \\
\hline Exposure time, at home outdoors, $\mathrm{ET}_{\mathrm{o}}$ & 0.3 & 0.14 & h/dav & U.S. EPA (1989a) \\
\hline Exposure time, in shower or bath, $\mathrm{ET}_{\mathrm{sb}}$ & 0.27 & 0.6 & $\mathrm{~h} / \mathrm{day}$ & James and Knuiman (1987) \\
\hline Exposure time swimming, ET & 0.5 & 0.5 & $\mathrm{~h} / \mathrm{d}$ & U.S. EPA (1992a) \\
\hline Exposure frequency, swimming, EF $F_{s w}$ & 15 & 4 & $d / y$ & U.S. EPA (1992a) \\
\hline Water ingestion while swimming, $I_{\text {sww }}$ & 0.0007 & 1 & $\mathrm{~L} / \mathrm{kg}-\mathrm{d}$ & U.S. EPA (1989b) \\
\hline $\begin{array}{l}\text { Fraction of water needs provided by } \\
\text { ground water, } f_{g w}^{w}\end{array}$ & 0.8 & 0.1 & none & van der Leeden et al. 1990) \\
\hline Water use in the shower, $W_{\text {shower }}$ & 8 & 0.4 & $\mathrm{~L} / \mathrm{min}$ & James and Knuimen (1987) \\
\hline Water use in the House $W_{\text {house }}$ & 40 & 0.4 & $\mathrm{~L} / \mathrm{h}$ & van der Leeden, et al. (1990) \\
\hline House air ventilation rate, $V R_{\text {house }}$ & 750 & 0.3 & $m^{3} / h$ & Mckone and Bogen (1992) \\
\hline Bathroom air ventilation rate, $V_{\text {bath }}$ & 1 & 0.4 & $\mathrm{~m}^{3} / \mathrm{min}$ & McKone and Bogen (1992) \\
\hline Indoor soil-dust load, dust in & $3.0 \times 10^{-8}$ & 0.4 & $\mathrm{~kg} / \mathrm{m}^{3}$ & Murphy and Yocom, 1986) \\
\hline Soil ingestion by children 0 to $15 \mathrm{y}, I_{\mathrm{sl}}$ & $2.2 \times 10^{-6}$ & 3 & $\mathrm{~kg} / \mathrm{kg}-\mathrm{d}$ & U.S. EPA (1989a) \\
\hline Soil ingestion by adults 15 to $70 \mathrm{y}, \mathrm{I}_{\mathrm{sl}}$ & $1.4 \times 10^{-7}$ & 2 & $\mathrm{~kg} / \mathrm{kg}-\mathrm{d}$ & U.S. EPA (1989a) \\
\hline Lifetime a verage soil ingestion, $I_{s l}$ & $3.5 \times 10^{-7}$ & 3 & $\mathrm{~kg} / \mathrm{kg}-\mathrm{d}$ & U.S. EPA (1989a) \\
\hline Exposure frequency to soil, $\mathrm{EF}_{\mathrm{sl}}$ & 137 & 0.6 & events/y & U.S. EPA (1992a) \\
\hline Bodv surface fraction with soil contact & 0.3 & 0.04 & none & U.S. EPA (1992a) \\
\hline Soil adherence to skin, $\mathrm{Sl}_{\text {sk }}$ & 0.5 & 0.4 & $\mathrm{mg} / \mathrm{cm}^{2}$ & U.S. EPA (1992a) \\
\hline Breast-milk ingestion by infants, $I_{b m}$ & 0.11 & 0.2 & $\mathrm{~kg} / \mathrm{kg}-\mathrm{d}$ & $\begin{array}{c}\text { Butte et al. (1984), } \\
\text { Whitehead and Paul (1981) }\end{array}$ \\
\hline
\end{tabular}




\section{Activity Patterns and Exposure Times}

CAirTOX requires as input the average number of hours per day spent indoors at home, spent outdoors at home, and spent in bathrooms (including showering and bathing time) during the exposure duration. We also use the number of days per year and hours per day spent in contact with surface water during swimming or other water recreation.

According to the U.S. EPA (1989a), the average time spent at home indoors is $16 \mathrm{~h} / \mathrm{d}$ and the time spent at home outdoors is $0.3 \mathrm{~h} / \mathrm{d}$. We estimate the $\mathrm{CV}$ in these numbers to be 0.14 . James and Knuiman (1987) analyzed data on domestic water use from 3,000 households in Australia and report the mean duration of a shower as 8 min with a geometric standard deviation (GSD) of roughly 1.8 (CV equal to 0.6 ). We double this time to account for additional time spent in the bathroom. The U.S. EPA (1992a) reports that swimming time ranges from a typical value of $0.5 \mathrm{~h} / \mathrm{d}$ to an upper bound of $1 \mathrm{~h} / \mathrm{d}$ and the frequency ranges from a typical value of $5 \mathrm{~d} / \mathrm{y}$ to an upper bound of $150 \mathrm{~d} / \mathrm{y}$. From this we obtain a mean exposure time of $0.5 \mathrm{~h} / \mathrm{d}$ with a $\mathrm{CV}$ of 0.5 , and because of climate and proximity to water, we use $15 \mathrm{~d} / \mathrm{y}(\mathrm{CV}$ of 4$)$ as representative of exposure frequency in California. Based on U.S. EPA (1989b) estimates, we use $0.0007 \mathrm{~L} / \mathrm{kg}-\mathrm{h}$ (CV equal to 1 ) as the ingestion rate of surface water by swimmers. Values and units of activity patterns and exposure times are listed in Table VI.

\section{Household Parameters}

Household factors relate to tap-water supply and use, room-ventilation rates, and dust concentrations within homes. In California, $70 \%$ of the water withdrawn by public-supply water systems and $90 \%$ of the water withdrawn in private domestic water systems is from ground water (van der Leeden et al. 1990). We assume the fraction of tap water withdrawn from ground water is 0.8 with a CV of 0.1. In their observation of Australian households, James and Knuiman (1987) found that the arithmetic-mean water use rate in showers is approximately $8 \mathrm{~L} / \mathrm{min}$ with a GSD of roughly 1.4 (a CV of approximately 0.4 ). van der Leeden et al. (1990) report that water use in U.S. households, excluding outdoor uses, averages $240 \mathrm{~L} / \mathrm{d}$ per person or $960 \mathrm{~L} / \mathrm{d}$ per household of four. We use this value, converted to $40 \mathrm{~L} / \mathrm{h}$ with a CV of 0.4 to represent water use in California homes. Room ventilation rates in the shower/bathroom and the remainder of the house are based on the assumption that the volumes of these compartments are 10 and $600 \mathrm{~m}^{3}$, respectively, and that the number of air changes per hour ranges from 2 to 10 in the bathroom and from 0.5 to 
2 in the remainder of the house (McKone, 1987; McKone and Knezovich, 1991; McKone and Bogen, 1992). This yields a bathroom ventilation rate of $1 \mathrm{~m}^{3} / \mathrm{min}$ with a CV of 0.4 and a house ventilation rate of $750 \mathrm{~m}^{3} / \mathrm{h}$ with a $\mathrm{CV}$ of 0.3 . House dust suspended in the indoor-air environment originates from three sources, (1) airborne particles that penetrate from outside air to indoor air; (2) surface soil and dust tracked into buildings on shoes or clothes, by pets, or other vectors; and (3) a variety of sources related to occupant activities, material degradation, and household products. Ambient levels of particles in outdoor air are on the order of 10 to $100 \mu \mathrm{g} / \mathrm{m}^{3}$, with 60 as a representative value (Schroder and Lane, 1988). The concentration of indoor particles attributable to surface soil is on the order of $3.0 x$ $10^{-8} \mathrm{~kg}$ (soil) $/ \mathrm{m}^{3}$ (air) (Murphy and Yocom, 1986). We use this latter value as the indoor dust load that is attributable to household soil and assign a CV of 0.4 .

\section{Other Human Exposure Factors}

\section{Soil Ingestion and Soil Contact on Skin}

General data on soil intake by age and sex have been reviewed or compiled by Paustenbach et al. (1986), LaGoy (1987), U.S. EPA (1989a), Calabrese et al. (1989), and Sedman (1989). The U.S. EPA (1989a) recommends that $0.2 \mathrm{~g} / \mathrm{d}$ be used as an average soil-ingestion rate for children under age 7 with $0.8 \mathrm{~g} / \mathrm{d}$ as an upper bound. Although the EPA report does not recommend rates to use for other ages, it does report four levels of soil ingestion for ages 0 to 18. One of these levels represents children with low soil-ingestion rates, two represent children with intermediate soil-ingestion rates, and one represents children with high soil-ingestion rates (U.S. EPA, 1989a). LaGoy (1987) suggests a soil-ingestion rate of $0.025 \mathrm{~g} / \mathrm{d}$ for adults. Combining the information in the EPA report with recommendations by Calabrese et al. (1991) and LaGoy (1987), we obtain soil-ingestion estimates of $2.2 \times 10^{-6}$ $\mathrm{kg}$ (soil) $/ \mathrm{kg}-\mathrm{d}\left(0.06 \mathrm{~g} / \mathrm{d}\right.$ equivalent) with a CV of 3 for children 0 to $15 \mathrm{y}, 1.4 \times 10^{-7}$ $\mathrm{kg}$ (soil) $/ \mathrm{kg}-\mathrm{d}\left(0.01 \mathrm{~g} / \mathrm{d}\right.$ equivalent) with a CV of 2 for adults 15 to $70 \mathrm{y}$, and $3.5 \times 10^{-7}$ $\mathrm{kg}($ soil $) / \mathrm{kg}-\mathrm{d}(0.02 \mathrm{~g} / \mathrm{d}$ equivalent) with a $\mathrm{CV}$ of 3 for a lifetime equivalent during ages 0 to 70 . These results are summarized in Table VI.

General data for soil deposition on skin surfaces are available from the U.S. EPA (1992a). According to this information, an adult with a body surface area of $18,000 \mathrm{~cm}^{2}$ can have 5,000 to $5,800 \mathrm{~cm}^{2}$ exposed to contact with soil and have a soilto-skin adherence of 0.2 to $1 \mathrm{mg} / \mathrm{cm}^{2}$ with an exposure frequency of 40 to 350 events per year. From this information, we calculate a daily soil-contact rate over the 
exposure duration (ED) as covering an average of 0.3 of the body surface (with CV of 0.04 for the value of this fraction), having a mean soil adherence of $0.5 \mathrm{mg} / \mathrm{cm}^{2}$ with a $\mathrm{CV}$ of 0.4 , and having a mean exposure frequency of $137 \mathrm{~d} / \mathrm{y}$ with a $\mathrm{CV}$ of 0.6 . These values are summarized in Table VI.

\section{Ingestion of Breast Milk by Infants}

Data on ingestion of breast milk by infants are available in Butte et al. (1984) and Whitehead and Paul (1981). We calculate the breast-milk ingestion per unit body weight for infants ages 0 to 12 months as $0.11 \mathrm{~kg} / \mathrm{kg}-\mathrm{d}$ with a CV of 0.2 . This $\mathrm{CV}$ is based on the variability in ingestion factors for children and adults, such as milk, meat, and vegetation intakes.

\section{Parameters Associated with Food Crops and Food-Producing Animals}

To calculate human exposures to contaminants through the produce, meat, dairy-product, and egg pathways, we must quantify the ratio of fresh mass to dry mass of pasture and food crops; parameters that describe the diet, weight, water intake, soil intake, and inhalation rates of food-producing animals; the fat content of animal-based food products; the organic-carbon content of soils; and the fraction of contaminants in irrigation water that are retained in soil-pore water after application.

We assume the ratio of dry mass to fresh mass, bio $_{\mathrm{dm}}$, for pasture and food crops is in the range 0.1 to 0.3 , with mean value 0.2 and a CV of 0.2 . Based on their review of ingestion and inhalation data for cattle, McKone and Ryan (1989) estimate arithmetic means and CVs (in parentheses) for vegetation intake as $17(0.2) \mathrm{kg}(\mathrm{dry}$ mass)/ $\mathrm{d}$ in diary cattle and $12(0.4) \mathrm{kg}$ (dry mass)/ $\mathrm{d}$ in beef cattle, for soil intake as $0.4(0.7) \mathrm{kg}(\mathrm{soil}) / \mathrm{d}$ in both diary cattle and beef cattle, and for inhalation rates as 122 (0.3) $\mathrm{m}^{3} / \mathrm{d}$ in beef and dairy cattle. Altman and Dittmer (1968) report chicken feed requirements in the range 0.11 to $0.125 \mathrm{~kg} / \mathrm{d}$. Because chickens require grit in their diet to aid digestion and because it has been noted that $2 \%$ by weight of grit in diet is an optimum for chickens (NRC, 1984), we assume soil intake by chickens to be on the order of $2 \%$ of feed intake. Altman and Dittmer (1968) report that total water turnover $(\mathrm{L} / \mathrm{h})$ in mammals, such as cattle, can be estimated as 4.9 times body weight raised to the 0.86 power and that water turnover (in $L / h$ ) in bird species, such as chickens, can be estimated as 2.2 times body weight raised to the 0.61 power. With adult cattle weights in the range 500 to $1000 \mathrm{~kg}$ and adult chicken weights in the range 1.8 to $2.5 \mathrm{~kg}$ (Altman and Dittmer, 1968), we estimate the daily 
Table VII. Parameters associated with food crops and food-producing animals.

\begin{tabular}{|c|c|c|c|c|}
\hline Parameter description and symbol & $\begin{array}{l}\text { Estimated } \\
\text { mean value }\end{array}$ & $\begin{array}{c}\text { Coefficient } \\
\text { of } \\
\text { variation }\end{array}$ & Units & Reference \\
\hline $\begin{array}{l}\text { Ratio of plant dry mass (DM) to fresh } \\
\text { mass (FM), bio dm }\end{array}$ & 0.2 & 0.2 & none & this report \\
\hline Ingestion of pasture by beef cattle, $I_{v b c}$ & 60 & 0.4 & $\mathrm{~kg}[\mathrm{FM}] / \mathrm{d}$ & $\begin{array}{l}\text { McKone and } \\
\text { Ryan (1989) }\end{array}$ \\
\hline Ingestion of pasture by dairy cattle, $I_{v d c}$ & 85 & 0.2 & $\mathrm{~kg}[\mathrm{FM}] / \mathrm{d}$ & $\begin{array}{l}\text { McKone and } \\
\text { Ryan (1989) }\end{array}$ \\
\hline Ingestion of pasture by hens, $I_{v h}$ & 0.12 & 0.04 & $\mathrm{~kg}[\mathrm{FM}] / \mathrm{d}$ & $\begin{array}{l}\text { Altman and } \\
\text { Dittmer (1968) }\end{array}$ \\
\hline Ingestion of water by dairy cattle, $\mathrm{I}_{\text {wdc }}$ & 35 & 0.2 & $L / d$ & $\begin{array}{l}\text { Altman and } \\
\text { Dittmer (1968) }\end{array}$ \\
\hline Ingestion of water by beef cattle, $I_{w b c}$ & 35 & 0.2 & L/d & $\begin{array}{l}\text { Altman and } \\
\text { Dittmer (1968) }\end{array}$ \\
\hline Ingestion of water by hens, $I_{w h}$ & 0.084 & 0.1 & $L / d$ & $\begin{array}{c}\text { Altman and } \\
\text { Dittmer (1968) }\end{array}$ \\
\hline Ingestion of soil by cattle, $\mathrm{I}_{\mathrm{sc}}$ & 0.4 & 0.7 & $\mathrm{~kg} / \mathrm{d}$ & $\begin{array}{l}\text { McKone and } \\
\text { Ryan (1989) }\end{array}$ \\
\hline Ingestion of soil by hens, $I_{\text {sh }}$ & 0.0024 & 1 & $\mathrm{~kg} / \mathrm{d}$ & NRC (1984) \\
\hline Inhalation by cattle $I_{n c}$ & 122 & 0.3 & $\mathrm{~m}^{3} / \mathrm{d}$ & $\begin{array}{l}\text { Mckone and } \\
\text { Ryan (1989) }\end{array}$ \\
\hline Inhalation by hens, $I_{\text {nh }}$ & 2.2 & 0.3 & $\mathrm{~m}^{3} / \mathrm{d}$ & this paper \\
\hline Fat content of milk & 0.04 & 0.1 & none & $\begin{array}{l}\text { Travis and } \\
\text { Arms(1988) } \\
\end{array}$ \\
\hline Fat content of meat & 0.25 & 0.3 & none & $\begin{array}{c}\text { Travis and } \\
\text { Arms(1988), } \\
\text { Coldman et al. } \\
\text { (1989). }\end{array}$ \\
\hline Fat content of eggs & 0.08 & 0.1 & none & $\begin{array}{c}\text { Coldman et al. } \\
\text { (1989). }\end{array}$ \\
\hline Fraction organic carbon in soil, $\mathrm{f}_{\boldsymbol{O}}$ & 0.012 & 0.6 & none & $\begin{array}{l}\text { Soil } \\
\text { Conservation } \\
\text { Service (1975) }\end{array}$ \\
\hline $\begin{array}{l}\text { Fraction of the contaminant } \\
\text { concentration in irrigation water retained } \\
\text { in soil water, } f_{\text {ir }}\end{array}$ & 0.25 & 1 & none & this report \\
\hline
\end{tabular}


water intakes by cattle and chickens as, respectively, $35 \mathrm{~L} / \mathrm{d}$ with a $\mathrm{CV}$ of 0.2 and 0.084 $\mathrm{L} / \mathrm{d}$ with a CV of 0.1 . We assume that inhalation rates in chickens are scaled to those for cattle and humans according to body weight to the $2 / 3$ power to obtain the estimated inhalation rate for hens. From this information, we obtain arithmetic mean and $\mathrm{CV}$ values for the intakes of pasture (fresh mass), soil, water, and air by animals as listed in Table VII.

We assume that the fat content of meat averages 0.25 with range 0.1 to 0.4 and a CV of 0.3 , that the fat content of whole milk averages 0.04 with range 0.03 to 0.05 and a CV of 0.1 , and that the fat content of eggs averages 0.08 with a CV of 0.1 (Travis and Arms, 1988; Goldman et al., 1989). The fat content values that we use in the exposure model are listed in Table VII.

As a result of lower humidity and less rainfall, soils in the Western U.S. can have lower organic carbon contents than is typical of soils from regions east of the Mississippi River, and the reported fraction of organic carbon, $f_{o c}$ in the Western U.S. is in the range 0.0012 to 0.044 (Soil Conservation Service, 1975). As noted in Table VII, we use an average $f_{o c}$ value of 0.012 with a CV of 0.6 to represent soils in California.

The fraction of the contaminant concentration in water used for irrigation that is retained in the water phase of soil on which that water is applied, $f_{i r}$ is used to calculate contamination of food crops by irrigation water. This factor includes the fraction of time that irrigated water is used to water the homegrown fruits, vegetables, and grains and the fraction of contaminant that is not lost by evaporation, biodegredation, or infiltration. We use 0.25 for this parameter and CV of 1 to reflect that this parameter is likely to be much lower than 1 but no greater than 1 .

\section{Multiple-Pathway Exposures and Total Dose: The Ingestion Route}

In our multiple-pathway approach, total ingestion exposure is attributable to contaminated air, water, and soil. Concentrations of contaminants in six environmental media are used in the multiple-pathway assessment for ingestion exposures: (1) the contaminant concentration in ambient-air gases, $C_{a}$ in $\mathrm{mg} / \mathrm{m}^{3}$;

(2) the concentration of contaminant bound to air particles, $C_{a p}$ in $\mathrm{mg} / \mathrm{m}^{3}$;

(3) contaminant concentration in surface soil, $C_{g}$ in $\mathrm{mg} / \mathrm{kg}$; (4) contaminant concentration in root-zone soil below the surface layer, $\mathrm{C}_{\mathrm{s}}$ in $\mathrm{mg} / \mathrm{kg}$; (5) contaminant concentration in ground water, $\mathrm{C}_{\mathrm{q}}$ in $\mathrm{mg} / \mathrm{L}$; and (6) contaminant concentration in surface water, $C_{w}$ in $\mathrm{mg} / \mathrm{L}$. Total ingestion intake includes potential doses from the 
ingestion of tap water; the ingestion of local or homegrown truits, vegetables, grains, milk, meat, and eggs; ingestion of locally or recreationally caught fish; ingestion of soil; and the ingestion of surface water while swimming. In terms of the basic exposure model, expressed in equation [94], the ingestion intake of contaminants involves the intermedia transfer of contaminants from an environmental mertium, $k$, to the exposure medium, $i$, which is the ingested water, produce, animal product, fish, or soil. The environmental medium, $k$, is one of the six media described above. For each pathway we derive an intermedia-transfer factor, $C_{i} / C_{k}$, to express this ratio. For the intake rate of the exposure medium per unit body weight, $\left[\mathrm{In}_{\mathrm{i}} / \mathrm{BW}\right]$, we use the daily average ingestion rates per unit body weight as listed in Table $V$. The exposure frequency for all ingestion exposures is assumed to be 365 days per year. However, adjustments for dilution of the exposure media are made to account for seasonal unavailability of local foods and use of irrigation water.

In the sections below, $\mathrm{C}_{\mathrm{tw}}$ represents the contaminant concentration in the environmental medium used to supply tap water, which is a combination of $\mathrm{C}_{\mathrm{w}}$, the contaminant concentration in surface water and $C_{q}$ represents the contaminant concentration in ground water. Tap water concentration is calculated as

$$
C_{t w}=f_{g w}^{w} \times C_{g}+\left(1-f_{g w}^{w}\right) \times C_{w}
$$

where $\mathrm{f}_{\mathrm{gw}}^{\mathrm{w}}$ is the fraction of water needs provided by ground water as described in the section on exposure factors.

\section{Ingestion of Tap Water}

For tap water, the intermedia-transfer factor, $C_{i} / C_{k}$, is the ratio of contaminant concentration tap water, $\mathrm{mg} / \mathrm{L}$, to contaminant concentration, $\mathrm{mg} / \mathrm{L}$, in the nearest ground or surface water at the contaminated site and is assigned a default value of unity. When there is a mix of ground and surface water being used, the intermedia-transfer factors can be written as

$$
C_{t w} / C_{w}=\left(1-f_{g w}^{w}\right)
$$


The average daily dose (ADD) to contaminants in drinking water is calculated using the daily intake of tap water per unit body weight, $I_{f l}$, for the individual exposed for the assumed exposure duration, ED, and is given by

$$
A D D \text { (drinking water ingestion) }=I_{\mathfrak{f l}} \times C_{t w} \text {. }
$$

The potential dose factors (PDFs), in L/kg-d, for this exposure pathway are simply the ratios of ADDs, in $\mathrm{mg} / \mathrm{kg}-\mathrm{d}$, to water-supply concentrations, in $\mathrm{mg} / \mathrm{L}$ multiplied by the fraction of water supplied by that water source.

Ingestion of Contaminated Homegrown Fruits, Vegetables, or Grains

We consider contamination of fruits, vegetables, and grains by air (both the gas phase and particles), water, surface soil, and root-zone soil. For these environmental media, the associated average daily doses are expressed as the average daily dose to the individual exposed for the assumed exposure duration, ED. For ingestion of contaminants through fruits, vegetables, or grains (FVG), the ratio of average daily dose (ADD), in $\mathrm{mg} / \mathrm{kg}-\mathrm{d}$, of contaminants to water concentration, in $\mathrm{mg} / \mathrm{L}$; air concentration, in $\mathrm{mg} / \mathrm{m}^{3}$; and soil concentration, in $\mathrm{mg} / \mathrm{kg}$, can be expressed using potential dose factors (PDF) with respective units of $L / k g-d$, $\mathrm{m}^{3} / \mathrm{kg}-\mathrm{d}$, and $\mathrm{kg} / \mathrm{kg}-\mathrm{d}$,

$$
\begin{gathered}
\text { ADD(FVG ingestion) }=\text { PDF(air gases to FVG) } \times C_{a}+P D F\left(\text { air particles to FVG) } \times C_{a p}\right. \\
+P D F\left(\text { surface water to FVG) } \times C+P D F\left(\text { ground soil to FVG) } \times C_{g} .\right.\right.
\end{gathered}
$$

\section{Contamination by Ambient-Air Contaminants}

The ingestion intake of contaminants in fruits, vegetables, and grains contaminated by air involves the transfer of contaminants from air through deposition/resuspension of particle-bound contaminants or through foliar uptake of gas-phase contaminants. The intermedia-transfer factor, $C_{\text {plant }} / C_{a}$ is the ratio of contaminant concentration in fresh produce, $\mathrm{mg} / \mathrm{kg}$ (fresh mass), to contaminant concentration, $\mathrm{mg} / \mathrm{m}^{3}$, in the gas phase of the ambient outdoor air and equal to the plant-air partition coefficient, $K_{\mathrm{pa}}^{\mathrm{gs}}$. The intermedia-transfer factor, $\mathrm{C}_{\text {plant }} / \mathrm{C}_{\mathrm{ap}}$ is the ratio of contaminant concentration in fresh produce, $\mathrm{mg} / \mathrm{kg}$ (fresh mass), to contaminant concentration, $\mathrm{mg} / \mathrm{m}^{3}$, in the particle (or dust) phase of the ambient outdoor air and equal to the plant-air partition coefficient, $K_{\mathrm{pa}}^{\mathrm{pt}}$. Both $\mathrm{K}_{\mathrm{pa}}^{\mathrm{gs}}$ and $\mathrm{K}_{\mathrm{pa}}^{\mathrm{pt}}$ are discussed above and defined in terms of a mean value and a CV in Table V. The 
inclusion of ingestion rates and exposure factors from Tables V and VI with these intermedia-transfer factors gives the PDFs for estimating doses through the air/plant/ingestion pathway,

$$
\begin{aligned}
& P D F(\text { air gases to FVG })=K_{p a}^{g s} \times\left(I_{f v} \times f_{a b v-g r d}^{v} \times f_{\text {local }}^{v}+I_{g} \times i_{\text {local }}^{g}\right) \text { and } \\
& \text { PDF (air particles to FVG) }=K_{\mathrm{pa}}^{\mathrm{pt}} \times\left(\mathrm{I}_{\mathrm{v}} \times \mathrm{f}_{\mathrm{abv}-\mathrm{grd}}^{\mathrm{V}} \times \mathrm{f}_{\text {local }}^{\mathrm{v}}+\mathrm{Ig}_{\mathrm{g}} \times \mathrm{f}_{\text {local }}^{\mathrm{g}}\right) .
\end{aligned}
$$

\section{Contamination by Irrigation Water}

For this exposure pathway, there are two intermedia-transfer factors, $C_{i} / C_{k}$ one for ground ivater and one for surface water. These ratios express the ratio of contaminant concentration in fresh produce, $\mathrm{mg} / \mathrm{kg}$ (fresh mass), to contaminant concentration, $\mathrm{mg} / \mathrm{L}$, in the nearest ground or surface water at a contaminated site. For exposed produce these ratios are based on rainsplash and transfers to aboveground plant parts and are given by

$$
C_{e p} / C_{w}=\left(1-f_{g w}^{w}\right) \times\left(K_{p s}^{\text {sain }}+K_{p s}\right) \times K_{D} \times f_{i r} \quad \text { (for surface water) }
$$

where $\mathrm{C}_{\mathrm{ep}}$ refers to exposed produce. For protected produce and root crops, these ratios are based the root concentration factor, $K_{p s}$ (roots), discussed above and are given by

$$
C_{p p} / C_{w}=\left(1-f_{g w}^{w}\right) \times K_{p s}(\text { roots }) \times K_{d} \times f_{i r} \quad \text { (for surface water) and }
$$

where $C_{p p}$ refers to protected produce. Other partition coerficients and parameters used in this expression are discussed above and summarized in terms of mean values and coefficients of variation in a companion report on ITF factors. The inclusion of ingestion rates and exposure factors from Tables V and VI with the intermedia-transfer factor gives the following PDF for this exposure pathway, 


$$
\begin{aligned}
\text { PDF(surface water to FVG) } & =\left(1-f_{g w}^{w}\right) \times\left\{\left[I_{f v} \times f_{\text {local }}^{v}\right] \times\left[35 K_{p s} \times\left(1-f_{v}^{\text {abg }}\right)\right.\right. \\
& \left.+\left(K_{p s}^{\text {rain }}+K_{p s}\right) \times f_{v}^{a b g}\right] \\
& \left.+\left(I_{g} \times f_{\text {local }}^{g}\right) \times\left(K_{p s}^{\text {rain }}+K_{p s}\right)\right\} \times K_{D} \times f_{i r}
\end{aligned}
$$

Parameters in these expressions are discussed above and summarized in Tables $\mathrm{V}$ through VII.

\section{Contamination by Surface Soil}

The ingestion intake of contaminants in fruits, vegetables, and grains contaminated by surface soil involves the transfer of contaminants from soil to plants. The intermedia-transfer factor, $C_{e p} / C_{\text {soil }}$, is the ratio of contaminant concentrations in exposed produce (ep) in $\mathrm{mg} / \mathrm{kg}$ (fresh mass) to contaminant concentration, in $\mathrm{mg} / \mathrm{kg}$, in surface soil and equal to the rainsplash partition coefficient, $\mathrm{K}_{\mathrm{pe}}^{\mathrm{rain}}$, which is discussed above and defined in terms of mean value and $\mathrm{CV}$ in Table $\mathrm{V}$. The inclusion of ingestion rates for exposed produced from Table $\mathrm{V}$ and exposure factors from Table VI with this intermedia-transfer factor gives the following PDF for exposure through the soil/plant/ingestion pathway for homegrown fruits, vegetables, and grains,

$$
P D F(\text { surface soil to FVG })=K_{p s}^{\text {rain }} \times\left[\left(I_{f v} \times f_{f v}^{a b g} \times f_{\text {local }}^{v}\right)+\left(I_{g} \times f_{\text {local }}^{g}\right)\right]
$$

\section{Contamination by Root-Zone Soil}

The ingestion intake of contaminants in fruits, vegetables, and grains contaminated by root-zone soil involves the transfer of contaminants from soil to both exposed produce (ep) and protected produce (pp). The corresponding intermedia-transfer factors, $C_{e p} / C_{s}$ and $C_{p p} / C_{s}$ are the ratios of contaminant concentration in exposed and protected produce, $\mathrm{mg} / \mathrm{kg}$ (fresh mass), to contaminant concentration, $\mathrm{mg} / \mathrm{kg}$, in root-zone soil and equal to $\mathrm{K}_{\mathrm{ps}}$ and $K_{p s}$ (roots), respectively. These factors are discussed above and defined in terms of mean value and $C V$ in Table $V$. The inclusion of ingestion rates of exposed and protected produce from Table $\mathrm{V}$ and exposure factors from Table VI with these intermedia-transfer factors gives the following PDF for exposure through the rootsoil/plant/ingestion pathway for homegrown fruits, vegetables, and grains, 


$$
\begin{aligned}
\operatorname{PDF}(\text { root - zone soil to FVG })= & K_{p s} \times\left[\left(I_{f v} \times f_{\text {local }}^{v} \times f_{f v}^{a b g}\right)+\left(I_{g} \times f_{\text {local }}^{g}\right)\right] \\
& +K_{p s}(\text { roots }) \times I_{f v} \times f_{\text {local }}^{v} \times\left(1-f_{f v}^{a b g}\right) .
\end{aligned}
$$

Ingestion of Contaminated Meat, Milk, and Eggs

Ingestion doses to humans through local or homegrown meat, milk, and/or eggs is based on potential contamination from air gases, air particles, surface soil, root-zone soil, surface water, and ground water. For these environmental media, the associated average daily doses are expressed as the average daily dose to the individual exposed for the assumed exposure duration, ED. The ratio of average daily dose (ADD) of contaminants, in $\mathrm{mg} / \mathrm{kg}$-d, to soil concentrations, in $\mathrm{mg} / \mathrm{kg}$; air concentrations, in $\mathrm{mg} / \mathrm{m}^{3}$; and water concentrations, in $\mathrm{mg} / \mathrm{L}$, can be expressed using potential dose factors (PDF) with respective units of $\mathrm{kg} / \mathrm{kg}-\mathrm{d}, \mathrm{m}^{3} / \mathrm{kg}-\mathrm{d}$, and L/kg-d,

$A D D$ (milk, meat, eggs) $=[$ PDF(air gas to milk) + PDF(air gases to meat)

+ PDF(air gases to eggs) ] $\times \mathrm{C}_{\mathrm{a}}+$ [ PDF(air particles to milk)

+ PDF(air particles to meat) + PDF(air particles to eg8s)] $\times C_{a p}$

+ ( PDF(surface water to milk) + PDF(surface water to meat)

$+P D F($ surface water to eggs) $] \times C_{w}$

[108]

+ ( PDF(surface soil to milk) + PDF(surface soil to meat)

$+\operatorname{PDF}$ (surface soil to eggs) $] \times C_{g}+[$ PDF(root-zone-soil to milk)

$+\mathrm{PDF}$ (root-zone-soil to meat) $+\mathrm{PDF}($ root-zone-soil to eggs) $] \times \mathrm{C}_{s}$.

\section{Contamination by Transfer from Air te Animal Products}

Contaminants in air can be transferred from air to meat-, milk-, and eggproducing animals both directly by inhalation and indirectly by animal ingestion of plants that have taken up contaminants from air. We consider the gas phase of the air and air particles separately. For the gas phase of ambient air, the intermediatransfer factors, $C_{\text {meat }} / C_{a}, C_{\text {milk }} / C_{a}$ and $C_{e g g} / C_{a}$ express the ratio of contaminant concentration in fresh food product, $\mathrm{mg} / \mathrm{kg}$ (fresh mass), to contaminant concentration, $\mathrm{mg} / \mathrm{m}^{3}$, in ambient air gases, 


$$
\begin{array}{ll}
C_{\text {meat }} / C_{a}=\left[I_{n c}+K_{p a}^{g s} \times I_{v b c}\right) \times B_{q} & \text { for meat, } \\
C_{\text {milk }} / C_{a}=\left[I_{n c}+K_{p a}^{g a} \times I_{v d c}\right] \times B_{k} & \text { for milk, and } \\
C_{e g g} / C_{a}=\left(I_{n h}+K_{p a}^{g s} \times I_{v h}\right] \times B_{e} & \text { for eggs. }
\end{array}
$$

For particle-bound contaminants in ambient air, the intermedia-transfer factors, $C_{\text {meat }} / C_{\text {ap }}, C_{\text {milk }} / C_{\text {ap }}$ and $C_{\text {egg }} / C_{\text {ap }}$ express the ratio of contaminant concentration in fresh food product, $\mathrm{mg} / \mathrm{kg}$ (fresh mass), to contaminant concentration, $\mathrm{mg} / \mathrm{m}^{3}$, attached to particles in ambient air,

$$
\begin{array}{ll}
C_{\text {meat }} / C_{a p}=\left[I_{n c}+K_{p a}^{p t} \times I_{v b c}\right] \times B_{t} & \text { for meat, } \\
C_{\text {milk }} / C_{a p}=\left[I_{n c}+K_{p a}^{p t} \times I_{v d c}\right] \times B_{k} & \text { for milk, and } \\
C_{e g g} / C_{a p}=\left[I_{n h}+K_{p a}^{p t} \times I_{v h}\right] \times B_{e} & \text { for eggs. }
\end{array}
$$

$I_{n c}$ and $I_{\text {nh }}$ are the daily inhalation rates by, respectively, cattle and egg-laying hens in $\mathrm{m}^{3 / d}$ and $I_{v d c}, I_{v b c}$ and $I_{v h}$ are the daily intakes of pasture by, respectively, beef cattle, dairy cattle, and egg-laying hens in $\mathrm{kg}$ (dry mass)/ $\mathrm{d}$. These and other parameters have been defined previously and are listed in Table VII.

In order to calculate the exposure to the local population that results from intermedia transfers from ambient air as derived above, we combine these intermedia-transfer factors with intake rates and local consumption fractions to obtain the following PDFs,

$$
\begin{aligned}
& P D F \text { (air-gases to meat) }=I_{m t} \times\left[I_{n c}+K_{p a}^{g s} \times I_{v b c}\right] \times B_{t} \times f_{\text {local }}^{m t}, \\
& P D F\left(\text { air-gases to milk) }=I_{m k} \times\left[I_{n c}+K_{p a}^{g s} \times I_{v d c}\right] \times B_{k} \times f_{\text {local }}^{m k},\right. \\
& P D F \text { (air-gases to eggs) }=I_{e g g} \times\left[I_{n h}+K_{p a}^{g s} \times I_{v h}\right] \times B_{e} \times f_{\text {local }}^{\text {egg }},
\end{aligned}
$$




$$
\begin{aligned}
& P D F\left(\text { air-particles to meat) }=I_{m t} \times\left[I_{n c}+K_{p a}^{p t} \times I_{v b c}\right] \times B_{1} \times t_{\text {local }}^{m t},\right. \\
& P D F\left(\text { air-particles to milk) }=I_{m k} \times\left[I_{n c}+K_{p a}^{p t} \times I_{v d c}\right] \times B_{k} \times t_{\text {local }}^{m k}\right. \text {, and } \\
& P D F\left(\text { air-particles to eggs) }=L_{e g 8} \times\left[I_{n h}+K_{p a}^{p t} \times I_{v h}\right] \times B_{e} \times t_{l o c a l}^{g 8 g} .\right.
\end{aligned}
$$

The fractions of meat, milk, or eggs obtained from local sources is the fraction of the exposed population's intake of meat, milk, or eggs that comes from animals that are exposed to ambient air with contaminant concentrations $C_{a}$ and $C_{a p}$.

\section{Contamination by Transfer from Water to Animal Products}

The ingestion intake of contaminants in local or homegrown milk, meat, and eggs involves the transfer of contaminants from water to animal products both through the direct ingestion of water by the animals and through ingestion of pasture and feed contaminated by the use of contaminated irrigation water. The intermedia-transfer factors, $C_{\text {meat }} / C_{w}, C_{\text {milk }} / C_{w}$, and $C_{e g g} / C_{w}$, express the ratio of cor taminant concentration in fresh food product, $\mathrm{mg} / \mathrm{kg}$ (fresh mass), to contaminant concentration, $\mathrm{mg} / \mathrm{L}$, in the nearest surface water at the contaminated site and the intermedia-transfer factors, $C_{\text {meat }} / C_{q}, C_{\text {milk }} / C_{q}$, and $C_{e g g} / C_{q}$ expreas the ratio of contaminant concentration in fresh-food product, $\mathrm{mg} / \mathrm{kg}$ (fresh mass), to contaminant concentration, $\mathrm{mg} / \mathrm{L}$, in the nearest ground water at the contaminated site. These intermedia ratios are given by the expressions,

$$
\begin{array}{ll}
C_{\text {meat }} / C_{w}=\left[\left(1-f_{g w}^{w}\right) \times I_{w b c}+\left(I_{v b c} \times \frac{C_{e p}}{C_{w}}\right)\right] \times B_{t} & \text { for meat, } \\
C_{\text {milk }} / C_{w}=\left[\left(1-f_{g w}^{w}\right) \times I_{w d c}+\left(I_{v d c} \times \frac{C_{e p}}{C_{w}}\right)\right] \times B_{k} & \text { for milk, } \\
C_{e g g} / C_{w}=\left[\left(1-f_{g w}^{w}\right) \times I_{w h}+\left(I_{v h} \times \frac{C_{e p}}{C_{w}}\right)\right] \times B_{e} & \text { for eggs, }
\end{array}
$$

where, $I_{w b c}, I_{w d c}$ and $I_{w h}$ are the daily intakes of water by, respectively, beef cattle, dairy cattle, and egg-laying hens in $L / d$ and $I_{v b c}, I_{v d c}$ and $I_{v h}$ are the daily intakes of 
pasture by, respectively, beef cattle, dairy cattle, and egg-laying hens in $\mathrm{kg}$ (dry mass)/d. The intermedia-transfer factors, $C_{e p} / C_{w}$ and $C_{e p} / C_{w}$ are the intermediatransfer factor for pasture or feed and are modeled as exposed produce and set equal to the terms derived above for intermedia transfer from irrigation water to expoeed produce. Other factors have been defined previously.

In order to calculate the exposure to the local population that results from intermedia transfers from ground and surface water as derived above, we use the following PDFs,

$$
\begin{aligned}
\text { PDF(surface water to meat) }= & I_{m t} \times f_{\text {local }}^{\text {mt }} \times\left(1-f_{g w}^{w}\right) \\
& \times\left\{I_{w b c}+\left[I_{v b c} \times\left(K_{p s}^{\text {rain }}+K_{p s}\right) \times K_{D} \times f_{i r}\right]\right\} \times B_{t}, \\
\text { PDF(surface water to milk })= & I_{\text {mk }} \times f_{\text {local }}^{\text {mk }} \times\left(1-f_{g w}^{w}\right) \\
& \times\left\{I_{w d c}+\left[I_{v d c} \times\left(K_{p s}^{\text {rain }}+K_{p s}\right) \times K_{D} \times f_{i r}\right]\right\} \times B_{k}, \\
\text { PDF(surface water to eggs) }= & I_{\text {egg }} \times f_{\text {local }}^{\text {egg }} \times\left(1-f_{g w}^{w}\right) \\
& \times\left\{I_{w h}+\left[I_{v h} \times\left(K_{p s}^{\text {rain }}+K_{p s}\right) \times K_{D} \times f_{i r}\right]\right\} \times B_{e},
\end{aligned}
$$

The fractions of meat, milk, or eggs obtained from local sources are the fractions of the exposed population's intakes of meat, milk, or eggs that comes from animals that ingest water having estimated concentrations of $C_{w}$ or $C_{q}$.

\section{Contamination by Transfer from Surface Soil to Animal Products}

Contaminants in surface soil can enter meat, milk, or eggs through either the direct ingestion of soil by animals or the ingestion by animals of pasture vegetation that has taken up a contaminant from surface soil through rainsplash. The intermedia-transfer factors, $C_{\text {meat }} / C_{g}, C_{\text {milk }} / C_{g}$, and $C_{e g g} / C_{g}$ express the ratio of contaminant concentration in fresh-food product, $\mathrm{mg} / \mathrm{kg}$ (fresh mass), to contaminant concentration, $\mathrm{mg} / \mathrm{kg}$, in the surface soil associated with the contaminated site. These intermedia ratios are given by the expressions,

$$
\mathrm{C}_{\text {meat }} / \mathrm{C}_{\mathrm{g}}=\left[\mathrm{I}_{\mathrm{sc}}+\left(\mathrm{K}_{\mathrm{ps}}^{\text {rain }} \times \mathrm{I}_{\mathrm{vbc}}\right)\right] \times \mathrm{B}_{\mathrm{t}} \quad \text { for meat, }
$$




$$
\begin{array}{ll}
C_{\text {millk }} / C_{g}=\left[L_{s c}+\left(K_{p s}^{\text {rain }} \times I_{v d c}\right)\right] \times B_{k} & \text { for milk, and } \\
C_{e g g} / C_{g}=\left[L_{s h}+\left(K_{p b}^{\text {rain }} \times I_{v h}\right)\right] \times B_{e} & \text { for eggs, }
\end{array}
$$

where $I_{s c}$ and $I_{s h}$ are the daily intakes of soil by, respectively, cattle and egg-laying hens in $\mathrm{kg} / \mathrm{d}$. Other factors have been defined previously.

In order to calculate the exposure to the local population that results from intermedia transfers from surface soil as derived above, we combine these intermedia-transfer factors with intake rates and local consumption fractions to obtain the following PDFs.

$$
\begin{aligned}
& P D F\left(\text { surface soil to meat) }=I_{m t} \times f_{\text {local }}^{m t} \times\left[I_{s b c}+\left(K_{p s}^{\text {rain }} \times I_{v b c}\right)\right] \times B_{t}\right. \\
& P D F\left(\text { surface soil to milk) }=I_{m k} \times f_{\text {local }}^{m k} \times\left[I_{s d c}+\left(K_{p s}^{\text {rain }} \times I_{v d c}\right)\right] \times B_{k}\right. \\
& \text { PDF(surface soil to eggs) }=I_{\text {egg }} \times f_{\text {local }}^{\text {ggg }} \times\left[I_{s h}+\left(K_{p s}^{\text {rain }} \times I_{v h}\right)\right] \times B_{e}
\end{aligned}
$$

The fractions of meat, milk, or eggs obtained from local sources is the fraction of the exposed individual's intake of meat, milk, or eggs that comes from animals exposed to soil having an estimated contaminant concentration $C_{\boldsymbol{g}}$.

\section{Contamination by Transfer from Root-Zone Soil to Animal Products}

Contaminants in surface soil can enter meat, milk, or eggs through either the either ingestion by animals of pasture vegetation or feed derived from vegetation that has taken up a contaminant from root soil. The intermedia-transfer factors, $C_{\text {meat }} / C_{g} C_{\text {milk }} / C_{s}$ and $C_{\text {egg }} / C_{s}$ express the ratio of contaminant concentration in fresh food product, $\mathrm{mg} / \mathrm{kg}$ (fresh mass), to contaminant concentration, $\mathrm{mg} / \mathrm{kg}$, in the root-zone soil associated with the contaminated site. These intermedia ratios are given by the expressions,

$$
\begin{array}{ll}
C_{\text {meat }} / C_{s}=K_{p s} \times I_{v b c} \times B_{t} & \text { for meat, } \\
C_{\text {milk }} / C_{s}=K_{p s} \times I_{v d c} \times B_{k} & \text { for milk, and }
\end{array}
$$




$$
\mathrm{C}_{\mathrm{egg}} / \mathrm{C}_{\mathrm{s}}=\mathrm{K}_{\mathrm{ps}} \times \mathrm{I}_{\mathrm{vh}} \times \mathrm{B}_{\mathrm{e}} \quad \text { for eggs, }
$$

which include parameters that have all been defined previously. In order to calculate the exposure to the local population that results from intermedia transfers from root-zone soil as derived above, we combine these intermedia-transfer factors with intake rates and local-consumption fractions to obtain the following PDFs.

$$
\begin{aligned}
& \text { PDF(root-zone soil to meat) }=I_{m t} \times f_{\text {local }}^{m t} \times K_{p s} \times I_{v b c} \times B_{t} \\
& \text { PDF(root-zone soil to milk) }=I_{m k} \times f_{\text {local }}^{m k} \times K_{p s} \times I_{v d c} \times B_{k} \\
& \text { PDF(root-zone soil to eggs) }=I_{\text {egg }} \times f_{\text {local }}^{\text {egg }} \times K_{p s} \times I_{v h} \times B_{e}
\end{aligned}
$$

The fractions of meat, milk, or eggs obtained from local sources is the fraction of the exposed individual's intake of meat, milk, or eggs that comes from animals exposed to root-zone soil having an estimated contaminant concentration $\mathrm{C}_{\mathrm{s}}$.

Ingestion of Contaminated Fish

Ingestion doses to humans through locally caught fish is based on potential contamination from surface water with contaminant concentration, $C_{w}$ in $\mathrm{mg} / \mathrm{L}$. The intermedia-transfer factor between fish and surface water is the bioconcentration factor, $\mathrm{BCF}$. The average daily dose to an individual within the exposed population during the exposure duration, ED, is

$$
A D D(\text { fish ingestion })=I_{\text {fsh }} \times B C F \times f_{\text {local }}^{\text {fsh }} \times C_{w} \text {. }
$$

The fraction of fish from local waters, $\frac{\mathrm{f} \text { focal }}{\text { loch }}$ is the fraction of a representative individual's annual intake of fish that comes from local sources that are contaminated by runoff from the contaminated site and have an estimated water concentration, $C_{w}$. The PDF for this exposure pathway is the ratio of ADD to $C_{w}$ and is equal to the product, $I_{\mathrm{fsh}} \times \mathrm{BCF} \times \mathrm{f}_{\text {local }}^{\text {fsh }}$. 


\section{Soil Ingestion by Human}

For household soil, the intermedia-transfer factor, $C_{i} / C_{k}$, is the ratio of contaminant concentration in household surface soil, $\mathrm{mg} / \mathrm{kg}$, to contaminant concentration, $\mathrm{mg} / \mathrm{kg}$, in the surface soil of the contaminated site and is assigned a default value of unity. The average daily dose (ADD) to contaminants through soil ingestion is calculated using soil ingestion per unit body weight for the individual exposed for the assumed exposure duration, ED, and is given by

$$
\mathrm{ADD}(\text { soil ingestion })=\mathrm{I}_{\mathrm{sl}} \times \mathrm{C}_{\mathrm{g}} \text {. }
$$

The PDF in $\mathrm{kg} / \mathrm{kgg}-\mathrm{d}$ for this exposure pathway is simply the ratio of average daily dose (ADD), in $\mathrm{mg} / \mathrm{kg}-\mathrm{d}$, to surface-soil concentration, $C_{\mathrm{g}}$, in $\mathrm{mg} / \mathrm{kg}$ and equal to $\mathrm{I}_{\mathrm{gl}}$.

Ingestion of Surface Water During Swimming

For a recreational surface-water body, the intermedia-transfer factor, $C_{i} / C_{k}$ is the ratio of contaminant concentration in the recreational water, $C_{w}$ in $\mathrm{mg} / \mathrm{L}$, to contaminant concentration, $\mathrm{mg} / \mathrm{L}$, in the surface water that is contaminated either directly or through contaminant runoff. This ratio is assigned a default value of unity. The average daily dose (ADD) to contaminants through swimming-water ingestion is calculated using swimming ingestion per unit body weight, L/ kg-d, for the individual exposed for the assumed exposure duration, ED, times the exposure frequency of swimming, $E F_{s w}$ in $d / y$, and is given by

$$
A D D\left(\text { swimming-water ingestion) }=I_{s w w} \times E F_{s w} \times C_{w}\right. \text {. }
$$

Parameters in this expression are defined in terms of expected value and $\mathrm{CV}$ in Table VI. The PDF, in L/kg-d, for this exposure pathway is simply the ratio of average daily doses (ADD), in $\mathrm{mg} / \mathrm{kg}-\mathrm{d}$, to surface water concentration, $C_{w}$ in $\mathrm{mg} / \mathrm{L}$ and equal to $I_{\mathrm{sww}} \times \mathrm{EF}_{\mathrm{Sw}}$.

\section{Multiple Pathway Exposures and Total Dose: The Inhalation Route}

In the total-dose assessment-model used in CAirTOX, we consider for the inhalation route all transfers of contaminants from contaminated environmental media to personal air. Personal air is the envelope of air contacted by an individual during a 24-h period and is based on both activity patterns and time-weighted 
breathing rates. Concentrations of contaminants in six environmental media are used in the multiple pathway assessment for inhalation exposures: (1) the contaminant concentration in ambient air gases, $\mathrm{C}_{\mathrm{a}}$ in $\mathrm{mg} / \mathrm{m}^{3}$; (2) the concentration of contaminant bound to air particles, $\mathrm{C}_{\mathrm{ap}}$ in $\mathrm{mg} / \mathrm{m}^{3}$; (3) contaminant concentration in surface soil, $C_{g}$ in $\mathrm{mg} / \mathrm{kg}$; (4) contaminant concentration in root-zone soil below the surface layer, $C_{g}$ in $\mathrm{mg} / \mathrm{kg}$; (5) contaminant concentration in ground water, $C_{q}$ in $\mathrm{mg} / \mathrm{L}$; and (6) contaminant concentration in surface water, $\mathrm{C}_{\mathrm{w}}$ in $\mathrm{mg} / \mathrm{L}$. In terms of the basic exposure model, expressed in equation [94], the inhalation intake of contaminants involves the intermedia transfer of contaminants from the environmental medium, $k$, which is one of the six media described above to the exposure medium $i$, which is personal air. For each pathway we derive an intermedia-transfer factor, $C_{i} / C_{k}$ to express this ratio. For the intake rate of the exposure medium per unit body weight, $\left[\mathrm{In}_{\mathrm{i}} / \mathrm{BW}\right.$ ], we use the daily average inhalation rates per unit body weight listed in Table $V$. The exposure frequency for all inhalation exposures is assumed to be 365 days per year.

Inhalation of Contaminants in Ambient Air

Inhalation exposure is based on the average concentration in an exposed individual's personal air. In the case of ambient air, there are two intermediatransfer factors, $C_{i} / C_{k}$. The first is the ratio of contaminant concentration in the personal air breathed by individuals to the contaminant concentration in the gas phase of ambient air, $\mathrm{C}_{\mathrm{a}}$ in $\mathrm{mg} / \mathrm{m}^{3}$. The second is the ratio of contaminant concentration in the personal air to the concentration in ambient-air of particlebound contaminant, $C_{a p}$ in $\mathrm{mg} / \mathrm{m}^{3}$. We assume that, for both gases and particles, the ambient-air concentrations exist both indoors and outdoors so that the ratio $C_{i} / C_{k}$ is equal to the total hours per day spent at by an individual at a household either indoors or outdoors divided by 24 , that is $\left(E T_{h}+E T_{o}\right) / 24 . E_{h}$ and $E T_{o}$ are summarized in Table VI. The average daily potential doses to these gas-phase and particle-phase contaminants are related to the active and resting breathing rates listed in Table $V$, under the assumption that one spends $8 \mathrm{~h}$ breathing at the resting rate and $16 \mathrm{~h}$ breathing at the active rate (ICRP, 1975). This results in a average daily potential dose estimates of the form,

$$
\mathrm{ADD}(\text { ambient-air gases })=\left(16 \mathrm{BR}_{\mathrm{a}}+8 \mathrm{BR}_{\mathrm{r}}\right) \times \frac{\left(E T_{\mathrm{h}}+\mathrm{ET}_{\mathrm{o}}\right)}{24} \times \mathrm{C}_{\mathrm{a}} \text { and }
$$


$\mathrm{ADD}($ ambient-air particles $)=\left(16 \mathrm{BR}_{\mathrm{a}}+8 \mathrm{BR}_{\mathrm{r}}\right) \times \frac{\left(E T_{\mathrm{h}}+\mathrm{ET}_{\mathrm{O}}\right)}{24} \times \mathrm{C}_{\mathrm{ap}}$.

The PDFs for these exposures are the ratio of ADD to ambient-air concentration and are the same for both particles and gases.

Inhalation of Contaminants Transferred from Soil to Indoor Air

Contaminants in soil can be transferred from soil to indoor air either by tracking of surface soil as dust into the house on shoes, clothing, or pets or by the migration of vapors into the house from soil below the house. These two scenarios can increase indoor concentrations to levels higher than those associated with the migration of ambient-air contaminants into the house as described above.

\section{Dust migration from Surface Soil}

This scenario is used to account for exposures that occur when contaminated soil is tracked into the home by shoes of occupants and by pets. The scenario is used for situations in which the household is proximate to a site with contaminated soil. The source of contaminated soil is assumed to be surface soil with contaminant concentration $\mathrm{C}_{\mathrm{g}}$ in $\mathrm{mg} / \mathrm{kg}$. The intermedia-transfer factor is equal to the contaminant concentration in personal air, $C_{\text {pair }}$ in $\mathrm{mg} / \mathrm{m}^{3}$ attributable to surface soil divided by the contaminant concentration, $C_{g}(\mathrm{mg} / \mathrm{kg})$ in surface soil and is given by the expression,

$$
\mathrm{C}_{\text {pair }} / \mathrm{C}_{\mathrm{g}}=\text { dust }_{\text {in }} \times E T_{\mathrm{h}} / 24
$$

where dust $t_{\text {in }}$ is the particle concentration (or dust load) inside a home in $\mathrm{kg} / \mathrm{m}^{3}$, $\mathrm{ET}_{h}$ is the number of hours per day an individual spends at home, and $\mathrm{ET}_{h} / 24$ is the assumed fraction of personal air that is contacted at home. These parameters are discussed in the section on household parameters and listed in Table VI. Under the assumption that one spends $8 \mathrm{~h}$ per day breathing at the resting rate and $16 \mathrm{~h}$ per day breathing at the active rate (ICRP, 1975), we estimate the average daily potential dose, ADD, in $\mathrm{mg} / \mathrm{kg}-\mathrm{d}$, from tracked-in soil as

$$
\mathrm{ADD}(\text { tracked-in soil })=\left(16 \mathrm{BR}_{\mathrm{a}}+8 \mathrm{BR}_{\mathrm{r}}\right) \times \text { dust }_{\text {in }} \times \mathrm{ET}_{\mathrm{h}} / 24 \times \mathrm{C}_{\mathrm{g}}
$$

The PDF for this exposure is the ratio of ADD to surface-soil concentration. 


\section{Vapor migration from Root-Zone Soil}

This scenario is used to represent exposure in homes built near or over contaminated soil such that the base of the foundation is within approximately $1 \mathrm{~m}$ of the contaminated root-zone soil. The intermedia-transfer factor for this pathway is equal to the magnitude of contaminant concentration in the gas phase of personal air, $\mathrm{C}_{\text {air }}$ in $\mathrm{mg} / \mathrm{m}^{3}$, attributable to soil-gas migration divided by the contaminant concentration in dry root-zone soil, $C_{s}$ in $\mathrm{mg} / \mathrm{kg}$, and this ratio is given by

$$
\mathrm{C}_{\text {air }} / \mathrm{C}_{s}=\alpha_{\text {inair }} \times \mathrm{ET}_{\mathrm{h}} / 24
$$

where $\alpha_{i n a i r}$ is the partition coefficient for indoor-air concentration relative to soil concentration as described previously in the section on partition factors and listed in Table $V$, and $\mathrm{ET}_{h} / 24$ is used as adescribed bove in the soil-tracking scenario. Under the assumption that an exposed individual spends $8 \mathrm{~h}$ per day breathing at the resting rate and $16 \mathrm{~h}$ per day breathing at the active rate (ICRP, 1975), we estimate the average daily potential dose, $A D D$, in $\mathrm{mg} / \mathrm{kg}-\mathrm{d}$, from soil-vapor migration as

$$
\mathrm{ADD}(\text { soil-vapor migration })=\left(16 \mathrm{BR}_{\mathrm{a}}+8 \mathrm{BR}_{\mathrm{r}}\right) \times \alpha_{\text {inair }} \times \mathrm{ET}_{\mathrm{h}} / 24 \times \mathrm{C}_{\mathrm{s}} .
$$

The PDF for this exposure is the ratio of ADD to root-zone soil concentration.

Inhalation of Contaminants Transferred from Water to Indoor Air

When surface water that provides a source of tap water for a household contain volatile contaminants, these contaminants can be transferred from tap water to personal air by showers, baths, and other household-water uses. In this case the environmental medium is surface water and the exposure medium is personal air. The intermedia-transfer factor for these transfers is equal to the contaminant concentration in personal air, $C_{\text {pair }}$, in $\mathrm{mg} / \mathrm{m}^{3}$ attributable to surface water divided by the contaminant concentrations $C_{w}$ and is given by the expression 


$$
\begin{aligned}
C_{\text {pair }} / C_{w}= & \left(1-f_{g w}^{w}\right) \times\left\{\frac{W_{\text {shower }} \times \phi_{x}(\text { bath/shower })}{V R_{\text {bath }}} \times E T_{\text {sb }} \times B R_{a}\right. \\
& \left.+\frac{\left.W_{\text {house }} \times \phi_{x} \text { (house }\right)}{V R_{\text {house }}} \times\left[\left(E T_{h}-8\right) \times B R_{a}+8 \times B R_{r}\right]\right\} \\
& \times\left[16 \times B R_{a}+8 \times B R_{r}\right]^{-1} .
\end{aligned}
$$

where $\mathrm{ET}_{\mathrm{h}}$ is the number of hours per day an individual spends at home, $\mathrm{ET}_{\mathrm{sb}}$ is the number of hours per day spent in the bathroom or shower, $E T_{s b} \times B R_{a} /\left[16 B R_{a}+8 B R_{\mathrm{T}}\right]$ is the assumed fraction of personal air that is contacted in the shower or bathroom, and $\left[\left(E T_{h}-8\right) \times B R_{a}+8 B R_{r}\right] /\left[16 B R_{a}+8 B R_{r}\right]$ is the assumed fraction of personal air contacted in the home outside of the bathroom and shower. These fractions are based on the assumption that one spends $8 \mathrm{~h}$ per day breathing at the resting rate and $16 \mathrm{~h}$ per day breathing at the active rate (ICRP, 1975). Other parameters in these equations are discussed in the section on household parameters and listed in Table VI. We multiply the expressions above by daily air intake per unit body weight to obtain estimates of average daily potential doses, ADD, in $\mathrm{mg} / \mathrm{kg}-\mathrm{d}$, associated with inhalation of waterborne contaminants transferred to personal air from either ground or surface water as

$$
A D D\left(\text { surface water to personal air) }=\left(16 \mathrm{BR}_{\mathrm{a}}+8 \mathrm{BR}_{\mathrm{r}}\right) \times\left(\mathrm{C}_{\text {pair }} / \mathrm{C}_{\mathrm{w}}\right) \times \mathrm{C}_{\mathrm{w}}\right. \text { and }
$$

The PDFs for these exposures are the ratios of ADDs to, respectively, surface-water and ground-water concentration.

\section{Multiple-Pathway Exposures and Total Dose: The Dermal-Uptake Route}

In the total-dose-assessment model developed for CAirTOX, we consider for the dermal-uptake-route transfers of contaminants from contaminated environmental media into the outer-skin layer, the stratum corneum. Concentrations of contaminants in two environmental media are used in the multiple-pathway assessment for dermal exposures: (1) contaminant concentration in surface soil, $C_{g}$ in $\mathrm{mg} / \mathrm{kg}$ and (2) contaminaitt concentration in surface water, $C_{w}$ in $\mathrm{mg} / \mathrm{L}$. In terms of the basic exposure model, expressed in equation [94], the uptake of contaminants into skin involves the intermedia transfer of contaminants 
from the environmental medium, $k$, which is one of the three media described above, to the exposure medium, $i$, which is household soil, tap water, or swimming water. For each pathway we derive an intermedia-transfer factor, $C_{i} / C_{k}$, to express this ratio.

\section{Dermal Contact While Swimming or Bathing}

For human exposures during swimming, both the environmental medium and the exposure medium are surface water and the intermedia-transfer factor is unity. Dermal uptake from surface or ground water that provide sources of tap water involves the intermedia transfer from surface or ground water to tap water and the intermedia-transfer factors, $C_{t w} / C_{w}$ and $C_{t w} / C_{q}$ are, respectively, the fraction of tap water obtained from surface water, $1-f_{\mathrm{gw}^{\prime}}^{\mathrm{W}}$ and the fraction of tap water obtained from ground water, $\mathrm{f}_{\mathrm{gw}}^{\mathrm{w}}$.

The average daily potential dose, ADD in $\mathrm{mg} / \mathrm{kg}-\mathrm{d}$, to an individual whose exposure time swimming is $E T_{s w} h / d$ and whose exposure frequency swimming is $\mathrm{EF}_{\mathrm{sw}} \mathrm{d} / \mathrm{y}$ is given by

$$
A D D \text { (dermal uptake swimming) }=\frac{U_{\mathrm{sw}}}{B W} \times \frac{E_{\mathrm{sw}}}{365 \mathrm{~d} / \mathrm{y}} \times C_{w},
$$

where $U_{\mathrm{sw}}$ expresses the dermal uptake during the exposure time $\mathrm{ET}_{\mathrm{sw}}$ in $\mathrm{mg} / \mathrm{d}$ per unit concentration (mg/L) in the water and is given by

$$
\frac{\mathrm{UF}_{\mathrm{sW}}}{\mathrm{BW}}=\mathrm{AR} \mathrm{R}_{\mathrm{water}} \times 1.0 \times \mathrm{SA}_{\mathrm{b}} \times 10 \mathrm{~L} / \mathrm{cm}-\mathrm{m}^{2} \text {, }
$$

where 1.0 is the fraction of total body surface area, $\mathrm{SA}_{b}\left[\mathrm{~m}^{2} / \mathrm{kg}(\mathrm{BW})\right]$, assumed to be in contact with water during swimming, and $\mathrm{AR}_{\text {water }}$ expresses the ratio of the absorbed dose per event of duration $\mathrm{ET}_{\mathbf{s w}}$ [this absorbed dose is referred to as $\mathrm{DA}_{\text {event }}$ by U.S. EPA (1992)] to exposure-medium concentration and is equal to uptake per unit area of skin per unit concentration in water, $\mathrm{mg} / \mathrm{cm}^{2}$ per $\mathrm{mg} / \mathrm{cm}^{3}$. Other parameters in this equation are discussed in the sections above on human anatomical data and activity patterns. Dividing equation [150] by $C_{w}$ gives the PDF for this exposure pathway.

For an individual whose exposure time showering or bathing is $\mathrm{ET}_{\mathrm{sb}} / 2$ hours per day (since $\mathrm{ET}_{\mathrm{sb}}$ is the total time spent in the bathroom and half of that time is 
assumed spent in either the shower or bath) and whose exposure frequency showering and bathing is assumed to be one event per day for $365 d / y$, the average daily dose, ADD in $\mathrm{mg} / \mathrm{kg}-\mathrm{d}$, is given by

$A D D\left(\right.$ shower/bath dermal uptake) $=\left(1-f_{g w}^{w}\right) \times \frac{U F_{s b}}{B W} \times C_{w}$

where $\mathrm{UF}_{\mathrm{sb}}$ expresses the dermal uptake during the exposure time $\mathrm{ET}_{\mathrm{sb}} / 2 \mathrm{in} \mathrm{mg} / \mathrm{d}$ per unit concentration $(\mathrm{mg} / \mathrm{mL})$ in the water. As was the case for swimming exposure, the term $\frac{U F_{s b}}{B W}$ is given by equation [151]. Dividing equation [152] by $C_{w}$ gives the surface-water PDF for this exposure pathway.

The parameter $A R_{\text {water }}$ can be divided by the exposure time to obtain the effective permeability $(\mathrm{cm} / \mathrm{h})$ of a contaminant from water into the stratum corneum. Based on the work of McKone and Howd (1992), we estimate $A R_{\text {water }}$ for organic chemicals in terms of the skin-water partition coefficient, $K_{m}$, and the skin thickness $\delta_{\text {skin, }}$ in $\mathrm{cm}$, as

$$
\mathrm{AR}_{\text {water }}=\frac{\delta_{\text {skin }} K_{m}}{2}
$$

when the lag time, LT in $h$, is less than or equal to the exposure time, ET (either ET $_{\mathbf{s b}}$ or $\mathrm{ET}_{\mathbf{s w}}$ ), and

$$
A R_{\text {water }}=\frac{\delta_{\text {skin }} K_{m}}{2}+(E T-L T) \times K_{p}^{w}
$$

when the exposure time is greater than the lag time. Based on McKone and Howd, (1992), the skin thickness, $\delta_{\text {skin }}$ is taken as $0.0025 \mathrm{~cm}$, the lag time, LT in $h$, is given by

$$
L T=\frac{\left(0.0017+0.00067 \mathrm{~K}_{\mathrm{ow}}^{0.8}\right)}{6 \mathrm{~K}_{\mathrm{p}}^{\mathrm{w}}}
$$


where $K_{o w}$ is the octanol-water partition coefficient and $K_{p}^{w}$ is the steady-state permeability coefficient in $\mathrm{cm} / \mathrm{h}$ for a contaminant from water on skin through stratum corneum and can either be based on a measured value or estimated as

$$
K_{p}^{W}=M W^{-0.6} \times\left[\frac{2.4 \times 10^{-6}+3.0 \times 10^{-5} \mathrm{~K}_{0 \mathrm{~W}}^{0.8}}{\delta_{\text {gkin }}}\right],
$$

where MW is the molecular weight of the chemical in question. Equation [156] is taken from McKone and Howd (1992), who recommend that it be used for compounds with $M W \leq 280$. For compounds with $M W>280$, an expression suggested by the U.S. EPA (1992) is used,

$$
K_{p}^{W}=0.0019 \times K_{o w}^{0.71} \times 10^{(-0.0061 \times M W)} .
$$

Equation [157] is only recommended for compounds with . $T W>$ than 280 , since its estimation error is lower than that associated with equation [156] (McKone and Howd, 1992). However, following the guidance of the U.S EPA (1992), we do not allow the value of $K_{p}^{W}$ to exceed $1 \mathrm{~cm} / \mathrm{h}$, since no value higher than this has been measured experimentally. When equation [156] or [157] predict a value higher than $1 \mathrm{~cm} / \mathrm{h}$, we use $1 \mathrm{~cm} / \mathrm{h}$ as a default.

\section{Dermal Contact with Soil}

For exposures to contaminants in soil on human skin, the environmental medium is surface soil, with concentration, $C_{g}(\mathrm{mg} / \mathrm{kg})$, and the exposure medium is household soil and the intermedia-transfer factor between household soil and environmental soil is assumed to be unity.

For an individual whose soil exposure time is $\mathrm{ET}_{\mathrm{sl}}$ in $\mathrm{h} / \mathrm{d}$ and whose exposure frequency is 1 event per day, the average daily dose, ADD in $\mathrm{mg} / \mathrm{kg}-\mathrm{d}$, is given by

$$
A D D(\text { dermal uptake from soil })=\frac{U F_{s l}}{B W} \times \frac{E F_{s l}}{365} \times(1 \text { event } / d) C_{g} .
$$

where $\mathrm{BW}$ is the body weight of the exposed individual, $\mathrm{EF}_{\mathrm{sl}}$ is the exposure frequency in $d / y$, and $U F_{s l}$ expresses the dermal uptake during the exposure time, 
$\mathrm{ET}_{\mathrm{gl}}$. UF, has units of $\mathrm{kg} / \mathrm{d}$, which is the $\mathrm{mg} / \mathrm{d}$ per unit concentration of contaminant, in $\mathrm{mg} / \mathrm{kg}$, in the surface-soil medium and is given by

$$
\frac{U F_{g l}}{B W}=A R_{\text {soil }} \times S A_{b} \times 0.3 \times 15 \mathrm{~kg} / \mathrm{cm} \cdot \mathrm{m}^{2}
$$

where 0.3 is the fraction of the total body surface area, $\mathrm{SA}_{b}\left[\mathrm{~m}^{2} / \mathrm{kg}(\mathrm{BW})\right]$, assumed to be in contact with soil during contact, $15 \mathrm{~kg} / \mathrm{cm}-\mathrm{m}^{2}$ is a conversion factor based on a soil density of $1500 \mathrm{~kg} / \mathrm{m}^{3}$, and $A R_{\text {soil }}$ expresses the ratio of the absorbed dose per event of duration $\mathrm{ET}_{\mathbf{s l}}$ to exposure medium concentration and is equal to uptake per unit area of skin per unit concentration in soil, $\mathrm{mg} / \mathrm{cm}^{2}$ per $\mathrm{mg} / \mathrm{cm}^{3}$. Based on the work of McKone and Howd (1992), we approximate $A R_{\text {soil }}$ as

$$
A R_{\text {soil }}=\delta_{\text {soil }} \times\left\{1-\exp \left(\frac{-K_{p}^{s} \times E T_{s 1}}{\delta_{\text {soil }}}\right)\right\},
$$

where $K_{p}^{s}$ is the permeability of a contaminant from soil into and through the stratum corneum in $\mathrm{cm} / \mathrm{h}$, and $\delta_{\text {soil }}$ is the thickness of the soil layer on skin. Based on a soil loading of $0.5 \mathrm{mg} / \mathrm{cm}^{2}$ (as described in the section on exposure parameters) and a soil density of $1500 \mathrm{mg} / \mathrm{cm}^{3}$, we calculate $\delta_{\text {soil }}$ as $3 \times 10^{-4} \mathrm{~cm}$. We assume the exposure time per exposure event, $\mathrm{ET}_{\mathrm{sl}}$, is equal to $\mathrm{ET}_{\mathrm{h}} / 2$, that is half the exposure time at home. The soil-skin permeability in $\mathrm{cm} / \mathrm{h}$ is derived from the water-skin permeability, $K_{p}^{w}$, according to

$$
K_{p}^{s}=\frac{K_{D}}{K_{m}} \times K_{p}^{w} \times 1.7
$$

where $K_{m}$ is the skin-water partition coefficient and $K_{D}$ is the soil-water partition coefficient discussed in the section on partition coefficients, and the factor 1.7 accounts for the difference in thickness between fully hydrated skin in contact with water and less-hydrated skin in contact with soil (McKone and Howd, 1992). Other parameters in these equations are discussed in the sections above on human anatomical data and exposure factors. Making the appropriate substitutions and dividing equation [97] by $C_{g}$ gives the PDF for this exposure pathway. 


\section{Contamination of Mother's Mulk}

Lactating women can transfer to breast milk their intake of contaminants from all intake routes-ingestion, inhalation, and dermal contact. Thus, ingestion of mother's milk by infants can be an important exposure in many situations. This possibility is addressed by calculating the average daily dose to the infant from ingestion of mother's milk. In terms of the basic exposure model, expressed in equation [94], the ingestion intake of contaminants through breast milk involves the transfer of contaminants from each environmental medium, $k$, air, water, and soil. For this exposure scenario there are three intermedia-transfer factors, $C_{i} / C_{k}$, that express the riatio of contaminant concentration breast milk, $C_{b m k}$ in $\mathrm{mg} / \mathrm{kg}$, to contaminant concentration in, repspectively, air $\left(\mathrm{mg} / \mathrm{m}^{3}\right)$, water $(\mathrm{mg} / \mathrm{L})$, and soll $(\mathrm{mg} / \mathrm{kg})$. For each medium, $k$, this intermedia-transfer factor is given by

$$
C_{b m k} / C_{k}=P D F(b y \text { mother from medium } k) \times B W_{m o} \times B_{b m k}
$$

where PDF is the average daily potential dose factor to the mother from all pathways linked to medium $k, \mathrm{BW}_{\text {mo }}$ is the mother's body weight, equal to $65.4 \mathrm{~kg}$ with $\mathrm{CV}$ 0.2 (Najjar and Roland, 1987). Bbmk is the milk-concentration-versus-intake biotransfer factor, described above and listed in Table $\mathrm{V}$. The average daily dose to the infant, $A D D$ (infant) in $\mathrm{mg} / \mathrm{kg}$-d, is

$$
A D D(\text { infant })=\left[C_{b m k} / C_{a i r}+C_{b m k} / C_{\text {water }}+C_{b m k} / C_{s o i l}\right] \times I_{b m} \times \frac{E D}{A T} \text {, }
$$

where $\mathrm{I}_{\mathrm{bm}}$ is the intake of breast milk per unit body weight per day by infants, $\mathrm{kg}$ (milk)/ $\mathrm{kg}$ - $\mathrm{d}$ as discussed above and listed in Table VI. We estimate the ADD for this exposure with ED equal to one year and AT set to $365 \mathrm{~d}$ to estimate dose to the infant for noncarcinogens and AT set to 25,550 days (70 years) for carcinogens. The PDFs for infant exposures are the ratios of ADDs of contaminants to the infant, in $\mathrm{mg} / \mathrm{kg}-\mathrm{d}$, to contaminant concentrations in water in $\mathrm{mg} / \mathrm{L}$, in soil in $\mathrm{mg} / \mathrm{kg}$, and in air in $\mathrm{mg} / \mathrm{m}^{3}$. These ratios are based on the summation, taken independently from each medium, of all potential exposures to the mother through inhalation, ingestion, and dermal contact exposure. 


\section{PART IV. SUMMARY COMPARISON TO HRA WITH EXAMPLES}

In this part of the report, we compare the existing HRA approach and predictions and the CAIrTOX exposure equations and predictions. We provide a summary table for the exposure scenarios in CAirTOX and compare these to the exposure scenarios in HIRA.

The matrix of equations in Table VIII summarizes the expressions for the PDFs developed in this report. Parameters used in these expressions are defined and assigned values in Tables V through VII.

The Health Risk Assessment (HRA) computer program has been developed by the State of Cilifornia Air Resources Board (ARB) and the Office of Environmental Health Hazard Assessment (OEHHA). This program is used to carry out multiple pathway exposure assessment. HRA assists the evaluation of health risks associated with toxic chemical emissions to air and allows users to assess the potential for exposure to air emissions through inhalation as well as noninhalation exposure routes. HRA has been used to carry out risk assessments for facilities subject to the California Air Toxics "Hot-Spots" Program and for municipal waste incinerators and medical wastes incinerators. HRA can calculate cancer risk and cancer burden and hazard indices for non-cancer health effects. The program requires as input atmospheric dispersion modeling results for the air shed in the vicinity of the facility being assessed. CAirTOX is intended to expand on the approach use in HRA. In order to make clear the differences in exposure pathways used in these two models. Table IX repeats the matrix of scenarios shown in Table IV as those covered by CAirTOX. The unshaded listings are exposure pathways included in both models and the shaded pathways are those included only in CAirTOX. 


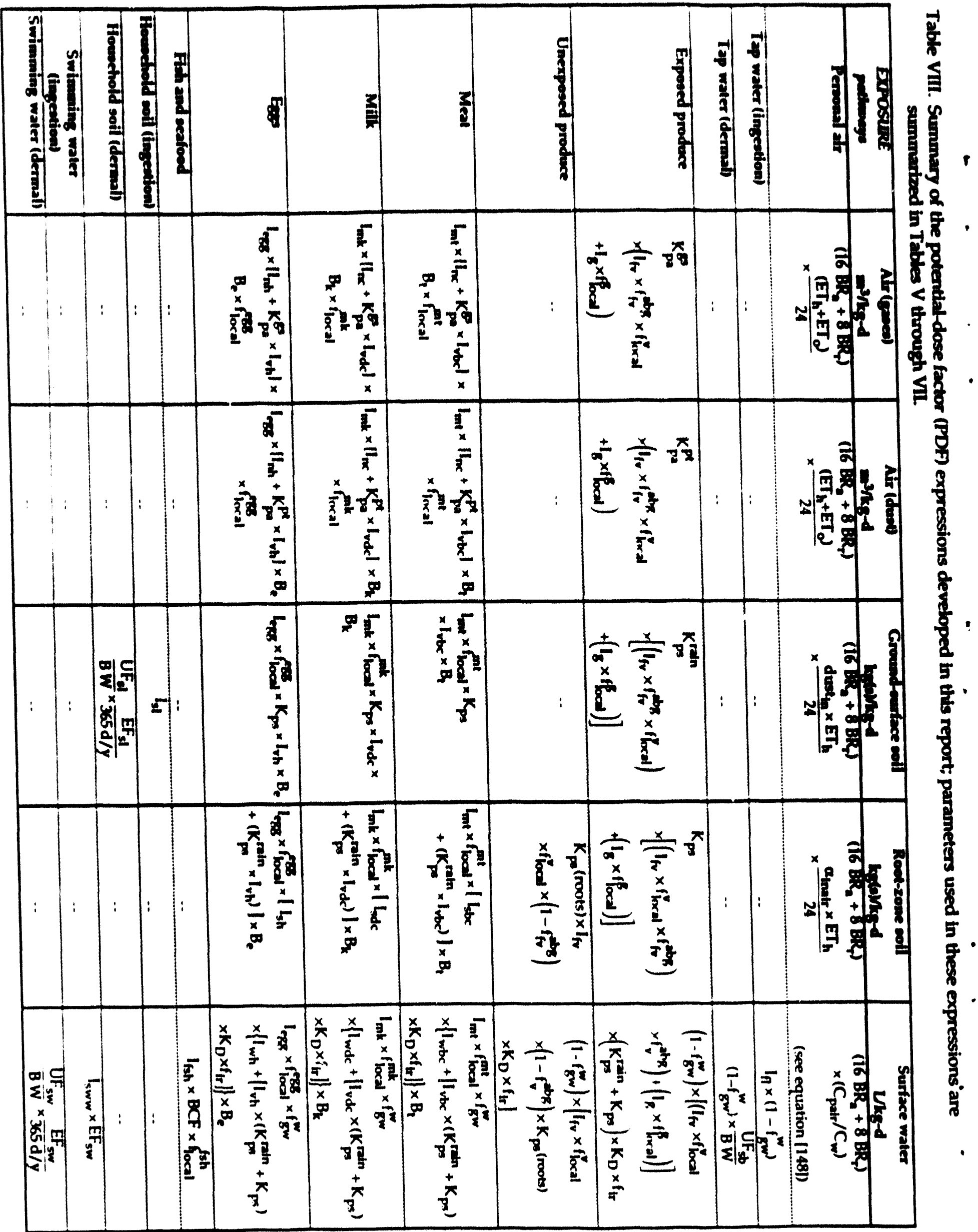


Table LX. Matrix of exposure pathways used in CAirTOX and HRA to link environmental media, exposure scenarios, and exposure routes. Those pathways included only in CAirTOX are shaded and those included in both HRA and CAirTOX are not shaded.

\begin{tabular}{|c|c|c|c|}
\hline \multirow{2}{*}{$\begin{array}{l}\text { Exposure } \\
\text { routes }\end{array}$} & \multicolumn{3}{|c|}{ Media } \\
\hline & $\begin{array}{l}\text { Air } \\
\text { (gases and particles) }\end{array}$ & $\begin{array}{l}\text { Soil (surface soil and } \\
\text { root-zone soill) }\end{array}$ & Water (surface water) \\
\hline Inhalation & $\begin{array}{l}\text { - Inhalation of gases and } \\
\text { particles in outdoor air } \\
\text { - Inhalation of gases and } \\
\text { particles transferred } \\
\text { from outdoor air to } \\
\text { indoor air }\end{array}$ & 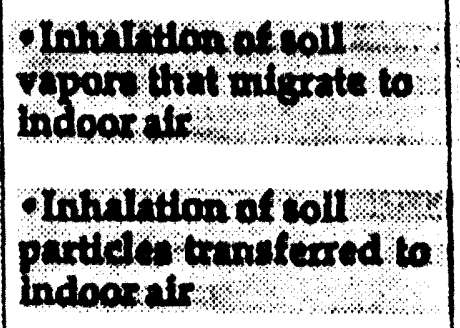 & $\begin{array}{l}\text { Indoor inhalate } \\
\text { contam inants trim } \\
\text { from tap water }\end{array}$ \\
\hline Ingestion & 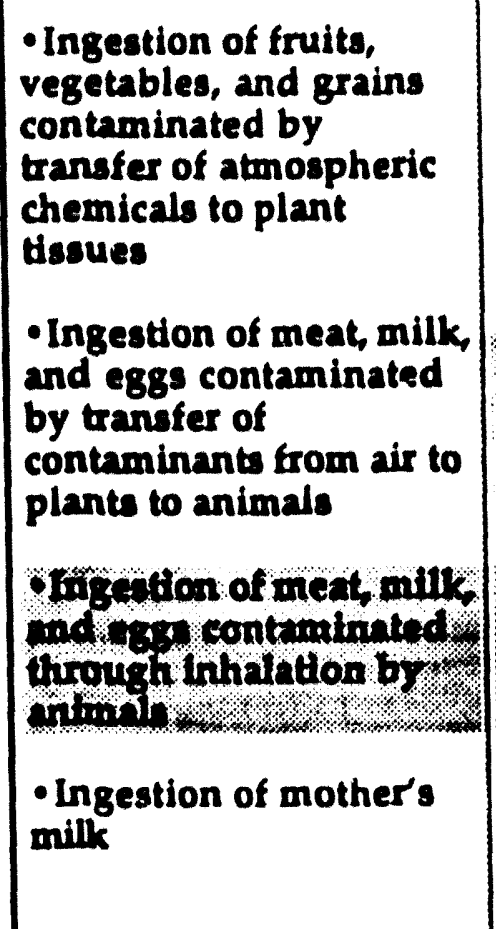 & 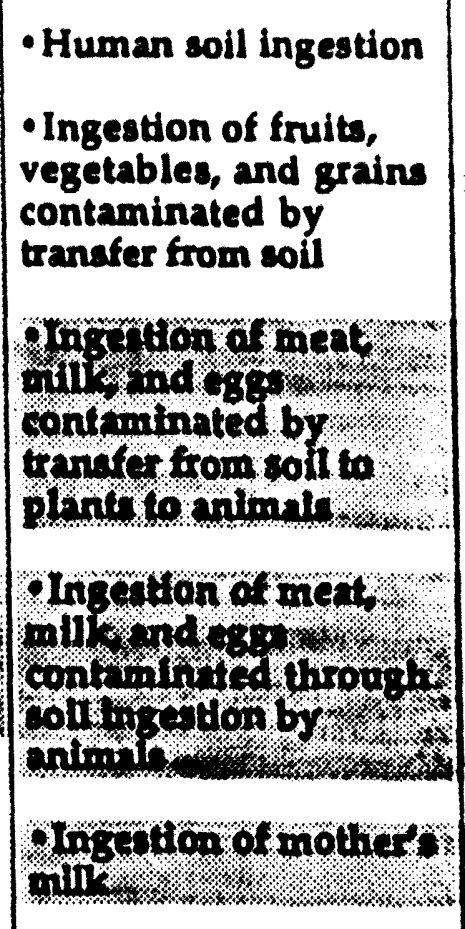 & 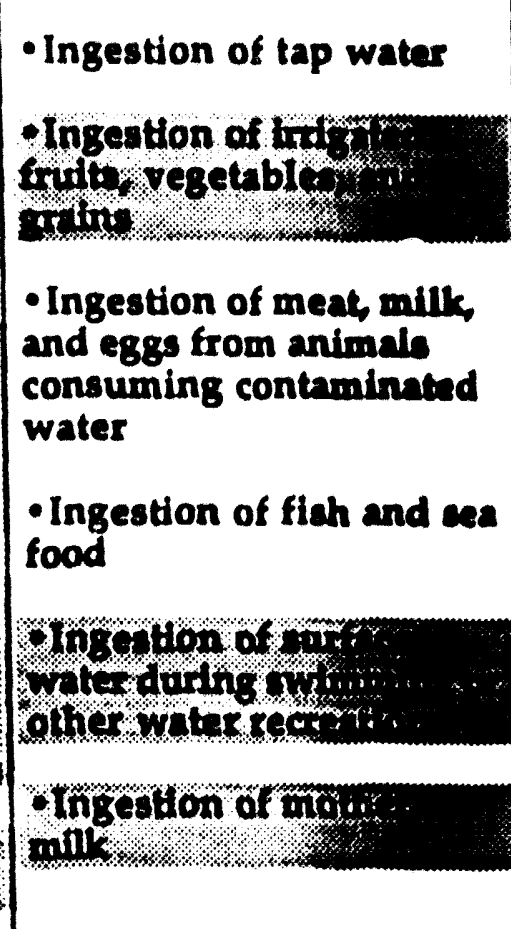 \\
\hline $\begin{array}{l}\text { Dermal } \\
\text { contact }\end{array}$ & (not considered) & $\begin{array}{l}\text { - Dermal contact with } \\
\text { soil }\end{array}$ & $\begin{array}{l}\text { Dermal contac } \\
\text { and showers } \\
\text { - Dermal contact ying } \\
\text { owimming }\end{array}$ \\
\hline
\end{tabular}


Another way to compare CAirTOX and HRA is to consider how the quantitative results of the models differ for specific chemicals. Tables $X$ and $X I$ list potential doses by route and pathway predicted by HRA and CAirTOX using similar landscape characteristics and chemical properties for dioxins and furans (TCDD) and inorganic arsenic. In this simulation the air concentration was fixed at $10^{-9} \mu \mathrm{g} / \mathrm{m}^{3}$ for TCDD and $10^{-3} \mu \mathrm{g} / \mathrm{m}^{3}$ for arsenic. In comparing these results, we note that

(1) the inhalation doses are comparable for both chemicals;

(2) surface-water-ingestion doses are similar between the two models for arsenic but not for TCDD;

(3) for both arsenic and TCDD, CAirTOX predicts higher potential does for homegrown produce than HRA;

Table X. Comparison of potential doses (mg/kg-d) to TCDD predicted by HRA and CAirTOX under similar landscape conditions and with an air concentration of $10^{-12} \mathrm{mg} / \mathrm{m}^{3}$.

\begin{tabular}{|c|c|c|}
\hline & HRA & CAirTOX \\
\hline INHALATION & $2.8 \times 10^{-13}$ & $3.5 \times 10^{-13}$ \\
\hline INGESTION: & & \\
Water & $2.2 \times 10^{-12}$ & $7.0 \times 10^{-15}$ \\
Exposed produce & - & $9.5 \times 10^{-11}$ \\
Unexposed produce & - & $8.4 \times 10^{-14}$ \\
Garden products & $5.7 \times 10^{-13}$ & - \\
Meat & $1.6 \times 10^{-11}$ & $2.3 \times 10^{-11}$ \\
Milk & $1.9 \times 10^{-11}$ & $7.0 \times 10^{-11}$ \\
Eggs & $\mathrm{n} / \mathrm{a}$ & $6.0 \times 10^{-13}$ \\
Fish & $1.1 \times 10^{-11}$ & $6.7 \times 10^{-13}$ \\
Soil & $2.1 \times 10^{-13}$ & $4.2 \times 10^{-15}$ \\
\hline Total INGESTION & $4.9 \times 10^{-11}$ & $1.9 \times 10^{-10}$ \\
\cline { 2 - 3 } DERMAL UPTAKE & $2.0 \times 10^{-13}$ & $2.6 \times 10^{-12}$ \\
\hline BREAST MILK & $3.6 \times 10^{-13}$ & $2.0 \times 10^{-11}$ \\
\hline Dose SUM & $5.0 \times 10^{-11}$ & $2.1 \times 10^{-10}$ \\
\hline
\end{tabular}


Table XI Comparison of potential doses $(\mathrm{mg} / \mathrm{kg}-\mathrm{d})$ to inorganic arsenic predicted by HRA and CAirTOX under similar landscape conditions and with an air concentration of $10^{-6} \mathrm{mg} / \mathrm{m}^{3}$.

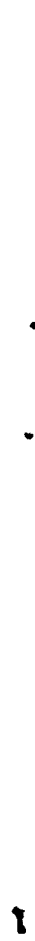

\begin{tabular}{|c|c|c|}
\hline & HRA & CAirTOX \\
\hline INHALATION & $2.8 \times 10^{-7}$ & $3.6 \times 10^{-7}$ \\
\hline INGESTION: & & \\
Water & $5.0 \times 10^{-6}$ & $1.0 \times 10^{-5}$ \\
Exposed produce & - & $1.0 \times 10^{-5}$ \\
Unexposed produce & - & $2.2 \times 10^{-5}$ \\
Garden products & $1.5 \times 10^{-6}$ & - \\
Meat & $2.0 \times 10^{-7}$ & $6.4 \times 10^{-7}$ \\
Milk & $7.7 \times 10^{-8}$ & $4.2 \times 10^{-7}$ \\
Eggs & $n / \mathrm{a}$ & $1.1 \times 10^{-8}$ \\
Fish & $9.4 \times 10^{-9}$ & $1.0 \times 10^{-5}$ \\
Soil & $1.3 \times 10^{-6}$ & $2.5 \times 10^{-8}$ \\
\cline { 2 - 3 } Total INGESTION & $8.1 \times 10^{-6}$ & $5.2 \times 10^{-5}$ \\
\cline { 2 - 3 } DERMAL UPTAKE & $\mathbf{2 . 8 \times 1 0 ^ { - 8 }}$ & $\mathbf{2 . 1 \times 1 0 ^ { - 7 }}$ \\
\hline BREAST MILK & $\mathrm{n} / \mathrm{a}$ & $2.2 \times 10^{-9}$ \\
\hline Dose SUM & $8.1 \times 10^{-6}$ & $5.3 \times 10^{-5}$ \\
\hline
\end{tabular}

(4) for TCDD predictions of doses through meat are comparable and predictions of doses through milk differ by roughly a factor of 3 between the two models;

(5) for arsenic, predictions of doses through meat are roughly a factor of 3 higher in CAirTOX and predictions of doses through milk are roughly a factor of 5 higher in CAirTOX;

(7) for TCDD, predictions of doses through fish are a factor of 16 higher in HRA than in CAirTOX (this is due primarily to the modeling of particle deposition in CAirTOX and the absence of this modeling in HRA);

(8) for arsenic, predictions of doses through fish are a factor of 1000 higher in CAirTOX than in HRA (this is due primarily to the modeling of particle runoff in CAirTOX and the absence of this modeling in HRA); 
(9) for both chemicals, soil-ingestion exposure is roughly a factor of 100 higher in HRA relative to CAirTOX;

(10) dermal uptake of TCDD is comparable in the two models and, for arsenic, a factor of 10 higher in CAirTOX;

(11) predicted breast milk dose to TCDD is 100 times higher in CAirTOX than in HRA (this is due primarily to the inclusion of more pathways for transferring contaminants from soil and food to human breast milk in CAirTOX); and

(12) the total dose predicted from all pathways differs between the two models by roughly a factor of 5 or less for both compounds.

\section{PART V. CRITICAL SENSITIVITIES AND UNCERTAINTIES}

There are five factors that determine the precision or reliability of an environmental transfer model. These are (1) specification of the problem (scenario development), (2) formulation of the conceptual model (the influence diagram), (3) formulation of the computational model, (4) estimation of parameter values, and (5) calculation and documentation of results including uncertainties . Parameter uncertainties and model sensitivities are addressed in a supplemental report on model inputs (including ranges and coefficients of variability). However, it should be recognized at the outset that there are some important inherent sensitivities and uncertainties in the CAirTOX multimedia approach.

Many of the model sensitivities are highly dependent on the chemical properties of the chemical species being modeled. Nonetheless, in all cases the model is very sensitive to source terms. All model predictions are directly proportional to the initial inventory or input rates used. For many applications of a model such as CAirTOX source data has large variability and/or uncertainty. This is particularly the case for contaminant measurements in soils. For most chemicals, another important model sensitivity is to the magnitude of the transformation rates in soils, air, surface water, and/or sediments. These rate constants can have a large impact on the predicted persistence of any chemical species and are often the most uncertain inputs to the model. For volatile chemicals, the model is sensitive to the magnitude of the air-water partition coefficient. For semi-volatile chemicals and inorganic species the model is more sensitive to the soil-water partition coefficients. It is assumed that these partition processes are linear and reversible. When this is 
not the case, the reliability of the model is reduced because of the uncertainties about how far soil partition processes are from this ideal behavior.

\section{REFERENCES}

Altman, P.L., and D.S. Dittmer (1968), Metabolism, (Federation of American Societies for Experimental Biology, Bethesda, Maryland), pp. 98-103 and 551-552.

Bacci, E., D. Calamari, C. Gaggi, and M. Vighi (1990), "Bioconcentration of Organic Chemical Vapors in Plant Leaves: Experimental Measurements and Correlation," Environ. Sci. Technol. 24, 885-889.

Benarie, M. M. (1980), Urban Air Pollution Modeling, (MrT Press, Cambridge, MA).

Bevington, P.R. (1969), Data Reduction and Error Analysis for the Physical Sciences, (McGraw-Hill, New York City, NY), pp. 56-65.

Bowen, H.J.M. (1979), Environmental Chemistry of the Elements (Academic Press, London, UK).

Briggs, G.G., R.H. Bromilow, and A.A. Evans (1982), "Relationships Between Lipophilicity and Root Uptake and Translocation of Non-Ionized Chemicals by Barley," Pestic. Sci. 13, 495-504.

Briggs, G.G., R.H. Bromilow, A.A. Evans, and M. Williams (1983), "Relationships Between Lipophilicity and the Distribution of Non-Ionized Chemicals in Barley Shoots Following Uptake by the Roots," Pestic. Sci. 14, 492-500.

Butte, N.F. , C. Garza, J.E. Stuff, E.O. Smith, and B.L. Nichols (1984), "Effect of Maternal Diet and Body Composition on Lactational Performance," Am. J. Clin. Nutr. 39, 296-306.

Calabrese, E.J., R. Barnes, E.J. Stanek, H. Pastides, C.E. Gilbert, P. Veneman, X. Wang, A. Lasztity, and P.T. Kostecki (1989), "How Much Soil Do Young Children Ingest, An Epidemiologic Study," Regul. Toxicol. Pharmacol. 10, 123-137.

Calabrese, E.J., E.S. Stank, and C.E. Gilbert (1991), "Chapter 19. A Preliminary Decision Framework for Deriving Soil Ingestion Rates," in Hydrocarbon Contaminated Soils Volume 1, E.J. Calabrese and P.T. Kostecki, Eds. (Lewis Publishers, Chelsea, MI), pp. 301-311.

Cohen, Y., and P.A. Ryan (1985), "Multimedia Modeling of Environmental Transport: Trichloroethylene Test Case," Environ. Sci. Technol. 9, 412-417.

Cohen, Y., W. Tsai, S.L. Chetty, and G.J. Mayer (1990), "Dynamic Partitioning of Organic Chemicals in Regional Environments: A Multimedia Screening-Level Approach," Environ. Sci. Technol. 24, 1549-1558. 
Diamond, M.L., D. Mackay, P.M. Welboum (1992), "Models of Multi-Media Partitioning of Multi-Species Chemicals: The Fugacity/Aquivalence Approach," Chemosphere, 25, 1907-1921.

Ershow, A.G., and F.P. Cantor (1989), Total Water Intake and Tapwater Intake in the United States: Population-Based Estimates of Quantiles and Sources, a report prepared under National Cancer Institute Order \#263-MD-810264 with the Life Sciences Research Office, Federation of American Societies for Experimental Biology, Betheseda, MD.

Fiedler, D. A., K. W. Brown, J. C. Thomas, and K. C. Donnelly (1991), "Mutagenic Potential of Plants Grown on Municipal Sewage Sludge-Amended Soil," Arch. Environ. Contam. Toxicol. 20, 385-390.

Formica, S.J., J.A. Baron, L.J. Thibodeaux, and K.T. Valsaraj (1988), "PCB Transport into Lake Sediments. Conceptual Model and Laboratory Simulation," Environ. Sci. Technol. 22, 1435-1440.

Gifford, F. A., and S. R. Hanna (1973), "Modeling Urban Air Pollution," Atmos. Environ. 7, 131-136.

Gleick, P.L. (1987), "The Development and Testing of a Water Balance Model for Climate Impact Assessment," Water Resour. Res. 23, 1049-1061.

Goldman, L.R, D.G. Hayward, J. Flattery, M.E. Harniy, D.G. Patterson, L.L. Needham, D. Siegel, R. Channg, R.D. Stephens, and K.W. Kizer (1989), "Serum, Adipose, and Autopsy Tissue PCDD and PCDF Levels in People Eating Dixon Contaminated Beef and Chicken Eggs," Chemosphere 19, 841-848.

Hammond, D., H.J. Simpson, and G. Mathieu (1975), "Methane and Radon-222 as Tracers for Mechanisms of Exchange Across the Sediment-Water Interface in the Hudson River Esiiary," in Marine Chemistry in the Coastal Environment, American Chemical Society Symposium Series 18, T.M. Church, Ed. (American Chemical Society, W'ashington, DC).

Hanna, S.R., G.A. Briggs, and R.P. Hosker, Jr., (1982), Handbook on Atmospheric Diffusion, U.S. Department of Energy, Washington, DC, DOE/TIC-11223.

Howard, P.H., J. Saxena, and H. Sikka (1978), "Determining the Fate of Chemicals," Environ. Sci. Technol. 12, 398-407.

International Commission on Radiological Protection (ICRP) (1975), Report of the Task Group on Reference Man, (Pergamon Press, New York City, NY), ICRP Publication No. 23.

James, I.R., and M.W. Knuiman (1987), "An application of Bayes Methodology to the Analysis of Diary Records from a Water Use Study," J. Am. Stat. Assoc. 82, 705-711. 
Junge, C.E. (1977), "Basic Considerations About Trace Constituents in the Atmosphere," in Fate of Pollutants in the Air and Water Enoironments, I.H. Suffet, Ed. (Wailey and Sons, New York City, NY), pp. 7-26.

Jury, W., W. Spencer, and W. Farmer (1983), "Behavior Assessment Model for Trace Organics in Soil: I. Model Description," J. Environ. Qual. 12, 558-564.

Jury, W.A., D. Russo, G. Streile, and H. El Abd (1990), "Evaluation of Volatilization by Organic Chemicals Residing Below the Soil Surface," Water Resources Res. 26, 13-20.

LaGoy, P. K. (1987), "Estimated Soil Ingestion Rates for Use in Risk Assessment," Risk Anal. 7, 355-359.

Layton, D.W. (1993), "Metabolically Consistent Breathing Rates for Use in Dose Assessments," Health Phys. 64, 23-36.

Lyman, W.J., W.F. Reehl, and D.H. Rosenblatt (1982), Handbook of Chemical Property Estimation Methods (McGraw-Hill, New York).

Mackay, D. (1979), "Finding Fugacity Feasible," Environ. Sci. Technol. 13, 1218-1223.

Mackay, D. (1991), Multimedia Environmental Models, the Fugacity Approach (Lewis Publishers, Chelsea, MI).

Mackay, D., and M. Diamond (1989), "Application of the QWASI (Quantitative Water Air Sediment Interaction) Model to the Dynamics of Inorganic Chemicals in Lakes," Chemosphere 18, 1343-1365.

Mackay, D., and S. Paterson (1981), "Calculating Fugacity," Environ. Sci. Technol. 15, 1006-1014.

Mackay, D., and S. Paterson (1982), "Fugacity Revisited," Enoiron. Sci. Technol. 16, 654-660.

Mackay, D., and S. Paterson (1991), "Evaluating the Multimedia Fate of Organic Chemicals: A Level III Fugacity Model," Environ. Sci. Technol. 25, 427-436.

Mackay, D., M. Joy, and S. Paterson (1983a), "A Quantitative Water, Air, Sediment Interaction (QWASI) Fugacity Model for Describing the Fate of Chemicals in Lakes," Chemosphere 12, 981-997.

Mackay, D., S. Paterson, and M. Joy (1983b), "A Quantitative Water, Air, Sediment Interaction (QWASI) Fugacity Model for Describing the Fate of Chemicals in Rivers," Chemosphere 12, 1193-1208.

Mackay, D., S. Paterson, and W.H. Schroeder (1986), "Model Describing the Rates of Transfer Processes of Organic Chemicals between Atmosphere and Water," Enoiron. Sci. Technol. 20, 810-816. 
McKone, T.E. (1987), "Human Exposure to Volatile Organic Compounds in Household Tap Water: The Indoor Inhalation Pathway," Environ. Sci. Technol. 21, 1194-1201.

McKone, T.E. (1993a)CalTOX, A Multimedia Total-Exposure Model for HazardousWastes Sites Part I: Executive Summary, prepared for the State of California, Department Toxic Substances Control, Lawrence Livermore National Laboratory, Livermore, CA, UCRL-CR-111456PtI.

McKone, T.E. (1993b) CalTOX, A Multimedia Total-Exposure Model for HazardousWastes Sites Part II: The Dynamic Multimedia Transport and Transformation Model, prepared for the State of California, Department Toxic Substances Control, Lawrence Livermore National Laboratory, Livermore, CA, UCRL-CR-111456PtII.

McKone, T.E. (19:13c) CalTOX, A Multimedia Total-Exposure Model for HazardousWastes Sites Part iII: The Multiple-Pathway Exposure Model, prepared for the California Department Toxic Substances Control, Lawrence Livermore National Laboratory, Livermore, CA, UCRL-CR-111456PtIII.

McKone, T.E., and K.T. Bogen (1992), "Uncertainties in Health-Risk Assessment: An Integrated Case Study Based on Tetrachloroethylene in California Groundwater," Regul. Toxicol. Pharmacol. 15, 86-103.

McKone,T.E., and J.I. Daniels (1991), "Estimating Human Exposure Through Multiple Pathways from Air, Water, and Soil," Regul. Toxicol. Pharmacol. 13, 36-61.

McKone, T.E., L.B. Gratt, M.J. Lyon, and B.W. Perry (1987), GEOTOX Multimedia Compartment Model User's Guide, Lawrence Livermore National Laboratory, Livermore, CA UCRL-15913.

McKone, T.E., and R.A. Howd (1992), "Estimating Dermal Uptake of Nonionic Organic Chemicals from Water and Soil: Part 1, Unified Fugacity-Based Models for Risk Assessments," Risk Analysis (In press; Lawrence Livermore National Laboratory, Livermore, CA, UCRL-JC-109111, April 1992).

McKone. T.E., and J.P. Knezovich (1991), "The Transfer of Trichloroethylene (TCE) from a Shower to Indoor Air: Experimental Measurements and Their Implications" J. Air Waste Manag. Assoc. 41, 282-286.

McKone, T.E., and D.W. Layton (1986), "Screening the Potential Risk of Toxic Substances Using a Multimedia Compartment Model: Estimation of Human Exposure," Regul. Toxicol. Pharmacol. 6, 359-380.

McKone, T.E., and P.B. Ryan (1989), "Human Exposures to Chemicals through Food Chains: An Uncertainty Analysis," Environ. Sci. Technol. 23, 1154-1163.

Murphy, B. L., and J. E. Yocom (1986), "Migration Factors for Particulates Entering the Indoor Environment," Proceedings of the 79th Annual Meeting of the Air Pollution Control Association, Minneapolis, MN, June 22-27, Paper No. 86-7.2. 
Najjar, M.F., and M. Roland (1987), Anthropometric Reference Data and Preoalence of Overweight United States 1976-1980 Vital and Health Statistics of the U.S.

Department of Health and Human Services (DHHS), Public Health Service (PHS), National Center for Health Statistics, Hyattsville, MD, DHHS

Publication N. (PHS) 87-1688.

National Research Council (NRC), Subcommittee on Poultry Nutrition, Committee on Animal Nutrition, Board on Agriculture (1984), Nutrient Requirements of Poultry (National Academy Press, Washington, DC), 8th rev. ed.

- Ng, Y. C. (1982), "A Review of Transfer Factors for Assessing the Dose from Radionuclides in Agricultural Products," Nucl. Safety 23, 57-71.

Pankow, J.F. (1987), "Review and Comparison Analysis of the Theories on Partitioning Between the Gas and Aerosol Phases in the Atmosphere," Atmos. Environ. 21, 2275-2283.

Paterson, S., and D. Mackay (1989), "Modeling the Uptake ar.d Distribution of Organic Chemicals in Plants," in Intermedia Pollutant Transport: Modeling and Field Measurements, D. T. Allen, Y. Cohen, and I. R. Kaplan, Eds. (Plenum Press, New York, NY), pp. 283-292.

Paustenbach, D.J., H.P. Shu, and F.J. Murray (1986), "A Critical Examination of - Assumptions Used in Risk Assessments of Dioxin Contaminated Soil," Regul. Toxicol. Pharmacol. 6, 284-307.

Reuber, B., D. Mackay, S. Paterson, and P. Stokes (1987), "A Discussion of Chemical Equilibria and Transport at the Sediment-Water Interface," Environ. Toxicol. Chem. 6, 731-739.

Riederer, M. (1990), "Estimating Partitioning and Transport of Organic Chemicals in the Foliage/Atmosphere System: Discussion of a Fugacity-Based Model," Environ. Sci. Technol. 24, 829-837.

Ryan, P., and Y. Cohen (198f), "Multimedia Transport of Particle Bound Organics, Benzo(a)Pyrene Test Case," Ciemosphere 15, 21-47.

Schnoor, J.L. (1981), "Fate and Transport of Dieldrin in Coraville Reservoir:

Residues in Fish and Water Following a Pesticide Ban," Science 211, 840-842.

Schnoor, J.L. and D.C. MacAvoy (1981), "A Pesticide Transport and Bioconcentration Model," J. Environ. Eng. Div, American Society of Civil Engineers 107, 1229-1245.

Schroeder, W.H., and D.A. Lane (1988), "The Fate of Toxic Airborne Pollutants," Environ. Sci. Technol. 22, 240-246.

Sedman, R.M. (1989), "The Development of Applied Action Levels for Soil Contact: A Scenario for the Exposure to Soil in A Residential Setting," Environ. Health

- Perspect. 79, 291-313. 
Soil Conservation Service (1975), Soil Taxonomy: A Basic System of Soil Classification System for Making and Interpreting Soil Surveys (U.S. Government Printing Office, Washington, DC), U.S. Department of Agriculture, Agricultural Handbook 436.

Southworth, G.R. (1979), "The Role of Volatilization in Removing Polycyclic Aromatics from Aquatic Environments," Bull. Environ. Contamin. Toxicol. 21, 507514.

Thibodeaux, L.J. (1979), Chemodynamics, Environmental Movement of Chemicals in Air, Water, and Soil, (John Wiley and Sons, New York).

Travis, C. C., and A. D. Arms (1988), "Bioconcentration of Organics in Beef, Millk, and Vegetation," Enoiron. Sci. Technol. 22, 271-274.

Turner, D. B. (1970), Workbook of Atmospheric Dispersion Estimates, U.S. Environmental Protection Agency, Research Triangle Park, NC, Office of Air Programs Publication N2. AP-26, Rev. 1970 (Reprinted by Federal Emergency Management Agency, Washington, DC, January 1982; Publication №. TD-18).

U.S. Department of Agriculture (USDA) (1978), Fredicting Rainfall Erosion Losses, A Guide to Conservation Planning, (U.S. Government Printing Office, Washington, DC), U.S. Department of Agriculture Handbook №. 537.

U.S. Department of Agriculture (USDA) (1983), Food Intakes: Individuals in 48 States, Year 1977-1978, NFCS 1977-1978, Human Nutrition Information Service, U.S. Department of Agriculture, Washington, DC, Report No. I-1.

U.S. Environmental Protection Agency (U.S. EPA) (1985), Development of Statistical Distributions or Ranges of Standard Factors Used in Exposure Assessments, Office of Health and Environmental Assessment, U.S. Environmental Protection Agency, Washington, DC, EPA/600/8-85/010.

U.S. Environmental Protection Agency (U.S. EPA) (1989a), Exposure Factors Handbook, Office of Health and Environmental Assessment, U.S. Environmental Protection Agency, Washington, DC, EPA/600/8-89/043.

U.S. Environmental Protection Agency (U.S. EPA) (1989b), Risk Assessment Guidance for Superfund Volume I Human Health Evaluation Manual (Part A), Office of Emergency and Remedial Response, U.S. Environmental Protection Agency, Washington, DC, EPA/540/1-89/002.

U.S. Environmental Protection Agency (U.S. EPA) (1992), Dermal Exposure Assessment: Principles and Applications, Office of Health and Environmental Assessment, U.S. Environmental Protection Agency, Washington, DC, EPA/600/8-91/011B.

U.S. National Oceanographic and Atmospheric Administration (NOAA) (1974), Climates of the States. Volume II. Western States (Water Information Center, Inc., Port Washington, NY). 
van der Leeden, F., F.L. Troise, and D.K. Todd (1990), The Water Encyclopedia second edition (Lewis Publishers, Chelsea, MD).

$! \quad$ Whicker, F.W., and T.B. Kirchner (1987) "PATHWAY: A Dynamic Food-Chain Model to Predict Radionucilde Ingestion After Fallout Deposition," Health Phys. 52, 717-737.

Whitby, K.T. (1978), "The Physical Characteristics of Sulfur Aerosols," Atmos. Enoiron. 12, 135-159.

Whitehead, R.G., and A.A. Paul (1981), "Infant Growth and Human Milk Requirements," Lancet 2, 161-163.

- Yang, Y.Y., and C.B. Nelson (1986), "An Estimation of Daily Food Usage Factors for Assessing Radionuclide Intakes in the U.S. Population," Health Phys. 50, 245-257. 


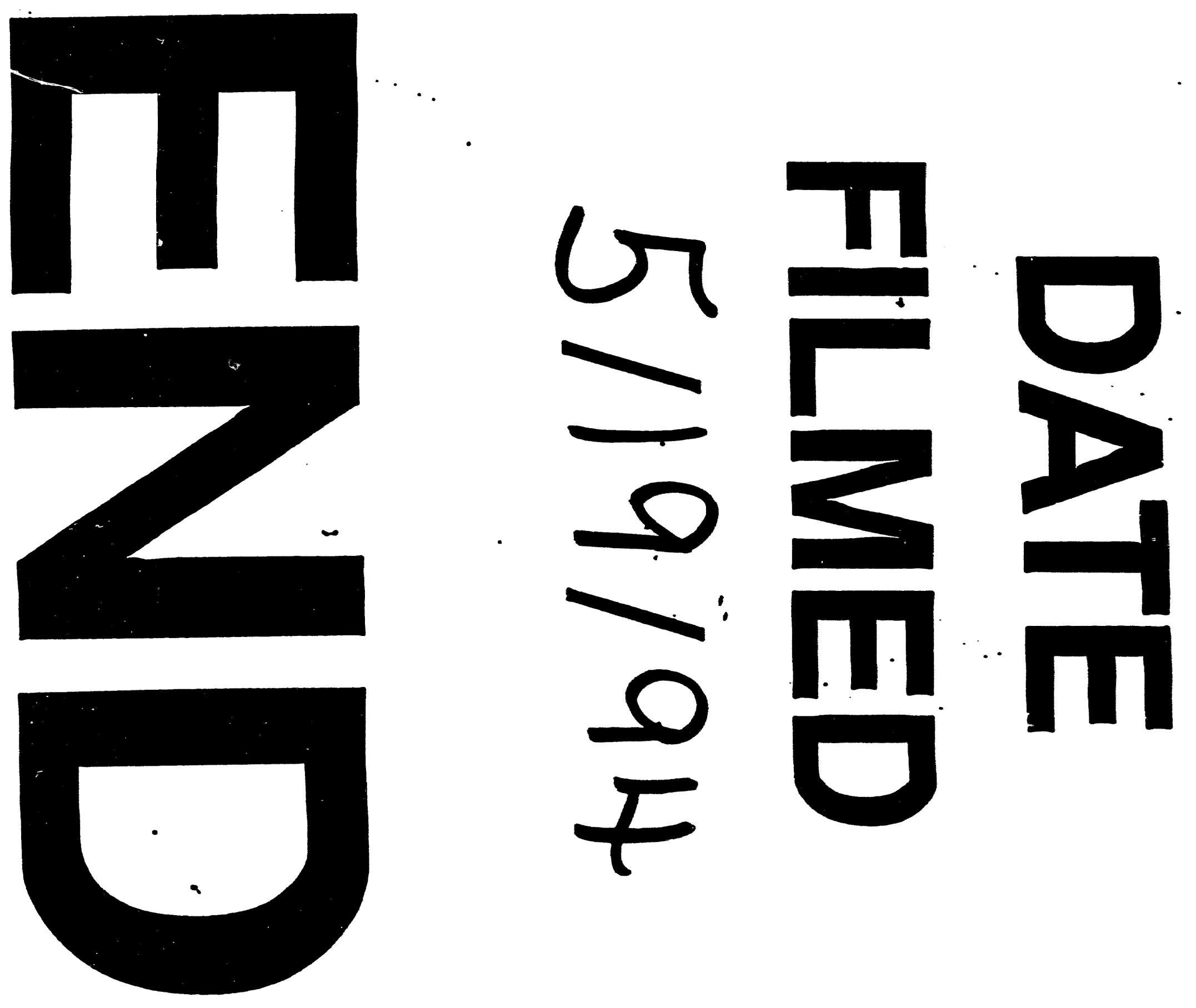


